MARIANA VENÂNCIO DOS SANTOS

Estudo de toxicidade oral e de neurotoxicidade em ratos expostos à Senna occidentalis

São Paulo

2015 
Estudo de toxicidade oral e de neurotoxicidade em ratos expostos à Senna occidentalis

Dissertação apresentada ao Programa de Pós-Graduação em Patologia Experimental e Comparada da Faculdade de Medicina Veterinária e Zootecnia da Universidade de São Paulo para a obtenção do título de Mestre em Ciências

Departamento:

Patologia

Área de Concentração:

Patologia Experimental e Comparada

Orientador:

Profa. Dra. Helenice de Souza Spinosa

São Paulo 
Autorizo a reprodução parcial ou total desta obra, para fins acadêmicos, desde que citada a fonte.

\section{DADOS INTERNACIONAIS DE CATALOGAÇÃO-NA-PUBLICAÇÃO}

(Biblioteca Virginie Buff D’Ápice da Faculdade de Medicina Veterinária e Zootecnia da Universidade de São Paulo)

T.3168

Santos, Mariana Venâncio dos

Estudo de toxicidade oral e de neurotoxicidade em ratos expostos à Senna

FMVZ occidentalis / Mariana Venâncio dos Santos. -- 2015.

$97 \mathrm{f}$. : il.

Dissertação (Mestrado) - Universidade de São Paulo. Faculdade de Medicina Veterinária e Zootecnia. Departamento Patologia, São Paulo, 2015.

Programa de Pós-Graduação: Patologia Experimental e Comparada.

Área de concentração: Patologia Experimental e Comparada.

Orientador: Profa. Dra. Helenice de Souza Spinosa.

1 Senna occidentalis. 2. Ratos. 3. Toxicidade. 4. OECD. I. Título. 


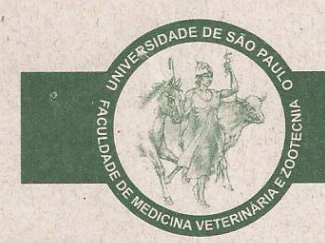

UNIVERSIDADE DE SÃO PAULO

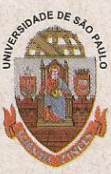

FACULDADE DE MEDICINA VETERINÁRIA E ZOOTECNIA

Comissão de Ética no uso de animais

\section{CERTIFICADO}

Certificamos que o Projeto intitulado "Estudo de toxicidade oral e de neurotoxicidade em ratos expostos a Senna occidentalis", protocolado sob o n²876, utilizando 160 (cento e sessenta) ratos, sob a responsabilidade da Profa. Dra. Helenice de Souza Spinosa, está de acordo com os princípios éticọs de experimentação animal da "Comissão de Ética no uso de animais" da Faculdade de Medicina Veterinária e Zootecnia da Universidade de São Paulo e foi aprovado em reunião do dia seis de fevereiro de 2013.

$$
\because \cdots
$$

We certify that the Research "Oral toxicity and neurotoxicity of Senna occidentalis in rats", protocol number 2876, utilizing 160 (one hundred sixty) rats, under the responsibility Profa. Dra. Helenice de Souza Spinosa, agree with Ethical Principles in Animal Research adopted by "Ethic Committee in the use of animals" of the School of Veterinary Medicine and Animal Science of University of São Paulo and was approved at the meeting on 6 February of two thousand and thirteen.

São Paulo, 14 de fevereiro de 2013.

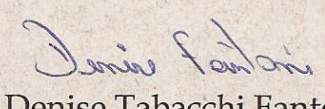

Denise Tabacchi Fantoni

Presidente 


\section{FOLHA DE AVALIAÇÃO}

Autor: SANTOS, Mariana Venâncio dos

Título: Estudo de toxicidade oral e de neurotoxicidade em ratos expostos a Senna occidentalis

Dissertação apresentada ao Programa de PósGraduação em Patologia Experimental e Comparada da Faculdade de Medicina Veterinária e Zootecnia da Universidade de São Paulo para a obtenção do título de Mestre em Ciências.

Data:

\section{Banca Examinadora}

Prof.Dr.

Instituição: Julgamento:

Prof.Dr.

Instituição: Julgamento:

Prof.Dr. Instituição: Julgamento: 


\section{Agradecimentos}

Agradeço a Фeus, pelo simples viver, por me fazer lutar sempre, não me deixar desistir mesmo quando não se via mais soluȩão. Jor me ajudar a manter viva a fé que já nasee em eada um de nós.

Agradeço aos meus pais, por me amarem, por me eduearem, por me permitirem. ter nascido e ereseido em uma família integra, rodeada sempre de muito earinho e amor, e dessa forma ter aprendido o eerto e o errado, e pelo o que se deve lutar. por sempre estarem ao meu lado, mesmo quando não mereeesse; por nunea desistirem de mim, e prineipalmente por me amarem INCONDICIONALLAENTE.

Agradeço a todas as pessoas, familiares \& amiģos que me ajudaram a enfrentar difieuldades ocorridas durante o desenvolvimento do trabalho. Que tiveram paciêneia comiģo quando eu mesma já não a tinha. Que me eederam, seus ouvidos, seus ombros, suas easas, enfim, suas amizades no momento que mais precisei, e com muito earinho. Agradecimento especial a Fernanda Mariano, simplesmente por me permitir ser sua amiga, por estar sempre ao meu lado, pelo simples fato de sempre estar presente, e dessa forma me proporeionar ealma e elareza para prosseguir.

Agradeço a minha amiģa Rúbia, pelos momentos de gargalhadas que só ela soube me proporeionar no momento que mais precisei. Por me apoiar e participar com toda a paciêneia e carinho de forma pessoal e profissional para a conclusão desse trabalho.

Aģradeço a minha irmã Juliana por toda ajuda prestada.

Agradeço a todas as pessoas que de alguma forma me ajudaram no desenvolvimento desse trabalho, e prineipalmente a Mariana Sayuri Berto Udo e Thaísa Meira Sandini pela amizade, pelo earinho, preocupaȩão, DACIÊACIA, TEMJO dedieados a mim. Admiro voêes, por serem exeelentes no que fazem, mas prineipalmente pela solidariedade, pela preocupação com a difieuldade do outro, qualidade essa vista tão pouco nos dias de hoje. Voểs são demais.

Agradeço a minha orientadora, Heleniee de Souza spinosa, por me coneeder a oportunidade de realização de um sonho profissional, pela paciêneia, amizade, confianȩa e orientaȩão.

Ağradeço a meus animais, Bionda, Sirius Black, Hermione Granger, Fleur Фelacour \& Фolly, por simplesmente serem eães, por latirem ineessantemente avisando minha chegada em easa, por todos os xixis, arranhões e lambidas feitos de al egria no momento da minha chegada, por me proporeionar reeeber um amor único e incondieional que consegue preencher eada pedaeinho do meu coração. 
Agrradeço à Universidade de são paulo por possibilitar a realização dessa importante etapa da minha vida profissional e por permitir que eu fizesse parte de um dos seus grupos de pós ģraduação e a Capes, pelo apoio finaneeiro eom a bolsa de mestrado. 
Mil poderão cair ao teu lado, e dez mil à tua direita; mas tu não serás atingido. pois que tanto me amou, eu o livrarei; pô-lo-ei num alto retiro, porque ele conhece o meu nome. Salmo 91. 


\section{RESUMO}

SANTOS, M. V. Estudo de toxicidade oral e de neurotoxicidade em ratos expostos a Senna occidentalis. [Study of oral toxicity and neurotoxicity in rats exposed to Senna occidentalis]. 2015. 97 f. Dissertação (Mestrado em Ciências) - Faculdade de Medicina Veterinária e Zootecnia, Universidade de São Paulo, São Paulo, 2015.

A Senna occidentalis, popularmente conhecida por fedegoso, é uma planta utilizada em várias culturas ao redor do mundo como alimento e como fitofármaco contra várias doenças em seres humanos, enquanto em medicina veterinária há relatos de intoxicações espontâneas em animais de produção, como, bovinos, equinos e suínos. A toxicidade dessa planta é atribuída à diantrona, princípio ativo encontrado em maior concentração nas sementes da planta, que promove o desacoplamento da fosforilação oxidativa mitocondrial, causando dano celular. Assim, o objetivo do presente trabalho foi avaliar os possíveis efeitos tóxicos, em particular, os neurotóxicos causados pela exposição oral a diferentes concentrações (1, 2, 3 e 4\%) de sementes de $S$. occidentalis na ração, durante 28 e 90, em ratos Wistar machos e fêmeas. Essas avaliações foram embasadas nos protocolos da OECD 407, 408 e 424. Foram avaliados: consumo de água e de ração; peso corpóreo; sinais clínicos de toxicidade (atividade geral, frêmito vocal, irritabilidade resposta ao toque, aperto de cauda, reflexo auricular, reflexo corneal e piloereção); comportamento no Campo Aberto, no Labirinto em Cruz e o Reconhecimento de Objetos; parâmetros hematológicos, bioquímicos séricos e exame anatomopatológico. Os resultados do estudo da exposição por 28 dias mostrou: redução de peso corpóreo apenas em fêmea do grupo 4\%; presença de piloereção em machos e fêmeas do grupo 4\%; no Campo Aberto redução da locomoção e aumento de grooming em fêmeas dos grupos 2 e 4\%; no labirinto em cruz elevado redução da porcentagem de tempo nos braços abertos (\%TBA) no grupo $1 \%$ e da avaliação de risco nos grupos 1, 2 e $4 \%$ em machos, enquanto em fêmeas apenas redução da \%TBA no grupo $1 \%$. No estudo de 90 dias observou-se: óbitos de animais dos grupos 3 e 4\%, redução de peso corpóreo em fêmeas (6 $6^{\underline{a}}$ semana de exposição) e em machos ( $9^{a}$ semana de

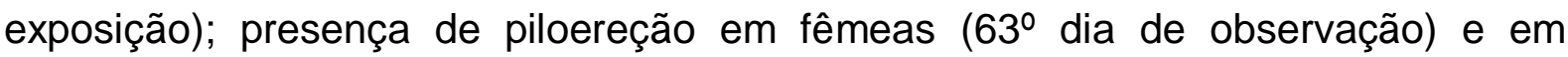
machos ( $70^{\circ}$ dia de observação); no Campo Aberto redução da locomoção e aumento de grooming em fêmeas dos grupos 2 e 4\%; no Labirinto em Cruz Elevado 
redução de \%TBA no grupo 1\% e na avaliação de risco em machos dos grupos 1 e $2 \%$, enquanto em fêmeas houve apenas redução do \%TBA no grupo $1 \%$. Em relação aos parâmetros hematológicos, bioquímicos e anatomopatológicos, a exposição a $S$. occidentalis não causou alterações significantes entre os grupos. Esses resultados, em conjunto, mostraram que a exposição a diferentes concentrações das sementes de S. occidentalis na ração de ratos por 28 e 90 dias foi capaz de causar toxicidade caracterizada pela ocorrência de óbitos, redução de peso corpóreo e piloereção, bem como promoveu um estado comportamental sugestivo de ansiedade, sendo esses efeitos concentração-dependente, tempodependente, e sugerindo ser as fêmeas mais susceptíveis.

Palavras-chave: Senna occidentalis. Ratos. Toxicidade. OECD. 


\begin{abstract}
SANTOS, M. V. Study of oral toxicity and neurotoxicity in rats exposed to Senna occidentalis. [Estudo de toxicidade oral e de neurotoxicidade em ratos expostos a Senna occidentalis]. 2015. 97 f. Dissertação (Mestrado em Ciências) Faculdade de Medicina Veterinária e Zootecnia, Universidade de São Paulo, São Paulo, 2015.
\end{abstract}

The Senna occidentalis, popularly known as fedegoso, is used by several cultures around the world as food and as phytochemical against many human diseases, while in veterinary medicine, there are several spontaneous intoxications reports of production animals as cattle, horses and pigs. This plant intoxication is due to the active compound named dianthrone, founded at high concentration at the seed; it promotes the oxidative phosphorylation uncoupling at mitochondria, leading cellular damages. Thus, the aim of the present study was to evaluate the toxic effects in rats (male and female), particularly the neurotoxic ones, attributable to the oral exposition to different $S$. occidentalis seed concentrations incorporated at the chow $(1,2,3$ and $4 \%$ ), for 28 and 90 days. The evaluation parameters were based on OECD guidelines 407, 408 and 424. We observed: water and chow intake; body weight; clinical signs of toxicity (general activity, vocal trill, irritability for toch, tail grip, auricular and corneal reflex and piloerection); the behavior at Open Field, Elevated Pluz Maze and Object Recognition tests; haematological, biochemistry and anatomopathological parameters. The 28 days study results showed: reducing body weight only at $4 \%$ female group; piloerections at $4 \%$ male and female animals; reducing locomotion and increase grooming by 2 and $4 \%$ female animals at open field test; at the Elevated Pluz Maze aparatus we observed: reducing porcentage time spent at open arms (\%TBA) by the 1\% group and risk assessment by 1, 2 and $4 \%$ males, while only the $1 \%$ females reduced the \%TBA. At the 90 days exposition, we observated: 3 and $4 \%$ animals death, reducing females (from $6^{\text {th }}$ week of exposition) and males (from $9^{\text {th }}$ week) body weight; piloerection presented by female (from $63^{\text {rd }}$ observation day) and male (from $70^{\text {th }}$ day of observation) animals; reducing locomotion and increase grooming by 2 and $4 \%$ female animals at open field test; At Elevated Pluz Maze test, we observed: reducing \%TBA by 1\% group animals and reducing risk assessment by 1 and $2 \%$ males, while reducing \%TBA 
only by $1 \%$ female animals. About the haematological, biochemistry and anatomopathological parameters, the $S$. occidentalis exposition did not caused significant changes between the groups. Taken together this finds, we can notice that the different seed concentrations of $S$. occidentalis exposition for 28 and 90 days was capable to induce toxicity featured by death, reducing body weight and piloerection, as well as anxiety behavior like, in a concentration and time-dependent way and the female animals are more susceptible to $S$. occidentalis toxic effects.

Keywords: Senna occidentalis. Rats. Intoxications. OECD. 


\section{LISTA DE ILUSTRAÇÕES}

Figura 1 - Senna occidentalis. A) Ilustração da Senna occidentalis. B) Fotografia de Senna occidentalis

Figura 2 - Fotografia do Campo Aberto....................................................... 32

Figura 3 - Fotografia do Labirinto em Cruz Elevado........................................

Figura 4 - Consumo médio semanal de água $(\mathrm{ml})$ e de ração $(\mathrm{g})$ de cinco ratos por caixa moradia (machos e fêmeas) expostos ou não (controle) à S. occidentalis na ração (1,2 e 4\%), durante 28 dias...

Figura 5 - Peso corpóreo (em gramas) dos machos expostos ou não (controle) à $S$. occidentalis durante 28 dias em diferentes concentrações incorporadas à ração

Figura 6 - Peso corpóreo (em gramas) das fêmeas expostas ou não (controle) à $S$. occidentalis durante 28 dias em diferentes concentrações incorporadas à ração.

Figura 7 Parâmetro piloereção da avaliação clínica de machos e fêmeas expostos ou não (controle) à Senna occidentalis durante 28 dias em diferentes concentrações incorporadas à ração.

Figura 8 - Parâmetro de levantar (em frequência) observados em machos no campo aberto, no $29^{\circ}$ dia de exposição ou não (controle) à $S$. occidentalis durante 28 dias em diferentes concentrações incorporadas à ração.

Figura 9 - Parâmetros de atividade geral (em frequência) observados em fêmeas no campo aberto, no $29^{\circ}$ dia de exposição ou não (controle) à $S$. occidentalis durante 28 dias em diferentes concentrações incorporadas à ração.

Parâmetros do comportamento de machos observados no labirinto em cruz elevado, no $30^{\circ}$ e $31^{\circ}$ dia de exposição ou não (controle) à $S$. occidentalis durante 28 dias em diferentes concentrações incorporadas à ração.

Figura 11 - Porcentagem de tempo nos braços abertos (\%TBA) observada no labirinto em cruz elevado em fêmeas no $30^{\circ}$ e $31^{\circ}$ dia de exposição ou não (controle) à $S$. occidentalis durante 28 dias em diferentes concentrações incorporadas à ração.

Figura 12 - Peso relativo do pulmão (em g- peso do órgão / peso corpóreo $x$ $100)$ de machos expostos ou não (controle) à $S$. occidentalis durante 28 dias em diferentes concentrações incorporadas à ração.

Figura 13 - Peso relativo do útero (em g- peso do órgão / peso corpóreo $x$ 100) de fêmeas expostas ou não (controle) à $S$. occidentalis durante 28 dias em diferentes concentrações incorporadas à ração.

Figura 14 - Consumo médio semanal de água (ml) e de ração $(\mathrm{g})$ de cinco ratos por caixa moradia (machos e fêmeas) expostos ou não (controle) à S. occidentalis na ração (1 e 2\%), durante 90 dias.....

Figura 15 - Peso corpóreo (em gramas) de machos expostos ou não (controle) à $S$. occidentalis durante 90 dias em diferentes concentrações incorporadas à ração................................................ 
Figura 16 - Peso corpóreo (em gramas) das fêmeas expostas ou não (controle) à $S$. occidentalis durante 90 dias em diferentes concentrações incorporadas à ração

Figura 17 - Parâmetro piloereção da avaliação clínica de machos expostos ou não (controle) à Senna occidentalis incorporadas à ração durante 90 dias.

Figura 18 - Parâmetro piloereção da avaliação clínica de fêmeas expostas ou não (controle) à Senna occidentalis incorporadas à ração durante 90 dias.

Figura 19 - Parâmetros de atividade geral (em frequência) observados em machos no campo aberto, no $91^{\circ}$ dia de exposição ou não (controle) à $S$. occidentalis durante 90 dias em diferentes concentrações incorporadas à ração.

Figura 20 - Parâmetros de atividade geral (em frequência) observados em fêmeas no campo aberto, no $91^{\circ}$ dia de exposição ou não (controle) à $S$. occidentalis durante 90 dias em diferentes concentrações incorporadas à ração.

Figura 21 - Parâmetros do comportamento de machos observados no labirinto em cruz elevado, no $91^{\circ}$ e $92^{\circ}$ dia de exposição ou não (controle) á Senna occidentalis durante 90 dias em diferentes concentrações incorporadas à ração

Figura 22 - Porcentagem de tempo nos braços abertos (\%TBA) observada no labirinto em cruz elevado, em fêmeas, no $91^{\circ}$ e $92^{\circ}$ dia de exposição ou não (controle) á Senna occidentalis durante 90 dias em diferentes concentrações incorporadas a ração.

Figura 23 - Valores de hemoglobina corpuscular média (HCM) de machos expostos ou não (controle) à $S$. occidentalis durante 90 dias em diferentes concentrações incorporadas à ração.

Figura 24 - Parâmetros hematológicos (série branca) de fêmeas expostas ou não (controle) à $S$. occidentalis durante 90 dias em diferentes concentrações incorporadas à ração

Figura 25 - Parâmetro hematológico (série vermelha) de fêmeas expostas ou não (controle) à $S$. occidentalis durante 90 dias em diferentes concentrações incorporadas à ração.

Figura 26 - Peso relativo de órgãos (em g- peso do órgão / peso corpóreo x 100) de machos expostos ou não (controle) à $S$. occidentalis durante 90 dias em diferentes concentrações incorporadas à ração.

Figura 27 - Peso relativo de órgãos (em g- peso do órgão / peso corpóreo x 100 ) de fêmeas expostas ou não (controle) à $S$. occidentalis durante 90 dias em diferentes concentrações incorporadas à ração.

Quadro 1 - Avaliações clínicas de ratos para observação da toxicidade aguda. 


\section{LISTA DE TABELAS}

Tabela 1 - Peso corpóreo (em gramas) de machos e fêmeas expostos ou não (controle) à $S$. occidentalis durante 28 dias em diferentes concentrações incorporadas ração.

Tabela 2 - Parâmetro piloereção da avaliação clínica de machos expostos ou não (controle) durante 28 dias em diferentes concentrações incorporadas ração

Tabela 3 - $\quad$ Parâmetro piloereção da avaliação clínica de fêmeas expostas ou não (controle) à S. occidentalis durante 28 dias em diferentes concentrações incorporadas

Tabela 4 - Parâmetro de atividade geral (em frequência) observados em machos e fêmeas no campo aberto, no $29^{\underline{a}}$ dia de exposição ou não (controle) à $S$. occidentalis durante 28 dias em diferentes concentrações incorporadas

Tabela 5 - Parâmetros do comportamento no labirinto em cruz elevado, de machos e fêmeas, no $30^{\underline{a}}$ e $31^{\underline{a}}$ dia de exposição ou não (controle) à $S$. occidentalis durante 28 dias em diferentes concentrações incorporadas

Tabela 6 - Índice de Reconhecimento de Objetos, observado em machos e fêmeas expostos ou não (controle) à S. occidentalis durante 28 dias em diferentes concentrações incorporadas à ração..................

Tabela 7 - Parâmetros hematológicos (série vermelha) de machos e fêmeas expostos ou não (controle) à S. occidentalis durante 28 dias em diferentes concentrações incorporadas à ração..

Tabela 8 - $\quad$ Parâmetros hematológicos (série branca) de machos e fêmeas expostos ou não (controle) à $S$. occidentalis durante 28 dias em diferentes concentrações incorporadas à ração

Parâmetros bioquímicos de machos e fêmeas expostos ou não (controle) à $S$. occidentalis durante 28 dias em diferentes concentrações incorporadas

Tabela 10 - Peso real (em gramas) e peso relativo de órgãos (em gramas peso do órgão / peso corpóreo x 100) de machos expostos à $S$. occidentalis durante 28 dias em diferentes concentrações incorporadas ração

Tabela 11 - Peso real (em gramas) e peso relativo de órgãos (em gramas peso do órgão / peso corpóreo x 100) de fêmeas expostas à $S$. occidentalis durante 28 dias em diferentes concentrações 
Tabela 12 - Número de óbitos ou eutanásias (eu) de ratos expostos à 3 e $4 \%$ de Senna occidentalis na ração durante 90 dias.

Tabela 13 - Peso corpóreo (em gramas) de machos e fêmeas expostos ou não (controle) à $S$. occidentalis durante 90 dias em diferentes concentrações incorporadas ração.

Tabela 14 - Parâmetro piloereção da avaliação clínica de machos expostos ou não (controle) à S. occidentalis durante 90 dias em diferentes concentrações incorporadas ração

Tabela 15 - Parâmetro piloereção da avaliação clínica de fêmeas expostas ou não (controle) à $S$. occidentalis durante 90 dias em diferentes concentrações incorporadas

Tabela 16 - Parâmetros de atividade geral observados em machos e fêmeas no teste de campo aberto, no $91^{\text {a }}$ dia de exposição ou não (controle) à S.occidentalis durante 90 dias em diferentes concentrações incorporadas

Tabela 17 - Parâmetros do comportamento de machos e fêmeas no teste de labirinto em cruz elevado no $91^{\mathrm{a}}$ e $92^{\mathrm{a}}$ dia de exposição ou não (controle) à $S$. occidentalis durante 90 dias em diferentes concentrações incorporadas

Tabela 18 - Índice de Reconhecimento de Objetos, observado em machos e fêmeas no $93^{\mathrm{a}}$ e $94^{\mathrm{a}}$ dia de exposição ou não (controle) à $S$. occidentalis durante 90 dias em diferentes concentrações incorporadas

Tabela 19 - Parâmetros hematológicos (série vermelha) de machos e fêmeas expostos ou não (controle) à S. occidentalis durante 90 dias em diferentes concentrações incorporadas à ração..

Tabela 20 - Parâmetros hematológicos (série branca) de machos e fêmeas expostos ou não (controle) à $S$. occidentalis durante 90 dias em diferentes concentrações incorporadas ração

Tabela 21 - Parâmetros bioquímicos séricos de machos e fêmeas expostos ou não (controle) à S. occidentalis durante 90 dias em diferentes concentrações incorporadas

Tabela 22 - Peso real e peso relativo de órgãos (em g- peso do órgão / peso corpóreo $\times 100$ ) de machos expostos ou não (controle) à $S$. occidentalis durante 90 dias em diferentes concentrações incorporadas 
Tabela 23 - Peso real e peso relativo de órgãos (em g- peso do órgão / peso corpóreo $\times 100$ ) de fêmeas expostas ou não (controle) à $S$. occidentalis durante 90 dias em diferentes concentrações incorporadas ração......................................................................... 


\section{SUMÁRIO}

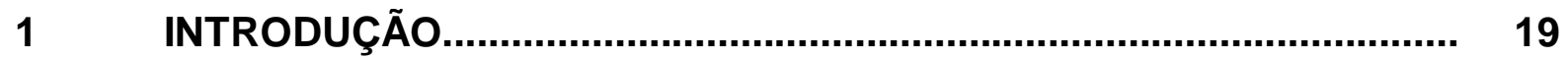

1.1 SENNA OCCIDENTALIS: DESCRIÇÃO E DISTRIBUIÇÃO................... 20

1.2 SENNA OCCIDENTALIS: USOS, PROPRIEDADES FARMACOLÓGICAS E TOXICOLÓGICAS........................................... 22

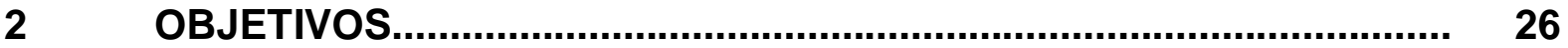

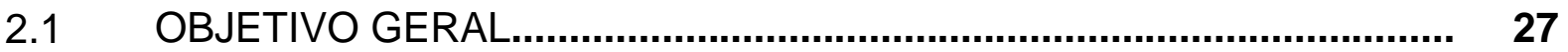

2.2 OBJETIVOS ESPECÍFICOS.............................................................. 27

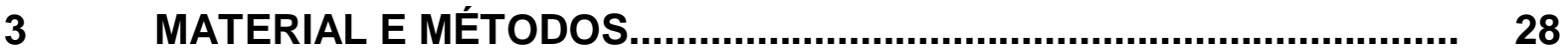

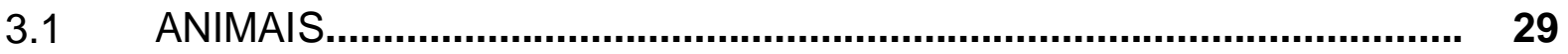

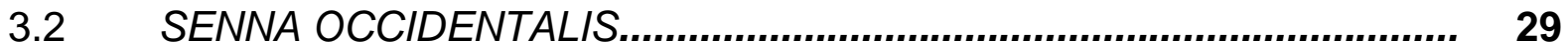

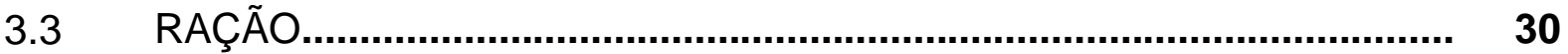

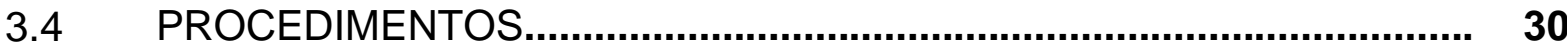

3.4.1 Consumo de água e de ração, mensuração do peso corpóreo e avaliação clínica (screening hipocrático)......................................... $\quad 30$

3.4.2 Atividade motora avaliada no Campo Aberto..................................... 31

3.4.3 Comportamento no Labirinto em Cruz Elevado................................. 33

3.4.4 Teste de Reconhecimento de Objetos.............................................. 34

3.4.5 Avaliação dos parâmetros hematológicos e bioquímicos

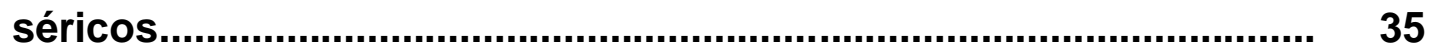

3.4.6 Estudo anatomopatológico......................................................... 36

3.5 DELINEAMENTO EXPERIMENTAL.................................................. 36

3.5.1 Exposição à S. occidentalis por 28 dias.......................................... 36

3.5.2 Exposição à S. occidentalis por 90 dias............................................ 37

3.6 ANÁLISE ESTATÍSTICA.................................................................. 37

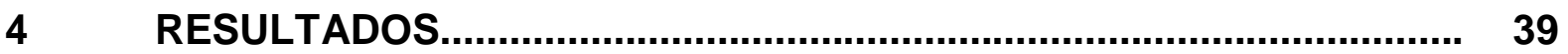

4.1 EXPOSIÇÃO À S. OCCIDENTALIS POR 28 DIAS................................ 40

4.1.1 Consumo de água e ração, peso corpóreo e avaliação clínica......... 40

4.1.2 Campo Aberto....................................................................... 45

4.1.3 Labirinto em Cruz Elevado....................................................... 47

4.1.4 Reconhecimento de Objetos...................................................... 49 


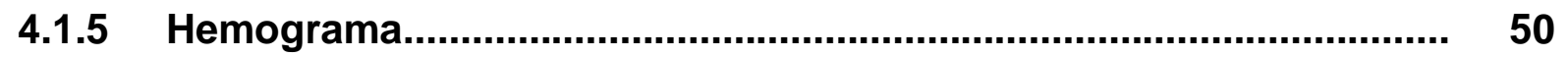

4.1.6 Bioquímica Sérica........................................................................... 51

4.1.7 Peso real e relativo de órgãos.......................................................... 52

4.1.8 Estudo anatomopatológico......................................................... 56

4.2 EXPOSIÇÃO À S. OCCIDENTALIS POR 90 DIAS.............................. 56

4.2.1 Consumo de água e ração, peso corpóreo e avaliação clínica......... 57

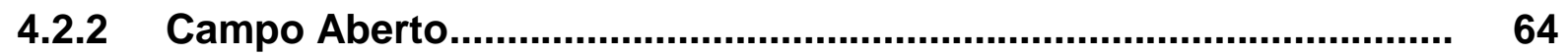

4.2.3 Labirinto em Cruz Elevado........................................................... 65

4.2.4 Reconhecimento de Objetos....................................................... 67

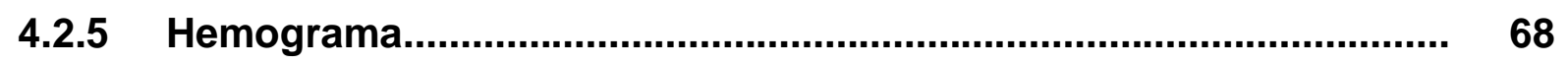

4.2.6 Bioquímica Sérica................................................................. 71

4.2.7 Peso real e relativo de órgãos...................................................... 72

4.2.8 Estudo anatomopatológico........................................................... 77

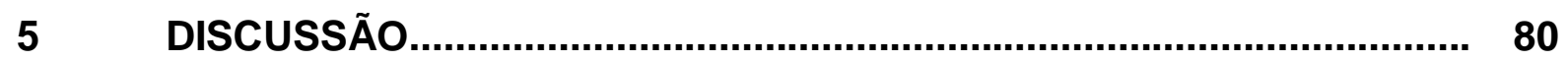

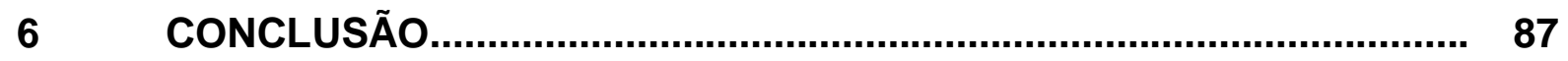

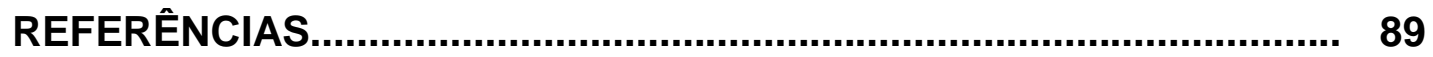




\section{INTRODUÇÃO}

\subsection{SENNA OCCIDENTALIS: DESCRIÇÃO E DISTRIBUIÇÃO}

Senna occidentalis, denominada antigamente como Cassia occidentalis (NAKAGE et al., 2000) é uma espécie herbácea cosmopolita tropical, comumente encontrada nas Américas, pertencente à família Fabaceae (Leguminosae) e subfamília Caesalpinioideae (LOMBARDO; KYIOTA; KANECO, 2009). É uma planta encontrada em pastagens, solos férteis, ao longo de estradas ou contaminando lavouras de soja, milho e sorgo (BARROS, 1999; TOKARNIA et al., 2000). Rodrigues et al. (2005) ressaltam que essa planta invasora é muito frequente no Estado de Mato Grosso do Sul em pastagens, pomares, terrenos baldios e solos cultivados, especialmente com a soja.

Como a $S$. occidentalis cresce junto às plantações, esta pode, além de competir com nutrientes úteis aos cereais, contaminá-los com suas sementes durante a coleta mecânica. Caso não haja separação adequada dos tipos de sementes, principalmente através da peneiragem e separção por densidade, as sementes desta planta invasora de cultura poderão vir a compor parte do produto final destinado à alimentação tanto animal como humana, acarretando um desbalanço nutricional, além do risco de incluir nesta dieta alguns componentes tóxicos que oderá ser previamente conhecido, ou não (BARBOSA-FERREIRA, 2008).

Essa planta possui flores amarelo-ouro e vagens curvas, com ápices voltados para cima (RAFFl et al., 2003). A brotação ocorre na primavera e as inflorescências no início do verão. É um arbusto ruderal de cerca de um metro de altura, podendo atingir dois metros, ou ainda quatro metros quando em crescimento livre (Figura 1). Geralmente, as flores amarelas são assimétricas, enantiostílicas, sem bractéolas no pedicelo, com androceu heteromórfico e anteras basifixas, bem como folhas comumente com nectários entre os pares de folíolos e frutos predominantemente indeiscentes (IRWIN; BARNEBY, 1982). Os frutos são formados dentro das vagens achatadas com 10 a $14 \mathrm{~cm}$ de comprimento. Essas vagens, quando imaturas, são 
verdes, com faixas transversais marrons; tornam-se secas e de coloração marrom no outono, com a maturação das sementes (LORENZI, 1991).

As denominações populares mais comuns, para esta espécie, são: "fedegoso", devido ao odor fétido característico; "mata-pasto", por ser facilmente encontrada como contaminante de áreas de pastoreio; e "café negro", visto que as suas sementes são usadas para preparar uma bebida semelhante ao café (CORREA 1926; TESKES; TRENTINI; 1994; LOMBARDO; KIYOTA; KANEKO, 2009).

Figura 1 - Senna occidentalis. A) llustração da S. occidentalis. B) Foto S. occidentalis

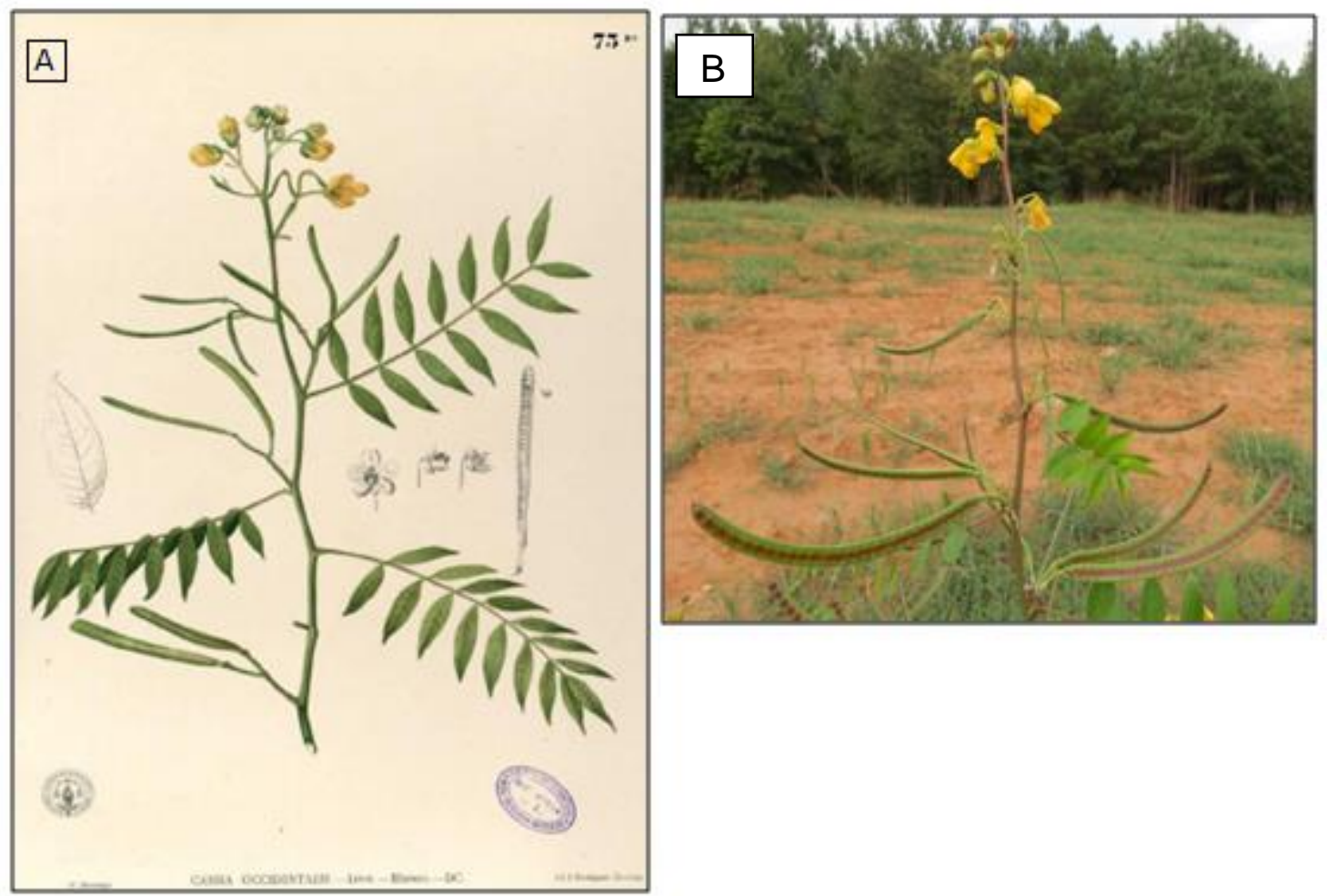

Fonte: indicar a fonte da figura

Legenda: A) Biblioteca digital do Jardim Botânico Real de Madri -Lám. 73BIS. Diponível em http://bibdigital.rjb.csic.es/ing/Libro.php?Libro=13. Accessado em 28 de abril 2015; B) Fotografia de S. occidentalis. Plantas do Monastério THE HOLY SPIRIT, Georgia, USA.

Disponível

em: http://www.jimbotany.com/Monastery_Plants/Senna\%20occidentalis.htm. Acessado em 28 de abril 2015. 


\subsection{SENNA OCCIDENTALIS: USO, PROPRIEDADES FARMACOLÓGICAS E TOXICOLÓGICAS}

Popularmente, a Senna occidentalis é utilizada tanto por via oral quanto por via tópica, sendo a sua principal aplicação como laxativo (BADKE et al., 2011) ou para afecções de pele (DELMUT et al., 2013). Muitos estudos demostram ainda, que esta planta apresenta diversas atividades terapêuticas como: ação antimicrobiana (LOMBADO et al., 2015); hepatoprotetora (JAFRI et al., 1999); antimutagênica e anticarcinogênica (SHARMA et al., 1999); antimalárica (TONA et al., 2001); antiparasitária (CORDEIRO; FÉLIX, 2014); antioxidante, analgésica, antiinflamatória, imunoestimulante, inseticida, hipoglicemiante, diurética e alivia a cólica em recém-nascidos (VIEGAS et al., 2006; LOMBARDO; KIYOTA; KANEKO, 2009; YADAV et al., 2010; LOMBADO et al., 2015). Contudo, suas propriedades fitoquímicas e eficácia medicinal são dependentes da localização geográfica e da estação do ano, pois as concentrações dos princípios ativos podem variar (YADAV et al., 2010).

Apesar das aplicações terapêuticas, existe grande preocupação quanto aos efeitos tóxicos dessa planta. Em medicina veterinária as intoxicações normalmente ocorrem no final de outono e no início do inverno, quando começa a escassez de pasto (TAKEUTI et al., 2011). A ingestão da planta pode ocorrer naturalmente, quando o animal pastoreia a planta invasora, ou acidentalmente pela ingestão de ração, feno ou cereais contaminados com as sementes desta (RAFIl et al., 2003). A contaminação desses alimentos ocorre pela colheita mecânica de lavouras contaminadas por S. occidentalis (NAKAGE et al., 2000). Todas as partes da planta são tóxicas (caule, folhas, vagem, sementes e raízes), porém são nas sementes que mais se concentram os princípios tóxicos (MÉNDEZ; RIET-CORREA, 2000; BARBOSA-FERREIRA et al., 2010).

Ainda, algumas pessoas (população local de Haryana - Índia) comumente fazem uso das sementes torradas da $S$. occidentalis como substituto do café (YADAV et al., 2010) e nas classes de baixa renda da Índia e do Sri Lanka, as sementes quando macias, são usadas cotidianamente como substituto do feijão (LOMBARDO; KIYOTA; KANEKO, 2009). Segundo Medoua e Mbofung (2007), não 
existe riscos nesse tipo de consumo, pois compostos tóxicos são eliminados durante o processo de torrefação e cozimento.

O quadro da intoxicação com a $S$. occidentalis já foi descrito em várias espécies de animais, como bovinos, caprinos, ovinos, suínos, entre outros, avaliados em diferentes protocolos experimentais (LOMBARDO; KIYOTA; KANEKO, 2009). Já as intoxicações espontâneas foram descrita em bovinos, suínos e equinos (MÉNDEZ; RIET-CORREA, 2000; CARMO et al., 2011; OLIVEIRA-FILHO et al., 2013).

Os sinais clínicos da intoxicação por $S$. occidentalis em geral incluem, independentemente da espécie animal, ataxia, fraqueza muscular, perda de peso corporal e morte. Degeneração do músculo esquelético é a lesão predominante encontrada na maioria dos animais intoxicados, causando palidez muscular acentuada de músculos esqueléticos individuais ou grupos musculares; pode também ser encontrado miopatia degenerativa do músculo do miocárdio, congestão e edema pulmonar, hipertrofia das células hepáticas e também vacuolização (BARBOSA-FERREIRA et al., 2010; OLIVEIRA-FILHO et al., 2013).

Em bovinos, a intoxicação ocorre geralmente em animais maiores de um ano de idade, sob a forma de surtos, afetando de 10 a $60 \%$ do rebanho, com alta letalidade (BARROS,1993; BARROS et al., 1999). Os sinais clínicos descritos em bovinos intoxicados são diarreia, mioglobinúria, fraqueza muscular, ataxia dos membros posteriores, relutância em mover-se, decúbitos esternal, lateral e morte. $\mathrm{Na}$ maioria das vezes, os animais permanecem alerta e conservam parcialmente o apetite até poucas horas antes da morte. Na fase final da doença, há marcada elevação da atividade sérica de creatinina fosfoquinase (CPK) e aspartato aminotransferase (AST); os animais podem adoecer até duas semanas após cessada a ingestão da planta (MÉNDEZ; RIET-CORREA, 2000).

A S. occidentalis também se mostra capaz de promover efeitos imunotóxicos e anemia microcítica e hipocrômica em aves (NAKAGE et al., 2000; SILVA et al., 2003) e ratos (MARIANO-SOUZA, 2005, 2009), bem como causar alterações na resposta inflamatória de ratos, mostrando ter um efeito antiflogístico (MARIANOSOUZA, 2005). Em intoxicações experimentais por S.occidentalis, a planta foi capaz de provocar queda no consumo de ração e água e diminuição do peso corporal em aves (SILVA et al., 2003) e mamíferos (TASAKA, 2000; BARBOSA-FERREIRA et al., 2005; MARIANO-SOUZA, 2005, 2009). Aragão et al. (2009), ao estudar a toxicidade 
reprodutiva do extrato da planta $S$. occidentalis em ratas gestantes, observaram efeito abortivo nas doses de 250 e $500 \mathrm{mg} / \mathrm{kg}$.

Em relação a presença de princípios ativos presentes nas espécies do gênero Senna, estudos fitoquímicos revelaram uma grande diversidade de substâncias inéditas e bioativas, com padrões moleculares variados, como proteínas, carboidratos, taninos, alcaloides, saponinas, esteroides, ácidos graxos, sendo as antraquinonas e os flavonoides os constituintes mais frequentes na maioria das espécies (VIEGAS et al., 2006; LOMBARDO; KIYOTA; KANEKO, 2009). Rai e Shok (1983) relatam que as antraquinonas na $S$. occidentalis é bem maior nas sementes do que nas folhas e raízes.

As antraquinonas são definidas quimicamente como substâncias fenólicas derivadas da dicetona do antraceno. São abundantes na natureza, sendo encontradas em fungos, líquens e plantas. Os compostos antraquinonicos são usualmente laxativos devido aos derivados glicosídicos; estes irritam a mucosa do intestino grosso, aumentando a motilidade intestinal e, consequentemente, diminuindo a reabsorção de água (DAVE; LEDWANI, 2012).

Dentre as antraquinonas, destaca-se a diantrona como o princípio ativo tóxico mais relevante da S. occidentalis(SPINOSA; GÓRNIAK; PALERMO-NETO, 2008; DAVE; LEDWANI, 2012). O mecanismo de ação tóxica, determinado pela diantrona presente em maior concentração nas sementes da planta, é o desacoplamento da fosforilação oxidativa mitocondrial (YADAV et al., 2010). Esta antraquinona agiria diretamente sobre o metabolismo desta organela, desestabilizando-a (CAVALIERE et al., 1997) e possivelmente causando alterações na estrutura interna da mesma (SPINOSA; GÓRNIAK; PALERMO-NETO, 2008; BARBOSA-FERREIRA et al., 2011). Os danos mitocondriais ocorreriam especialmente nos órgãos com maior demanda de oxigênio (HARAGUICHI et al., 1998).

O'Hara e Pierce (1974) mostram que as sementes da Senna induziram desaclopamento da fosforilação oxidativa e depressão respiratória nas mitocôndrias isoladas do coração de coelhos intoxicados. Outros estudos bioquímicos das partículas mitocondriais realizados por Lewis e Shibamoto (1989) mostraram que os extratos de sementes de Senna inibem a oxidação de NADH e de transporte de elétrons em mitocôndrias de coração de bovinos e suínos.

Borghetti, Ferreira et al. (2004), empregando microscopia eletrônica, também relataram lesões de mitocôndrias em tecidos de ratos expostos por duas semanas a 
1, 2 e 4\% das sementes da S. occidentalis na ração. Observou-se em microscopia óptica degenerações da fibra nos músculos esqueléticos (tibial, peitoral e diafragma) e cardíaca, além de degeneração vacuolar no fígado, e nefrose leve nos túbulos contorcidos proximais além de vacuolizção da matéria branca (espongiose) do sistema nervoso central. Essas alterações ocorreram de forma dose-dependente moderada a severa.

Considerando que a $S$. occidentalis pode contaminar as pastagens e culturas de cereais e que em medicina popular atribui-se a ela efeitos terapêuticos, o presente estudo tem por objetivo avaliar em ratos o seu potencial tóxico, embasado nos protocolos da OECD (Organisation for Economic Co-operation and Development) 407, 408 e 424, os quais são recomendados para avaliar a toxicidade oral em 28 e 90 dias de exposição e a neurotoxicidade, respectivamente. Para isso foram usadas as concentrações de 1\%, 2\% 3\% e $4 \%$ de sementes da planta adicionada em ração comercial; a escolha dessas concentrações basearam-se em estudos prévios de toxicidade subaguda em ratos, que mostraram efeito dosedependente (BARBOSA-FERREIRA et al., 2005; CARVALHO, 2013). 
OBJETIVOS 


\section{OBJETIVOS}

\subsection{OBJETIVO GERAL}

Avaliar os possíveis efeitos tóxicos produzidos em ratos pelas sementes da $S$. occidentalis na ração, por 28 e 90 dias, em diferentes concentrações, considerando os protocolos da OECD 407 e 408 recomendados para a avalição da toxicidade oral, bem como o protocolo OECD 424, indicado para avaliação de neurotoxicidade.

\subsection{OBJETIVOS ESPECÍFICOS}

- Estudar os possíveis efeitos tóxicos produzidos pela administração da semente da planta S. occidentalis incorporadas à ração, por 28 dias (protocolo OECD 407), avaliando-se: consumo de água e de ração, peso corpóreo e sinais clínicos de toxicidade, bem como hemograma e exame bioquímico sanguíneo e achados anatomopatológico;

- Estudar os possíveis efeitos tóxicos produzidos pela administração da semente da planta S. occidentalis incorporadas à ração, por 90 dias (protocolo OECD 408), avaliando-se: consumo de água e de ração, peso corpóreo e sinais clínicos de toxicidade, bem como hemograma e exame bioquímico sanguíneo e achados anatomopatológico;

- Avaliar a neurotoxicidade (protocolo OECD 424) decorrente da exposição por 28 e 90 dias às sementes de $S$. occidentalis incorporadas à ração, empregando os testes comportamentais de campo aberto, labirinto em cruz elevado e reconhecimento de objetos. 
MATERIAL E MÉTODOS 


\section{MATERIAL E MÉTODOS}

\subsection{ANIMAIS}

Foram utilizados ratos Wistar, machos e fêmeas adultos, pesando aproximadamente 200-230 g, provenientes do Biotério do Departamento de Patologia, da Faculdade de Medicina Veterinária e Zootecnia da Universidade de São Paulo (FMVZ/USP). Os animais foram alojados, em número de cinco, em caixas moradia de plástico medindo $40 \times 50 \times 20 \mathrm{~cm}$, as quais foram mantidas em salas com temperatura e umidade ambiente aproximadamente constantes $\left(20 \pm 3^{\circ} \mathrm{C}\right.$ e 65 a $70 \%$ respectivamente) e com ciclo de doze horas de claro e escuro, sendo a luz acesa às 6:00 horas. Água e comida foram fornecidas ad libitum aos animais durante todo procedimento experimental.

Os animais submetidos aos procedimentos experimentais aqui descritos foram submetidos à Comissão de Ética no Uso de Animais (CEUA) da FMVZ/USP, tendo sido aprovados (Protocolado sob n2876, de 6 de fevereiro de 2013).

\subsection{SENNA OCCIDENTALIS}

As sementes maduras de $S$. occidentalis, utilizadas neste experimento, foram coletadas de uma plantação existente no Mato Grosso do Sul em março de 2006, sendo trazidas para o Centro de Pesquisa em Toxicologia Veterinária (CEPTOX) do Departamento de Patologia Veterinária (VPT) da FMVZ/USP, campus Pirassununga, São Paulo, e mantidas congeladas (freezer $-20^{\circ} \mathrm{C}$ ) até o momento do uso. A Senna occidentalis foi identificada pela Dra. Maria Eneida Fidalgo do Instituo Botânico de São Paulo, SP, Brasil e lá se encontra depositada sob o número SP-363817. 


\subsection{RAÇÃO}

As sementes de $S$. occidentalis foram separadas dos cotilédones, congeladas em nitrogênio líquido e trituradas em liquidificador comercial (Wallita®). Este procedimento foi realizado a frio devido à possibilidade de inativação dos princípios ativos, e consequente perda da toxicidade das sementes, pelo aquecimento na trituração em moinhos de facas. As sementes trituradas foram incorporadas à ração comercial (Nuvital $\left.{ }^{\circledR}\right)$, que foi esfarelada. Esta mistura foi homogeneizada em misturador (Marconi® modelo 206) e imediatamente peletizada. Foram preparadas quatro concentrações diferentes de sementes (1\%, 2\%, 3\% e 4\%) na ração. Para o grupo controle, a ração comercial foi esfarelada e repeletizada, sem adição de sementes.

\subsection{PROCEDIMENTOS}

\subsubsection{Consumo de água e de ração, mensuração do peso corpóreo e avaliação clínica (screnning hipocrático)}

O consumo de água e de ração do grupo de cinco animais contidos na caixa moradia foi mensurado a cada 2 dias, sendo obtido o consumo médio semanal de machos e de fêmeas. A mensuração do peso dos animais foi realizada uma vez por semana, sendo calculada a média e o respectivo erro padrão de cada grupo.

A avaliação clínica ou screnning hipocrático é utilizada para avaliar atividade e coordenação do sistema motor, reflexos, atividades sobre o sistema nervoso central e sistema nervoso autônomo. Os animais foram avaliados em sua própria gaiola moradia, inicialmente, diariamente na primeira semana e, posteriormente, uma vez por semana a partir da segunda semana. Foram observados os seguintes parâmetros: atividade geral, frêmito vocal, irritabilidade resposta ao toque, aperto de cauda, reflexo auricular, reflexo corneal e piloereção, conforme descrito no quadro 1. 
Quadro 1 - Avaliações clínicas de ratos para observação da toxicidade aguda. Adaptada de Brito, 1994

\begin{tabular}{|c|c|c|}
\hline $\begin{array}{l}\text { Observações } \\
\text { Gerais }\end{array}$ & Descrição dos sinais de toxicidade & $\begin{array}{l}\text { Pontuação } \\
\text { Basal* }^{*}\end{array}$ \\
\hline Atividade geral & $\begin{array}{l}\text { Verificar atividade geral do animal na gaiola } \\
\text { moradia após estímulo; entende-se, como } \\
\text { atividade geral, dentre outros comportamentos, } \\
\text { a presença de locomoção, levantar, farejar e/ } \\
\text { ou parado. }\end{array}$ & 3 \\
\hline Frêmito vocal & $\begin{array}{l}\text { Observar se há emissão de som sem nenhuma } \\
\text { estimulação ou toque. }\end{array}$ & 0 \\
\hline Irritabilidade & $\begin{array}{l}\text { Assoprar e tocar levemente para examinar } \\
\text { reação. }\end{array}$ & 0 \\
\hline $\begin{array}{l}\text { Resposta ao } \\
\text { toque }\end{array}$ & $\begin{array}{l}\text { Pegar, tocar num intervalo de tempo mais } \\
\text { prolongado (mais de } 15 \text { segundos) e examinar } \\
\text { respostas. }\end{array}$ & 4 \\
\hline $\begin{array}{l}\text { Aperto de } \\
\text { cauda }\end{array}$ & $\begin{array}{l}\text { Apertar região próxima a ponta da cauda com } \\
\text { bastante intensidade. }\end{array}$ & 3 \\
\hline $\begin{array}{l}\text { Reflexo } \\
\text { auricular }\end{array}$ & $\begin{array}{l}\text { Estalar dos dedos uma vez e analisar reflexo. } \\
\text { Logo após estalar várias vezes seguidas e } \\
\text { observar reflexos. }\end{array}$ & 3 \\
\hline $\begin{array}{l}\text { Reflexo } \\
\text { corneal }\end{array}$ & $\begin{array}{l}\text { Aproximar uma pinça, lentamente, até os olhos } \\
\text { do animal, sem encostá-la, e verificar se o } \\
\text { animal tem reflexo de fechá-los. }\end{array}$ & 4 \\
\hline Piloereção & $\begin{array}{l}\text { Observar se os pelos estão eretos e sua } \\
\text { intensidade. }\end{array}$ & 0 \\
\hline
\end{tabular}

Escores: $0=$ ausência do sinal; $1=$ raros sinais; $2=$ poucos sinais; $3=$ sinais moderados; $4=$ sinais intensos.

\subsubsection{Atividade motora avaliada no Campo Aberto}

A atividade motora foi avaliada no $29^{\circ}$ dia, para os animais expostos por 28 dias à planta (Protocolo da OECD 407) ou 91ํ dia, para os animais expostos por 90 dias (Protocolo da OECD 408). Para tanto cada animal foi colocado individualmente no centro do campo aberto, sendo observado por cinco minutos, sempre durante o mesmo período do dia (tarde). O campo aberto consiste de uma arena de madeira, com $97 \mathrm{~cm}$ de diâmetro, cercada por parede lateral de $27 \mathrm{~cm}$ de altura. $O$ chão da 
arena é dividido em vinte e cinco partes aproximadamente iguais (Figura 2). Entre a observação de um animal e outro, o aparelho foi limpo com solução de álcool a 5\% para evitar-se a interferência do odor do animal anterior. Observou-se a frequência de locomoção, de levantar e de grooming (autolimpeza). Define-se uma unidade de locomoção o ato de o animal penetrar com as quatro patas em uma das divisões do chão da arena; unidade de levantar corresponde à postura de o animal permanecer apoiado nas patas posteriores, com o tronco perpendicular ao chão, tendo a cabeça dirigida para cima, podendo ou não tocar com as patas dianteiras as paredes do campo aberto; e o comportamento de grooming ou autolimpeza quando o animal lambe as patas ou os pelos, fazendo sua higiene. O registro da frequência dos parâmetros foi feito por intermédio de um contador manual.

Figura 2 - Campo Aberto

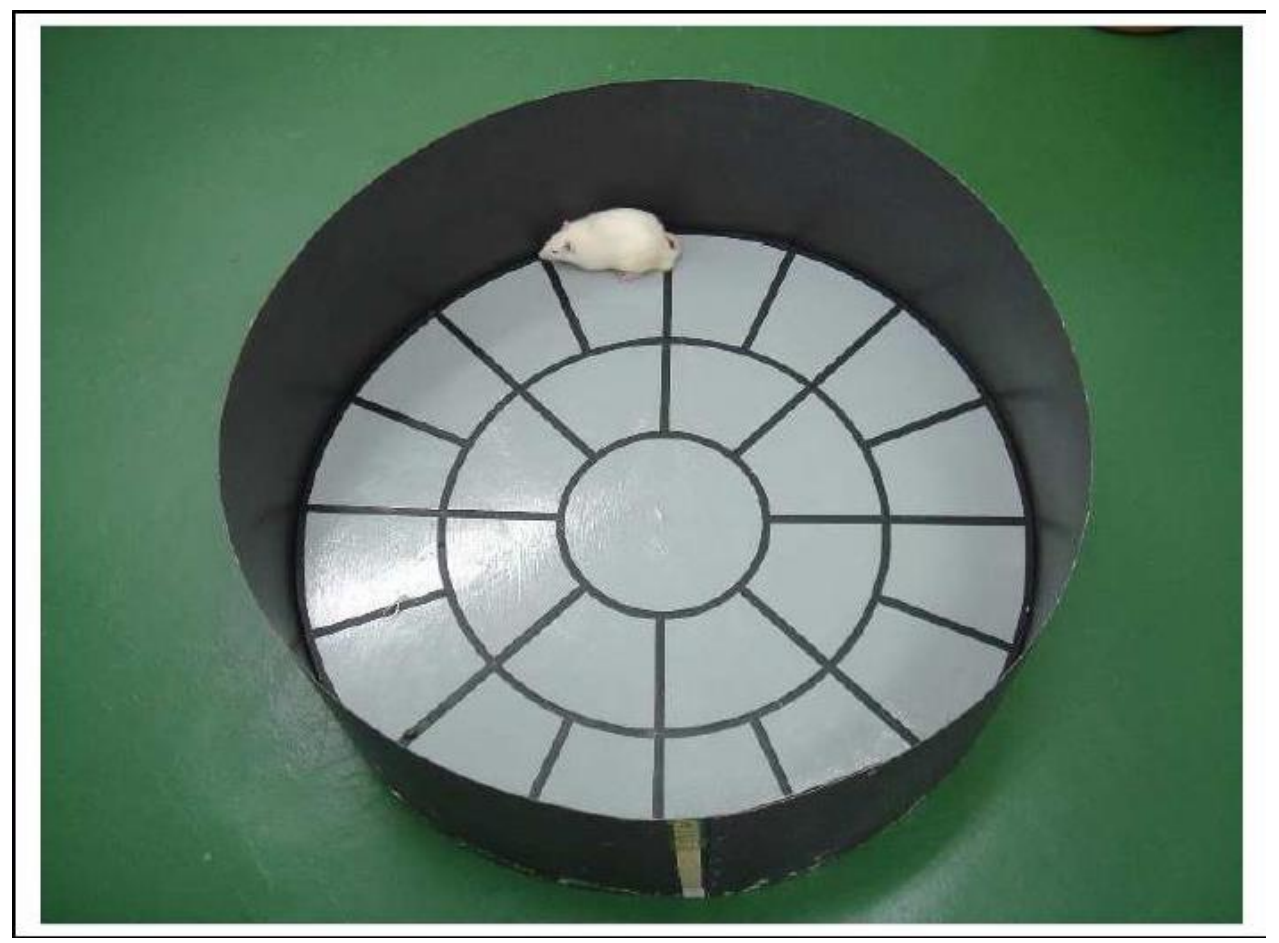

Fonte: (SANDINI, T. M., 2012). 


\subsubsection{Comportamento no Labirinto em Cruz Elevado}

O labirinto em cruz elevado tornou-se um dos modelos mais amplamente usados para detectar atividade ansiolítica de drogas (HOGG, 1996). O teste baseiase na aversão natural de roedores aos espaços abertos e foi validado em ratos (PELOW et al., 1985).

O labirinto é constituído de uma estrutura de madeira pintada de cor cinza chumbo fosco, em forma de cruz, com dois braços abertos (BA) $(50 \times 10 \mathrm{~cm})$ e dois braços fechados (BF) $(50 \times 10 \times 40 \mathrm{~cm})$ conectados por uma plataforma central $(10 \mathrm{x}$ $10 \mathrm{~cm}$ ) e elevado a $55 \mathrm{~cm}$ do chão (Figura 3).

O comportamento no labirinto em cruz elevado foi avaliado no $29^{\circ}-30^{\circ}$ dia ou 91-92º dia após o início da exposição à planta (Protocolos da OECD 407 e 408, respectivamente), sempre no período da tarde.

$\mathrm{O}$ rato foi colocado, individualmente, no centro do labirinto, com a cabeça voltada para um dos braços fechados e, durante 5 minutos, observaram-se os parâmetros: números de entradas nos braços abertos (EBA); tempo de permanência nos braços abertos (TBA); número de avaliação do risco (quando o animal explora o espaço vazio dos braços abertos do labirinto), autolimpeza, número de levantar e frequência de locomoção (número de entradas nos BA + número de entradas nos $\mathrm{BF})$.

O registro de entradas nos braços abertos e fechados foi feito por intermédio de contador manual. Cronometrou-se (em segundos) o tempo de permanência nos braços do labirinto. Entre as observações de cada animal, o labirinto foi limpo com solução de álcool $5 \%$.

A avaliação do comportamento foi feita diretamente dos animais no labirinto por um período de cinco minutos.

Com os dados obtidos, calculou-se a porcentagem de entradas e do tempo dispendido nos braços abertos, conforme mostrado a seguir:

$$
\% E B A=\frac{E B A \times 100}{E B A+E B F} \quad \% \mathrm{TBA}=\frac{\mathrm{TBA} \times 100}{\mathrm{TBA}+\mathrm{TBF}}
$$


Calculou-se também o número total de cruzamentos entre braços abertos e braços fechados:

№ T. CRUZ. = № EBA + № EBF

Figura 3 - Labirinto em cruz elevado

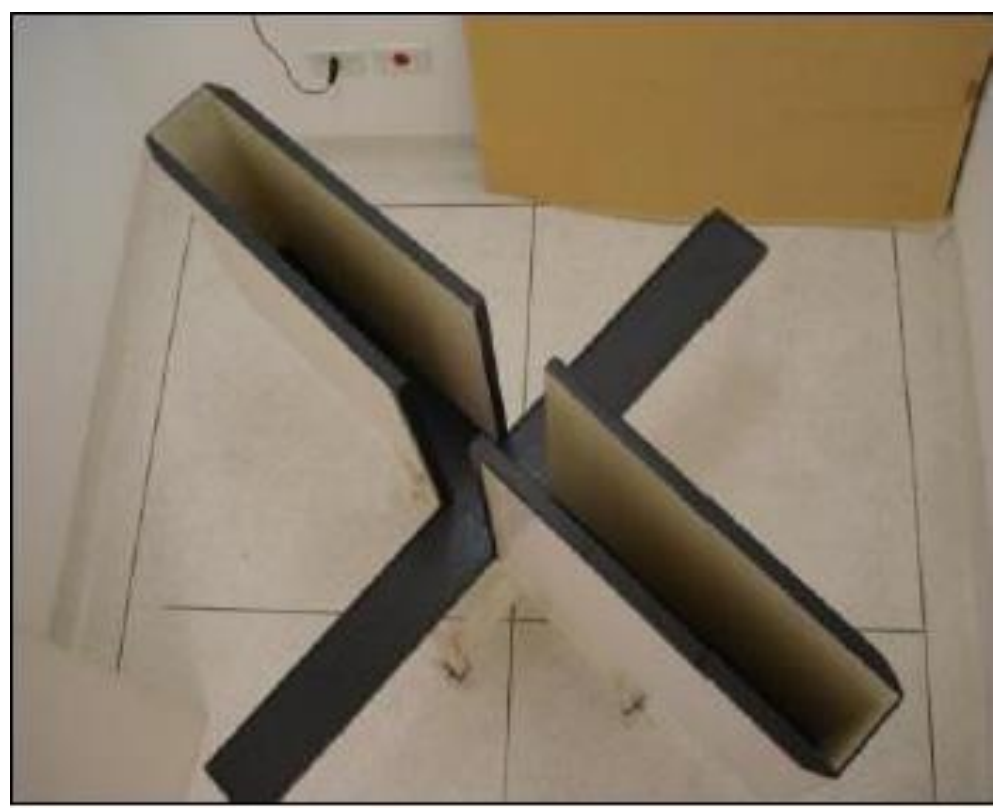

FONTE: (SANDINI, T. M., 2012).

\subsubsection{Teste de Reconhecimento de Objetos}

Quando os roedores são apresentados a objetos familiares e novos, eles passam a maior parte do tempo explorando o novo objeto. Este comportamento típico tem sido utilizado para desenhar um paradigma comportamental conhecido como tarefa de reconhecimento de objetos (CRUZ et al., 2010; ENNACEUR; DELACOUR, 1988).

O teste de reconhecimento de objetos foi avaliado no $31^{\circ}$ e $32^{\circ}$ dia (Protocolo da OECD 407) ou no 93ํ e 94 dia (Protocolo da OECD 408) após o início da exposição à planta, sempre no período da tarde.

$O$ aparato utilizado para esse experimento foi o campo aberto descrito no item 3.4.2. Os objetos utilizados para o reconhecimento foram dois objetos idênticos (A) e 
um objeto diferente $(B)$. Inicialmente 0 rato foi colocado individualmente no campo aberto com a presença dos objetos idênticos $(A)$ para livre exploração por 5 minutos. Após 2 horas, o animal foi recolocado no campo aberto na presença dos objetos $\mathrm{A} e$ $B$, permitindo a livre exploração de ambos os objetos por 5 minutos, para avaliar a memória de curta duração. $O$ teste foi repetido 24 horas depois na presença dos objetos A e B para avaliar a memória de longa duração. Foi quantificado o tempo (em segundos) de permanência do animal junto aos objetos, quer tocando ou farejando-os.

Com os dados obtidos foi calculado o índice de reconhecimento pela fórmula (CRUZ et al. 2010):

Índice de reconhecimento $=$ TB

$$
T A+T B
$$

Onde: $\mathrm{TA}=\mathrm{o}$ tempo (s) gasto para explorar um objeto familiar, $\mathrm{TB}=$ tempo (s) gasto para explorar o novo objeto

\subsubsection{Avaliação dos parâmetros hematológicos e bioquímicos séricos}

Para a coleta de sangue os animais foram anestesiados com xilazina e cetamina ( 5 e $50 \mathrm{mg} / \mathrm{kg}$ respectivamente, por via intraperitoneal); posteriormente, a coleta foi realizada através da técnica de punção cardíaca. Utilizou-se anticoagulante EDTA para a avaliação do hemograma completo, série vermelha e branca. O hemograma foi realizado por meio de um sistema automatizado ( $A B X$ VET®, HORIBA).

Para a realização da análise bioquímica, coletou-se amostras de sangue, sem anticoagulante, que foram mantidas em temperatura ambiente por 30 minutos para retração do coágulo, e, em seguida, estas foram submetidas à centrifugação (4000 rpm, 10 minutos) para a coleta do soro, o qual foi acondicionado em eppendorfs de 2 $\mathrm{ml}$, congelados e armazenados a $-80^{\circ} \mathrm{C}$, até o dia das diferentes avaliações bioquímicas.

As determinações dos níveis séricos de alanina aminotransferase (ALT), aspartatotransferase (AST), gama-glutamiltransferase (GGT), ureia e creatinina 
foram realizados por meio da utilização de kit comercial da marca Bioclin em equipamento da CELM - SBA 200. A metodologia empregada para determinação dos níveis séricos atendeu as especificações recomendadas pelo fabricante.

\subsubsection{Estudo anatomopatológico}

Após a coleta do sangue descrita no item anterior e a eutanásia, foi feita a abertura e inspeção das cavidades torácica e abdominal de cada animal. A seguir, os seguintes órgãos foram retirados e pesados: rins, pulmão, coração, fígado, baço, adrenal, testículos, epidídimos, vesícula seminal, ovários e úteros. Os pesos relativos desses órgãos foram obtidos, através da seguinte fórmula: (peso do órgão / peso corpóreo) x 100.

Para o estudo histológico utilizou-se o fígado, rim, baço pulmão e adrenal, que foi fixado em formol $10 \%$ tamponado, processado seguindo as técnicas de rotina do laboratório.

\subsection{DELINEAMENTO EXPERIMENTAL}

\subsubsection{Exposição à S. occidentalis por 28 dias}

Foram utilizados 80 ratos, sendo 40 machos e 40 fêmeas. Tanto os machos quanto as fêmeas foram separados em cinco grupos iguais $(n=10$ animais por grupo), sendo três experimentais que receberam diferentes concentrações de semente de $S$. occidentalis na ração (1, 2 e 4\%) e um grupo controle que recebeu apenas a ração repeletizada, durante 28 dias. Durante o período de exposição, durante a primeira semana, os animais foram observados diariamente quanto aos sinais de toxicidade clínica(item 3.4.1) e, posteriormente, essa avaliação foi realizada uma vez por semana. Além disso, foram mensurados o peso corpóreo e o consumo de água e de ração, conforme descrito no item 3.4.1. Ao término da 
exposição por 28 dias iniciaram-se as observações comportamentais, conforme descrito nos itens 3.4.2, 3.4.3 e 3.4.4, sendo mantida a exposição à planta. No $35^{\circ}$ dia após o início da administração da planta, os animais foram anestesiados para coleta de sangue e posterior eutanásia para o estudo anatomopatológico, conforme mencionado nos itens 3.4 .5 e 3.4.6.

\subsubsection{Exposição a S. occidentalis por 90 dias}

Foram empregados 100 ratos, sendo 50 machos e 50 fêmeas. Tanto os machos como as fêmeas foram separados em cinco grupos iguais ( $n=10$ animais por grupo): sendo quatros experimentais que receberam diferentes concentrações de semente de $S$. occidentalis na ração (1, 2, 3 e 4\%) e um grupo controle que recebeu apenas a ração, durante 90 dias. Durante o período de administração, os animais

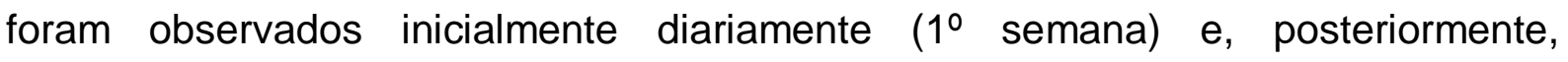
semanalmente para avaliar sinais de toxicidade, conforme descrito no item 3.4.1. Além disso, foram mensurados o peso corpóreo e o consumo de água e de ração, conforme descrito no item 3.4.1. Ao término da exposição por 90 dias iniciou as observações comportamentais, conforme descrito nos itens 3.4.2, 3.4.3 e 3.4.4, sendo mantida a exposição à planta. No 97º dia após o início da administração da planta, os animais foram anestesiados para coleta de sangue e posterior eutanásia para os estudos anatomopatológico, bioquímico e hematológico, conforme mencionado nos itens 3.4 .5 e 3.4.6.

\subsection{ANÁLISE ESTATÍSTICA}

Empregou-se o programa estatístico GraphPadPrism 6.00® (GraphPad Software, Inc., San Diego, CA, USA). Uma vez que os dados foram paramétricos, foi utilizada a análise de variância ANOVA de uma via ou quando existiram dois fatores (tempo e tratamento) para serem avaliados, empregou-se a ANOVA de duas vias seguida pelo teste de comparações múltiplas de Dunnet e Bonferroni, 
respectivamente. Para análise não paramétrica foi utilizado Kruskal-Wallis seguida pelo Dunn's. Em todas as análises efetuadas, as diferenças foram consideradas significantes quando $p<0,05$. 
RESULTADDOS 


\section{RESULTADOS}

4.1 EXPOSIÇÃO À S. OCCIDENTALIS POR 28 DIAS

\subsubsection{Consumo de água e de ração, peso corpóreo e avaliação clínica}

O consumo de água e de ração não foi submetido à análise estatística, uma vez que cada grupo foi constituído de 10 animais, os quais foram alojados em duas caixas moradias distintas ( $n=5$ animais por caixa), sendo obtido apenas o consumo médio semanal de cada grupo. Esses dados são ilustrados pela figura 4. Assim, nota-se algumas flutuações no consumo de água e de ração entre os grupos, em particular, no de ração das fêmeas. 
Figura 4 - Consumo médio semanal de água $(\mathrm{ml})$ e de ração $(\mathrm{g})$ de cinco ratos por caixa moradia (machos e fêmeas) expostos ou não (controle) a Senna occidentalis na ração (1, 2 e 4\%), durante 28 dias
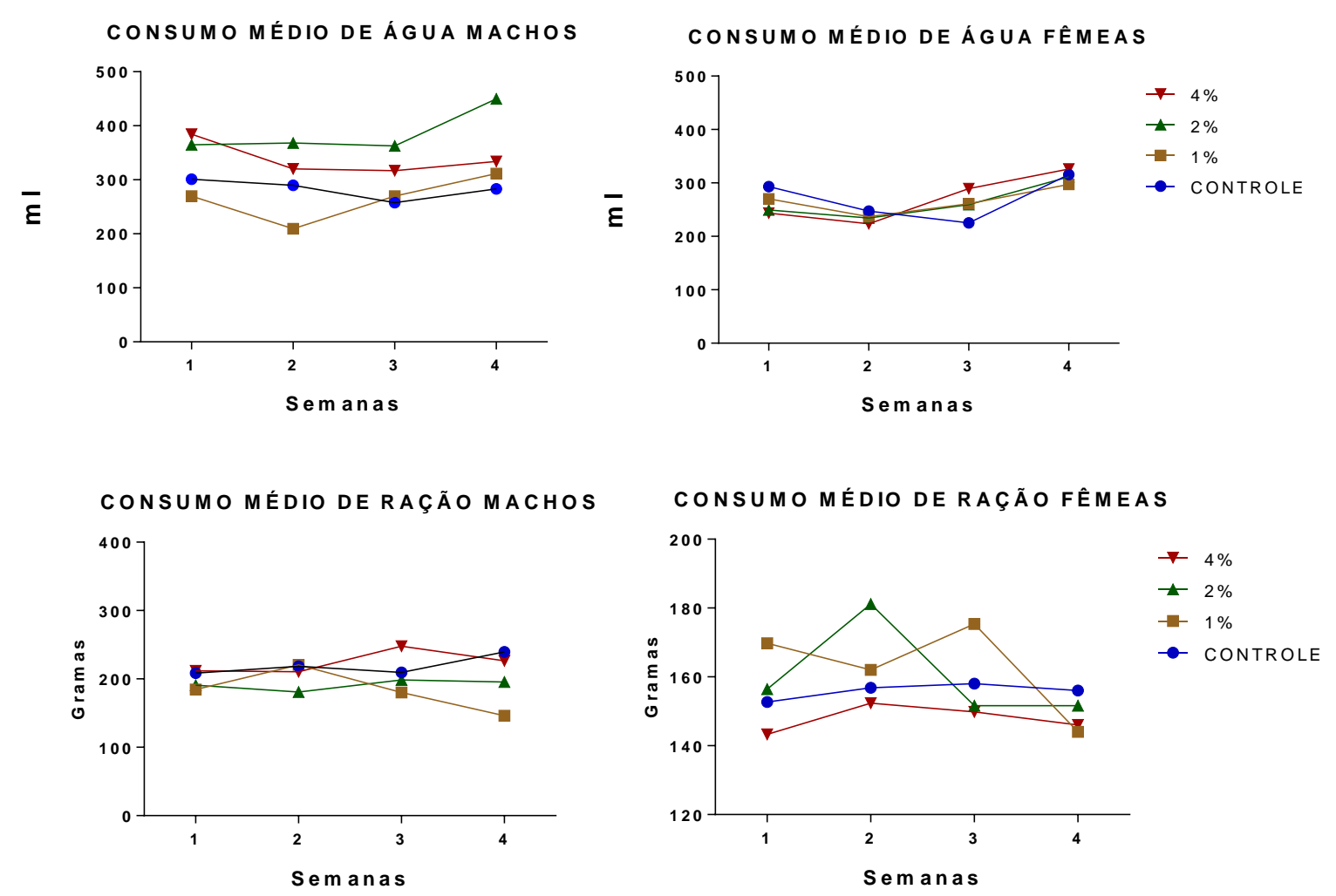

Fonte: (SANTOS, M. V., 2015).

A tabela 1 e as figuras 5 e 6 mostram os resultados referentes ao peso corpóreo de machos e fêmeas expostos ou não (controle) à $S$. occidentalis incorporadas à ração em diferentes concentrações durante 28 dias. A Anova de duas vias mostrou que em machos não houve diferenças significantes entre os grupos.

Em fêmeas, a Anova de duas vias mostrou diferenças significantes entre os grupos em relação ao tratamento $[F(3 / 36)=18,16 \quad p<0,0001]$; semanas $[F(3 / 108)=18,74 \quad p<0,0001]$, sem interação entre os fatores. O pós-teste de Bonferroni apontou redução significante de peso em todas as semanas de tratamento apenas no grupo tratado de $4 \%$, $\left(p<0,001\right.$ na $1^{\text {a }}$ semana; $p<0,0001$ na $2^{\text {a }}$ semana; $p<0,01$ na $3^{\text {a }}$ semana; $p<0,0001$ na $4^{\text {a }}$ semana) quando comparado ao controle. 
Tabela 1 - Peso corpóreo(em gramas) de machos e fêmeas expostos ou não (controle) à Senna occidentalis por 28 dias em diferentes concentrações na ração. Dados expressos em média \pm erro padrão ( $n=10$ animais/ grupo). ${ }^{* *} p<0,01,{ }^{* * *} p<0,001$ e ${ }^{* \star *} \mathrm{p}<0,0001$, Anova de duas vias seguida do teste Bonferroni

\begin{tabular}{llcccc}
\hline \multirow{2}{*}{ SEMANAS } & \multirow{2}{*}{ SEXO } & \multirow{2}{*}{ CONTROLE } & \multicolumn{3}{c}{ Senna occidentalis } \\
\cline { 4 - 6 } & & & $1 \%$ & $2 \%$ & $4 \%$ \\
\hline \multirow{2}{*}{ PRIMEIRA } & MACHOS & $294,89 \pm 7,78$ & $274,37 \pm 8,88$ & $290,42 \pm 8,98$ & $281,74 \pm 3,37$ \\
& FÊMEAS & $199,41 \pm 2,70$ & $205,80 \pm 2,42$ & $195,91 \pm 4,17$ & $178,57 \pm 3,47 * * *$ \\
\multirow{2}{*}{ SEGUNDA } & MACHOS & $314,55 \pm 9,14$ & $279,26 \pm 15,55$ & $304,67 \pm 10,26$ & $297,94 \pm 9,33$ \\
& FÊMEAS & $204,82 \pm 2,84$ & $208,59 \pm 2,74$ & $196,91 \pm 4,33$ & $181,88 \pm 3,43 * * * *$ \\
\multirow{2}{*}{ TERCEIRA } & MACHOS & $317,77 \pm 9,64$ & $282,57 \pm 16,42$ & $309,65 \pm 12,60$ & $319,28 \pm 14,13$ \\
& FÊMEAS & $211,84 \pm 2,82$ & $212,99 \pm 3,16$ & $204,74 \pm 4,73$ & $193,25 \pm 4,60^{* *}$ \\
\multirow{2}{*}{ QUARTA } & MACHOS & $356,34 \pm 8,36$ & $323,32 \pm 13,27$ & $326,05 \pm 13,29$ & $331,19 \pm 13,41$ \\
& FÊMEAS & $219,48 \pm 2,73$ & $216,69 \pm 3,01$ & $207,37 \pm 4,86$ & $192,63 \pm 5,29 * * * *$ \\
\hline
\end{tabular}

Fonte: (SANTOS, M. V., 2015).

Figura 5 - Peso corpóreo (em gramas) de machos expostos ou não (controle) à Senna occidentalis durante 28 dias em diferentes concentrações incorporadas à ração. Dados expressos em média \pm erro padrão ( $n=10$ animais/ grupo). Anova de duas vias seguida do teste Bonferroni

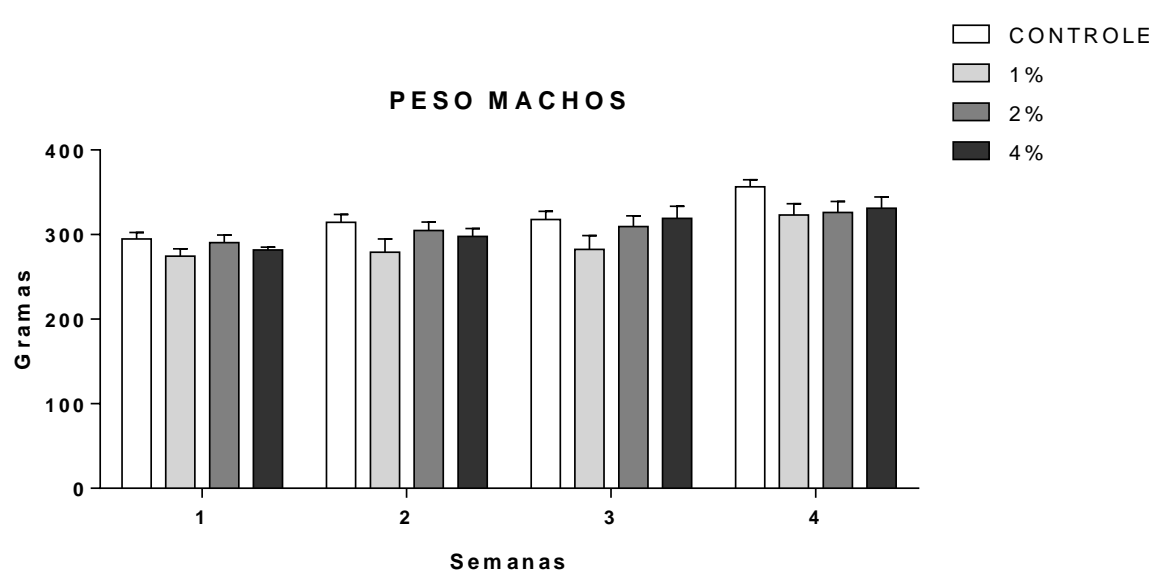

Fonte: (SANTOS, M. V., 2015). 
Figura 6 - Peso corpóreo (em gramas) defêmeas expostas ou não (controle) à Senna occidentalis durante 28 dias em diferentes concentrações incorporadas à ração. Dados expressos em média \pm erro padrão $(n=10$ animais/ grupo. ${ }^{* *} p<0,01 ;{ }^{* * *} p<0,001 ;{ }^{* * * *} p<0,0001$. Anova de duas vias seguida do teste Bonferroni

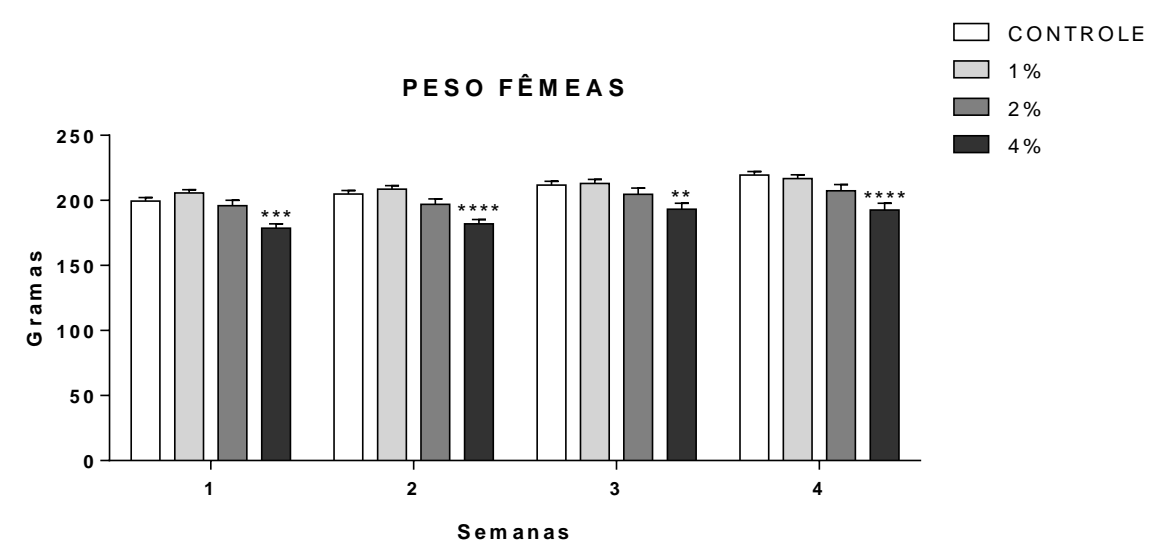

Fonte: (SANTOS, M. V., 2015).

Dentre os oito parâmetros da avaliação clínica observados, apenas piloereção mostrou diferenças significantes tanto em machos quanto em fêmeas. As tabelas $2 \mathrm{e}$ 3 e a figura 7 mostram os resultados desses parâmetros em machos e em fêmeas expostos ou não (controle) às diferentes concentrações de S.occidentalis incorporadas à ração durante 28 dias. Em machos, a Anova de duas vias mostrou diferenças significantes em relação ao tratamento $[F(3 / 36)=162,6, p<0,0001]$, aos dias de observação $[F(9 / 324)=95,77, p<0,0001]$, com interação entre os fatores $[F(27 / 324)=95,77, \quad p<0,0001]$. O pós-teste de Bonferroni mostrou aumento significante do escore do grupo $4 \%$, no $14^{\circ}, 21^{\circ}$ e $28^{\circ}$ dia de observação $(p<0,0001$ para todos os dias), em relação ao grupo controle.

Em fêmeas, a Anova de duas vias mostrou diferenças significantes em relação ao tratamento $[F(3 / 36)=182,3, \quad p<0,0001]$, aos dias de observação $[F(9 / 324)=83,14, \quad p<0,0001]$, com interação entre ao fatores $[F(27 / 324)=83,14$, $\mathrm{p}<0,0001)$. O pós-teste de Bonferroni mostrou aumento significante do escore do grupo $4 \%$ no $14^{\circ}, 21^{\circ}$ e $28^{\circ}$ dia de observação ( $p<0,0001$ para todos os dias), em relação ao grupo controle.

Vale destacar que, durante a avaliação clínica dos animais na caixa moradia, apenas na primeira semana de exposição à planta, foi constatadaa ocorrência de fezes amolecidas somente no grupo $4 \%$, tanto em machos como em fêmeas. 
Tabela 2 - Parâmetro piloereção da avaliação clínica de machos expostos ou não (controle) à Senna occidentalis durante 28 dias em diferentes concentrações incorporadas à ração. Dados expressos em média \pm erro padrão dos escores obtidos nos dias de observação. $\mathrm{N}=10$ animais por grupo. ${ }^{* * * *} p<0,0001$. Anova de duas vias seguida pelo pós-teste de Bonferroni

\begin{tabular}{ccccc}
\hline \multirow{2}{*}{ DIAS DE OBSERVAÇÃO } & \multirow{2}{*}{ CONTROLE } & \multicolumn{3}{c}{ S. occidentalis } \\
\cline { 2 - 5 } & $1 \%$ & $2 \%$ & $4 \%$ \\
\hline $1^{\circ}$ & $0 \pm 0$ & $0 \pm 0$ & $0 \pm 0$ & $0 \pm 0$ \\
$2^{\circ}$ & $0 \pm 0$ & $0 \pm 0$ & $0 \pm 0$ & $0 \pm 0$ \\
$3^{o}$ & $0 \pm 0$ & $0 \pm 0$ & $0 \pm 0$ & $0 \pm 0$ \\
$4^{\circ}$ & $0 \pm 0$ & $0 \pm 0$ & $0 \pm 0$ & $0 \pm 0$ \\
$5^{\circ}$ & $0 \pm 0$ & $0 \pm 0$ & $0 \pm 0$ & $0 \pm 0$ \\
$6^{o}$ & $0 \pm 0$ & $0 \pm 0$ & $0 \pm 0$ & $0 \pm 0$ \\
$7^{\circ}$ & $0 \pm 0$ & $0 \pm 0$ & $0 \pm 0$ & $0 \pm 0$ \\
$14^{\circ}$ & $0 \pm 0$ & $0 \pm 0$ & $0 \pm 0$ & $1,00 \pm 0^{* * * *}$ \\
$21^{\circ}$ & $0 \pm 0$ & $0 \pm 0$ & $0 \pm 0$ & $1,20 \pm 0,13^{* * * *}$ \\
$28^{\circ}$ & $0 \pm 0$ & $0 \pm 0$ & $0 \pm 0$ & $1,20 \pm 0,13^{* * * *}$ \\
\hline
\end{tabular}

Fonte: (SANTOS, M. V., 2015).

Escores: $0=$ ausência do sinal; $1=$ raros sinais; $2=$ poucos sinais; $3=$ sinais moderados; $4=$ sinais intensos

Tabela 3 - Parâmetro piloereção da avaliação clínica de fêmeas expostas ou não (controle) à Senna occidentalis durante 28 dias em diferentes concentrações incorporadas à ração. Dados expressos em média \pm erro padrão dos escores obtidos nos dias de observação. $\mathrm{N}=10$ animais por grupo. ${ }^{* * *} p<0,0001$. Anova de duas vias seguida pelo pós-teste de Bonferroni

\begin{tabular}{ccccc}
\hline \multirow{2}{*}{ DIAS DE OBSERVAÇÃO } & \multirow{2}{*}{ CONTROLE } & \multicolumn{3}{c}{ S. occidentalis } \\
\cline { 2 - 5 } & & $1 \%$ & $2 \%$ & $4 \%$ \\
\hline $1^{\circ}$ & $0 \pm 0$ & $0 \pm 0$ & $0 \pm 0$ & $0 \pm 0$ \\
$2^{\circ}$ & $0 \pm 0$ & $0 \pm 0$ & $0 \pm 0$ & $0 \pm 0$ \\
$3^{\circ}$ & $0 \pm 0$ & $0 \pm 0$ & $0 \pm 0$ & $0 \pm 0$ \\
$4^{\circ}$ & $0 \pm 0$ & $0 \pm 0$ & $0 \pm 0$ & $0 \pm 0$ \\
$5^{\circ}$ & $0 \pm 0$ & $0 \pm 0$ & $0 \pm 0$ & $0 \pm 0$ \\
$6^{\circ}$ & $0 \pm 0$ & $0 \pm 0$ & $0 \pm 0$ & $0 \pm 0$ \\
$7^{\circ}$ & $0 \pm 0$ & $0 \pm 0$ & $0 \pm 0$ & $0 \pm 0$ \\
$14^{\circ}$ & $0 \pm 0$ & $0 \pm 0$ & $0 \pm 0$ & $1,00 \pm 0^{* * * *}$ \\
$21^{\circ}$ & $0 \pm 0$ & $0 \pm 0$ & $0 \pm 0$ & $1,20 \pm 0,13^{* * * *}$ \\
$28^{\circ}$ & $0 \pm 0$ & $0 \pm 0$ & $0 \pm 0$ & $1,40 \pm 0,16^{* * * *}$ \\
\hline
\end{tabular}

Fonte: (SANTOS, M. V., 2015).

Escores: $0=$ ausência do sinal; $1=$ raros sinais; $2=$ poucos sinais; $3=$ sinais moderados; $4=$ sinais intensos 
Figura 7 - Parâmetro piloereção da avaliação clínica de machos e fêmeas expostos ou não (controle) à Senna occidentalis durante 28 dias em diferentes concentrações incorporadas à ração. Dados expressos em média \pm erro padrão dos escores obtidos nos dias de observação. $\mathrm{N}=10$ animais por grupo. ${ }^{* * \star \star} \mathrm{p}<0,0001$. Anova de duas vias seguida pelo pós-teste de Bonferroni
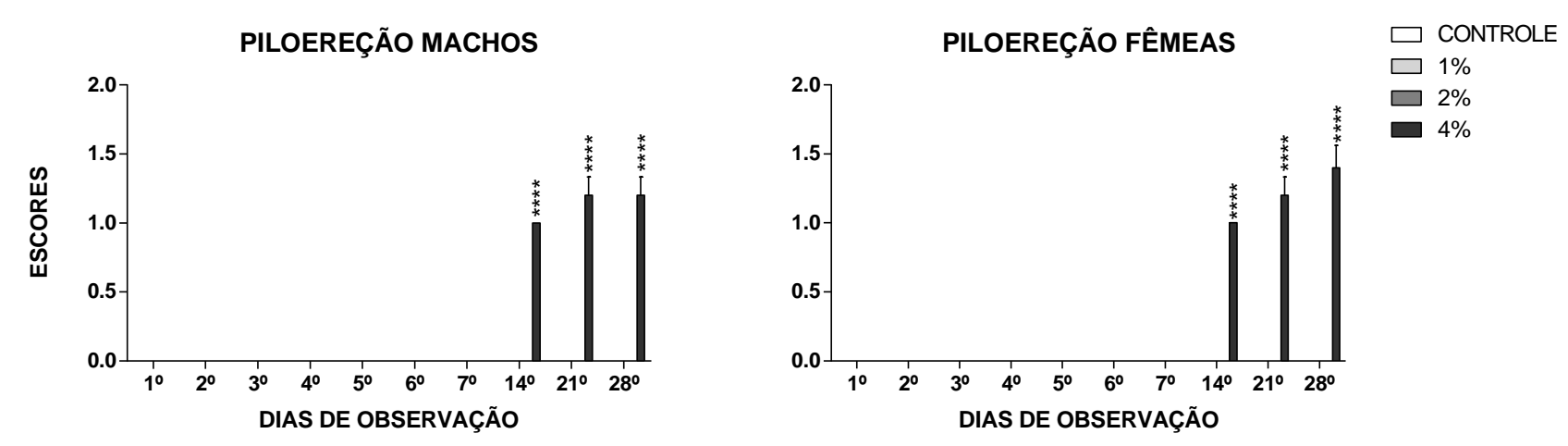

Fonte: (SANTOS, M. V., 2015).

\subsubsection{Campo aberto}

A tabela 4 e as figuras 8 e 9mostram os resultados do teste comportamental de Campo Aberto dos animais expostos à S. occidentalis por 28 dias. Em machos, a Anova de uma via mostrou que houve diferença significante entre os grupos apenas na frequência de levantar $[F(3 / 36)=4,25 p=0,01]$ e o teste de Dunnet mostrou redução desse parâmetro nos animais de $1 \%(p<0,05)$ em relação ao grupo controle.

Em fêmeas, a Anova de uma via mostrou diferenças significantes entre os grupos quanto a locomoção $[F(3 / 36)=3,24 \quad p=0,03]$ e grooming $[F(3 / 36)=7,98$ $\mathrm{p}=0,0003]$. O pós-teste de Dunnet mostrou redução da locomoção no grupo $2 \%$ $(p<0,05)$ em relação ao controle e do grooming nos grupos $2 \%(p<0,001)$ e $4 \%$ $(p<0,01)$, em relação ao grupo controle. 
Tabela 4 - Parâmetros de atividade geral (em frequência) observados em machos e fêmeas no campo aberto, no $29^{\circ}$ dia de exposição ou não (controle) àSenna occidentalis incorporada a ração. Dados expressos em média \pm erro padrão $(n=10$ animais/grupo). ${ }^{*} p<0,05,{ }^{* *} p<0,01,{ }^{* \star} p<0,001$, Anova seguida do teste de Dunnet

\begin{tabular}{cccccc}
\hline \multirow{2}{*}{ COMPORTAMENTOO } & \multirow{2}{*}{ SEXO } & \multirow{2}{*}{ CONTROLE } & \multicolumn{3}{c}{ Senna occidentalis } \\
\cline { 4 - 6 } & & & $1 \%$ & $2 \%$ & $4 \%$ \\
\hline \multirow{2}{*}{ LOCOMOÇÃO } & MACHOS & $101,70 \pm 13,21$ & $97,2 \pm 6,35$ & $111,30 \pm 7,33$ & $107,30 \pm 7,18$ \\
& FÊMEAS & $113,90 \pm 10,45$ & $102,80 \pm 5,96$ & $80,40 \pm 4,43 * *$ & $86,10 \pm 3,44 * *$ \\
\multirow{2}{*}{ LEVANTAR } & MACHOS & $26,70 \pm 4,78$ & $11,5 \pm 1,50 *$ & $30,8 \pm 4,27$ & $28,1 \pm 2,59$ \\
& FÊMEAS & $16,80 \pm 1,87$ & $25,6 \pm 3,77$ & $15,6 \pm 1,77$ & $15,00 \pm 2,03$ \\
\multirow{2}{*}{ GROOMING } & MACHOS & $6,70 \pm 1,33$ & $8,90 \pm 1,04$ & $7,90 \pm 1,18$ & $7,90 \pm 1,18$ \\
& FÊMEAS & $3,80 \pm 0,59$ & $6,50 \pm 1,42$ & $9,80 \pm 0,89 * * *$ & $8,80 \pm 0,65 * *$ \\
\hline
\end{tabular}

Fonte: (SANTOS, M. V., 2015).

Figura 8 - Parâmetro de levantar(em frequência) observado em machos no campo aberto, no 29ㅇ dia de exposição ou não (controle) à Senna occidentalisdurante 28 dias em diferentes concentrações incorporadas a ração. Dados expressos em média \pm erro padrão $(n=10$ animais/grupo). ${ }^{*} \mathrm{p}<0,05$, Anova seguida do teste de Dunnet

LEVANTAR MACHO

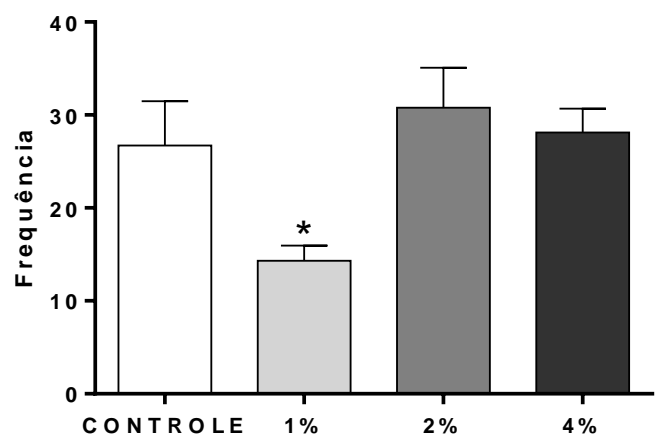

Fonte: (SANTOS, M. V., 2015). 
Figura 9 - Parâmetros de atividade geral (em frequência) observados em fêmeas no campo aberto, no 29ํํㄹ dia de exposição ou não (controle) à Senna occidentalis durante 28 dias em diferentes concentrações incorporadas a ração. Dados expressos em média \pm erro padrão ( $n=10$ animais/grupo). ${ }^{* *} p<0,01,{ }^{* * *} p<0,001$, Anova seguida do teste de Dunnet

LOCOMOÇÃ O FÊMEA

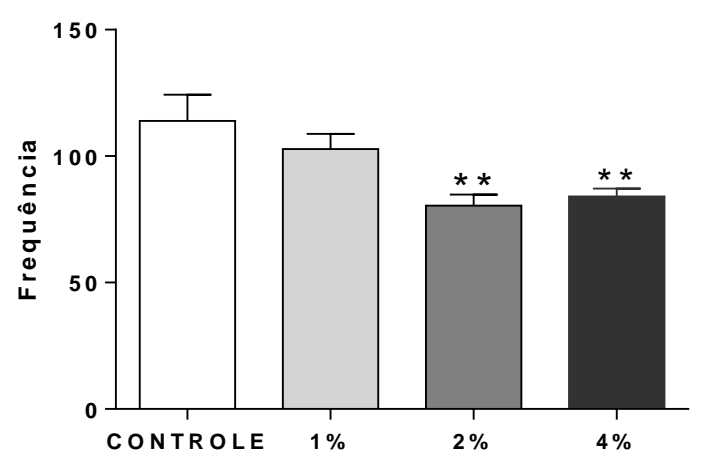

GROOMING FÊMEA

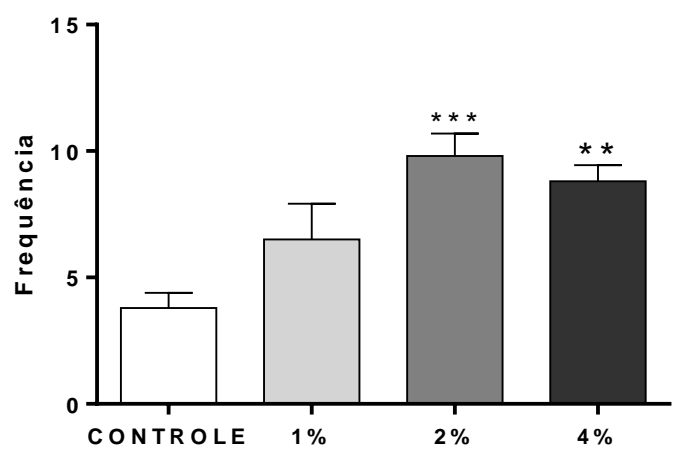

Fonte: (SANTOS, M. V., 2015).

\subsubsection{Labirinto em cruz elevado}

A tabela 5 e as figuras 10 e 11 apresentam os resultados de teste comportamental de Labirinto em Cruz Elevado dos animais expostos à $S$. occidentalis por 28 dias.

Em machos, a Anova de uma via mostrou que houve diferença significante entre os grupos em relação à frequência: do grooming $[F(3 / 36)=8,53 p<0,0002]$ onde houve diminuição do parâmetro nos animais de $2 \%$ (pós-teste Dunnet, $p<0,01$ ) e $4 \%$ (pós-teste Dunnet, $p<0,05)$; e na avaliação de risco $[F(3 / 36)=23,01 p<0,0001]$, com redução desse parâmetro em todos os grupos tratados (pós-teste Dunnet, $p<0,0001)$, em relação ao grupo controle. Em relação aos resultados obtidos em porcentagem, o teste de Kruskal-Wallis mostrou que em machos diferenças significantes entre os grupos na \%TBA [KW $(4 / 15,19), p=0,002]$, e o pós teste Dunn's mostrou que houve diminuição desse parâmetro no grupo $1 \%(p<0,001)$, em relação ao grupo controle.

Em fêmeas, nos resultados obtidos pelos cálculos de porcentagem, o teste de Kruskal-Wallis mostrou que houve diferenças significantes entre os grupos apenas no parâmetro \%TBA [KW(4/14,42), $\mathrm{p}=0,002]$ e o pós-teste Dunn's mostrou que 
houve diminuição desse parâmetro no grupo $1 \%(p<0,01)$, em relação ao grupo controle (Tabela 5 e Figura 10).

Tabela 5 - Parâmetros do comportamento no labirinto em cruz elevado, de machos e fêmeas, no $29^{\circ}$ e $30^{\circ}$ dia de exposição ou não (controle) à Senna occidentalis incorporada à ração. Dados expressos em média \pm erro padrão ( $n=10$ animais por grupo). ${ }^{*} p<0,05 ;{ }^{* *} p<0,01$; ${ }^{* * *} p<0,001 ;{ }^{* * * *} p<0,0001$, Anova seguida do teste de Dunnet (para dados paramétricos frequência) e Kruskal-Wallis seguido do teste de Dunn's (para dados não paramétricos $\%)$

\begin{tabular}{cccccc}
\hline \multirow{2}{*}{ PARÂMETROS } & \multirow{2}{*}{ SEXO } & \multirow{2}{*}{ CONTROLE } & \multicolumn{3}{c}{ Senna occidentalis } \\
\cline { 4 - 6 } & & & $1 \%$ & $2 \%$ & $4 \%$ \\
\hline \multirow{2}{*}{$\%$ EBA $^{1}$} & MACHOS & $6,08 \pm 2,25$ & $2,43 \pm 1,65$ & $8,95 \pm 3,33$ & $12,64 \pm 4,88$ \\
& FÊMEAS & $11,19 \pm 3,88$ & $11,85 \pm 5,49$ & $6,11 \pm 5,00$ & $8,54 \pm 3,25$ \\
\%TBA ${ }^{2}$ & MACHOS & $13,27 \pm 1,84$ & $4,29 \pm 0,52^{* * *}$ & $8,21 \pm 1,67$ & $11,66 \pm 2,86$ \\
& FÊMEAS & $11,73 \pm 2,55$ & $2,85 \pm 0,77^{* *}$ & $7,88 \pm 1,34$ & $10,33 \pm 2,33$ \\
No T. CRUZ. & MACHOS & $8,10 \pm 1,28$ & $7,90 \pm 0,59$ & $6,30 \pm 1,01$ & $7,50 \pm 1,41$ \\
(BA+BF) $^{3}$ & FÊMEAS & $9,12 \pm 1,19$ & $6,60 \pm 0,78$ & $7,10 \pm 0,62$ & $6,30 \pm 0,70$ \\
GROOMING & MACHOS & $6,40 \pm 0,73$ & $7,22 \pm 0,96$ & $2,40 \pm 0,62 * *$ & $3,20 \pm 0,88^{*}$ \\
& FÊMEAS & $2,80 \pm 0,74$ & $3,90 \pm 0,71$ & $4,30 \pm 0,84$ & $2,60 \pm 0,60$ \\
AVAL. RISCO & MACHOS & $18,10 \pm 1,40$ & $10,20 \pm 1,01 * * * *$ & $6,80 \pm 1,01 * * * *$ & $7,20 \pm 0,89 * * * *$ \\
& FÊMEAS & $6,00 \pm 0,84$ & $6,80 \pm 0,80$ & $5,10 \pm 1,10$ & $7,00 \pm 0,82$ \\
OLHAR PARA BAIXO & MACHOS & $8,80 \pm 1,33$ & $4,10 \pm 0,94$ & $6,60 \pm 1,45$ & $7,00 \pm 1,33$ \\
& FÊMEAS & $5,50 \pm 0,90$ & $4,60 \pm 0,90$ & $4,80 \pm 1,10$ & $6,00 \pm 1,23$ \\
\hline
\end{tabular}

Fonte: (SANTOS, M. V., 2015).

${ }^{1} \%$ EBA $=\%$ de entradas nos braços abertos; ${ }^{2} \%$ TBA $=\%$ de tempo nos braços abertos; ${ }^{3}$ número total de cruzamentos entre braços abertos e fechados

Figura 10- Parâmetros do comportamento de machos observados no labirinto em cruz elevado, no $29^{\circ}$ e $30^{\circ}$ dia de exposição ou não (controle) à Senna occidentalisdurante 28 dias em diferentes concentrações incorporadas a ração. \%EBA $=\%$ de entradas no braço aberto; \%TBA = \% de tempo nos braços abertos; Aval. Risco = avaliação de risco Dados expressos em média \pm erro padrão ( $n=10$ animais por grupo). ${ }^{*} p<0,05 ;{ }^{*} p<0,01$; ${ }^{* * *} \mathrm{p}<0,001 ;{ }^{* * * *} \mathrm{p}<0,0001$, Anova seguida do teste de Dunnet (para dados paramétricos - frequência) e Kruskal-Wallis seguido de Dunn's (para dados não paramétrico - \%)
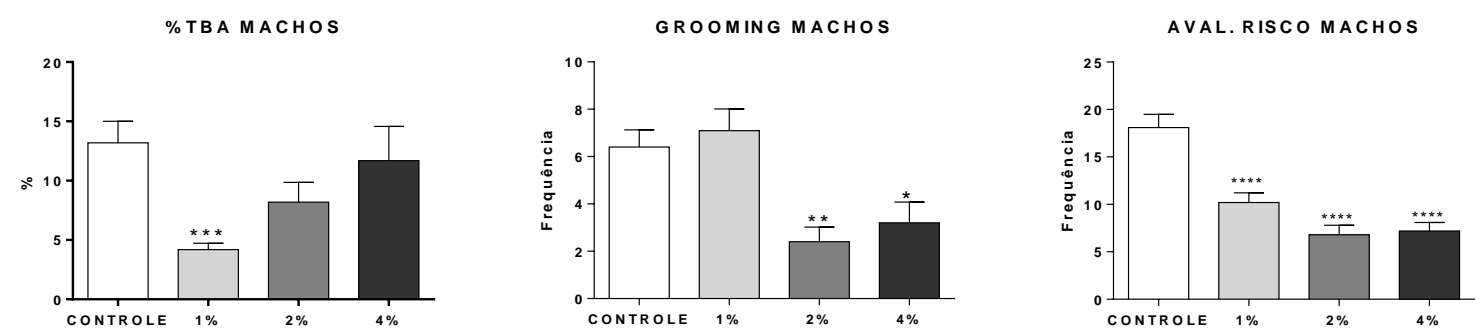

Fonte: (SANTOS, M. V., 2015). 
Figura 11 - Porcentagem de tempo nos braços abertos (\%TBA) observada no labirinto em cruz elevado, em fêmeas, no $29^{\circ}$ e $30^{\circ}$ dia de exposição ou não (controle) á Senna occidentalis durante 28 dias em diferentes concentrações incorporadas a ração. Dados expressos em média \pm erro padrão ( $\mathrm{n}=10$ animais por grupo). ${ }^{* *} p<0,01$, Kruskal-Wallis seguido do teste de Dunn's

\% TB A FÊMEAS

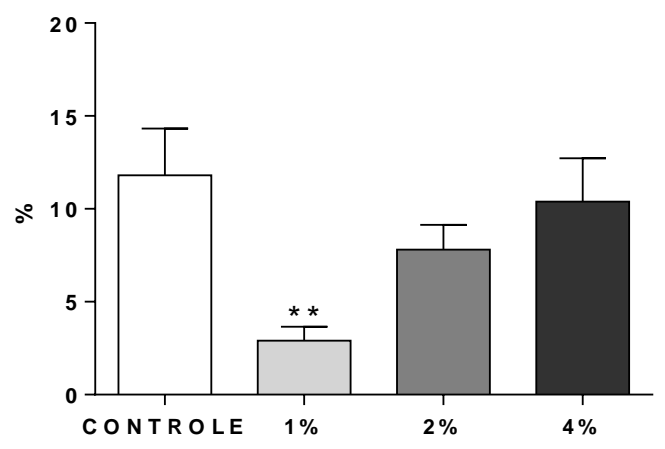

Fonte: (SANTOS, M. V., 2015).

\subsubsection{Reconhecimento de Objetos}

A tabela 6 apresenta os resultados referentes ao teste comportamental de Reconhecimento de Objetos de machos e fêmeas expostos ou não (controle) à $S$. occidentalis por 28 dias. A Anova de uma via mostrou que não houve diferença significante entre os grupos, tanto em machos como em fêmeas.

Tabela 6 - Índice de Reconhecimento de Objetos, observado em machos e fêmeas no $31^{\circ}$ e $32^{\circ}$ dia de exposição ou não (controle) àSenna occidentalis incorporada a ração. Dados expressos em média \pm erro padrão ( $n=10$ animais/grupo). Anova seguida do teste de Dunnet

\begin{tabular}{|c|c|c|c|c|c|c|c|c|}
\hline \multirow{2}{*}{ XO } & \multicolumn{2}{|c|}{ CONTROLE } & \multicolumn{2}{|c|}{ Senna 1\% } & \multicolumn{2}{|c|}{-Senna $2 \%$} & \multicolumn{2}{|c|}{ Senna $4 \%$} \\
\hline & $2 \mathrm{~h}$ & $24 \mathrm{~h}$ & $2 \mathrm{~h}$ & $24 \mathrm{~h}$ & $2 \mathrm{~h}$ & $24 \mathrm{~h}$ & $2 \mathrm{~h}$ & $24 \mathrm{~h}$ \\
\hline $\mathrm{HOS}$ & $44 \pm$ & $39 \pm 0,06$ & $7 \pm 0,05$ & $0,50 \pm 0,04$ & $0,44 \pm 0,07$ & $0,50 \pm 0,05$ & $0,48 \pm 0,05$ & $0,50 \pm 0,04$ \\
\hline FÊMEAS & $0,54 \pm 0,04$ & $0,49 \pm 0,05$ & $0,58 \pm 0,05$ & $0,49 \pm 0,05$ & $0,49 \pm 0,04$ & $0,55 \pm 0,04$ & $0,59 \pm 0,05$ & $0,62 \pm 0,05$ \\
\hline
\end{tabular}

Fonte: (SANTOS, M. V., 2015).

$p>0,05$, Anova de uma via. 


\subsubsection{Hemograma}

A tabela 7 (série vermelha) e a tabela 8 (série branca) mostram os resultados referentes à avaliação dos parâmetros hematológicos de ratos machos e fêmeas expostos ou não (controle) a diferente concentrações de Senna occidentalis incorporadas a ração durante 28 dias. A Anova de uma via não mostrou diferenças significantes entre os grupos em nenhum dos parâmetros avaliados.

Tabela 7 - Parâmetros hematológicos (série vermelha) machos e fêmeas expostos ou não (controle) àSenna occidentalis durante 28 dias. Os resultados são expressos como médias e respectivos erros padrão ( $\mathrm{n}=10$ animais por grupo)

\begin{tabular}{|c|c|c|c|c|c|}
\hline \multirow{2}{*}{ CÉLULAS } & \multirow{2}{*}{ SEXO } & \multirow{2}{*}{ CONTROLE } & \multicolumn{3}{|c|}{ Senna occidentalis } \\
\hline & & & $1 \%$ & $2 \%$ & $4 \%$ \\
\hline \multirow{2}{*}{$\operatorname{VCM}\left(\mu^{3}\right)$} & MACHOS & $55,10 \pm 0,28$ & $53,80 \pm 0,53$ & $55,00 \pm 0,21$ & $54,40 \pm 0,43$ \\
\hline & FÊMEAS & $56,80 \pm 0,36$ & $56,10 \pm 0,53$ & $56,11 \pm 0,53$ & $55,90 \pm 0,61$ \\
\hline \multirow{2}{*}{$\mathrm{HCM}(\mathrm{g} / \mathrm{dL})$} & MACHOS & $21,42 \pm 0,41$ & $20,87 \pm 0,49$ & $21,09 \pm 0,34$ & $20,85 \pm 0,39$ \\
\hline & FÊMEAS & $21,88 \pm 0,60$ & $21,60 \pm 0,51$ & $21,35 \pm 0,30$ & $21,09 \pm 0,26$ \\
\hline \multirow{2}{*}{$\begin{array}{c}\text { HEMÁCIAS } \\
\left(\text { Milhões } / \mathrm{mm}^{3} \text { ) }\right.\end{array}$} & MACHOS & $6,30 \pm 0,34$ & $6,90 \pm 0,25$ & $7,21 \pm 0,30$ & $6,43 \pm 0,51$ \\
\hline & FÊMEAS & $6,47 \pm 0,24$ & $5,83 \pm 0,35$ & $6,93 \pm 0,15$ & $6,51 \pm 0,28$ \\
\hline \multirow{2}{*}{$\mathrm{HGB}(\mathrm{g} / \mathrm{dL})$} & MACHOS & $13,48 \pm 0,74$ & $14,19 \pm 0,47$ & $15,26 \pm 0,71$ & $13,32 \pm 1,21$ \\
\hline & FÊMEAS & $14,10 \pm 0,50$ & $12,93 \pm 0,57$ & $14,63 \pm 0,22$ & $13,73 \pm 0,58$ \\
\hline \multirow{2}{*}{$\mathrm{Ht}(\%)$} & MACHOS & $34,69 \pm 1,89$ & $36,86 \pm 1,18$ & $39,69 \pm 1,66$ & $34,98 \pm 3,35$ \\
\hline & FÊMEAS & $36,79 \pm 1,40$ & $32,86 \pm 1,70$ & $38,74 \pm 0,93$ & $36,30 \pm 1,74$ \\
\hline \multirow{2}{*}{$\mathrm{CHCM}(\mathrm{g} / \mathrm{dL})$} & MACHOS & $38,87 \pm 0,61$ & $38,75 \pm 0,64$ & $38,35 \pm 0,60$ & $38,44 \pm 0,78$ \\
\hline & FÊMEAS & $38,53 \pm 1,06$ & $38,72 \pm 0,72$ & $37,98 \pm 0,68$ & $37,74 \pm 0,71$ \\
\hline
\end{tabular}

Fonte: (SANTOS, M. V., 2015).

VCM = volume corposcular médio; HCM = hemoglobina corposcular média; HGB $=$ hemoglobinaHt = hematócrito; $\mathrm{CHCM}=$ concentração de hemoglobina corposcular média; $p>0,05$, Anova de uma via. 
Tabela 8 - Parâmetros hematológicos (série branca) de machos e fêmeas expostos ou não (controle) àSenna occidentalisdurante 28 dias. Os resultados são expressos como médias e respectivos erros padrão( $n=10$ animais por grupo)

\begin{tabular}{cccccc}
\hline \multirow{2}{*}{ CÉLULAS } & \multirow{2}{*}{ SEXO } & \multirow{2}{*}{ CONTROLE } & \multicolumn{3}{c}{ Senna occidentalis } \\
\cline { 4 - 6 } & & & $\mathbf{1 \%}$ & $\mathbf{2 \%}$ & $\mathbf{4 \%}$ \\
\hline \multirow{2}{*}{ LEUCÓCITOS$\left(\times 10^{3} / \mathrm{mm}^{3}\right)$} & MACHOS & $4,49 \pm 0,52$ & $3,28 \pm 0,48$ & $3,88 \pm 0,41$ & $2,95 \pm 0,25$ \\
& FÊMEAS & $3,36 \pm 0,31$ & $3,48 \pm 0,40$ & $4,17 \pm 0,59$ & $4,23 \pm 0,50$ \\
MONÓCITOS & MACHOS & $1,40 \pm 0,42$ & $0,40 \pm 0,26$ & $0,80 \pm 0,39$ & $1,00 \pm 0,57$ \\
& FÊMEAS & $1,60 \pm 0,53$ & $1,20 \pm 0,61$ & $0,60 \pm 0,63$ & $0,40 \pm 0,42$ \\
\multirow{2}{*}{ LINFÓCITOS } & MACHOS & $77,40 \pm 0,85$ & $77,60 \pm 1,22$ & $76,80 \pm 1,42$ & $75,40 \pm 2,64$ \\
& FÊMEAS & $74,80 \pm 2,55$ & $76,60 \pm 3,83$ & $74,00 \pm 2,90$ & $72,60 \pm 3,31$ \\
BASÓFILOS & MACHOS & $0,40 \pm 0,26$ & $0,40 \pm 0,26$ & $0 \pm 0$ & $0,40 \pm 0,26$ \\
& FÊMEAS & $0,40 \pm 0,26$ & $0,20 \pm 0,21$ & $0 \pm 0$ & $0,40 \pm 0,42$ \\
EOSINÓFILOS & MACHOS & $0,60 \pm 0,42$ & $0,40 \pm 0,26$ & $0 \pm 0$ & $0 \pm 0$ \\
& FÊMEAS & $0,20 \pm 0,21$ & $0,80 \pm 0,39$ & $0 \pm 0$ & $0,40 \pm 0,17$ \\
NEUTRÓFILOS & MACHOS & $20,80 \pm 1,85$ & $20,40 \pm 1,50$ & $22,40 \pm 1,50$ & $23,20 \pm 2,59$ \\
& FÊMEAS & $23,00 \pm 2,27$ & $21,00 \pm 3,74$ & $24,00 \pm 2,41$ & $26,20 \pm 3,49$ \\
\hline
\end{tabular}

Fonte: (SANTOS, M. V., 2015).

$p>0,05$, Anova de uma via

\subsubsection{Bioquímica sérica}

A tabela 9 mostra os resultados referentes à avaliação dos parâmetros bioquímicos sanguíneos de ratos machos e fêmeas expostos ou não (controle) a diferente concentrações de Senna occidentalis incorporadas a ração durante 28 dias. A Anova de uma via não mostrou diferenças significantes entre os grupos em nenhum dos parâmetros avaliados. 
Tabela 9 - Parâmetros bioquímicos sanguíneos de machos e fêmeas expostos ou não (controle) à Senna occidentalis durante 28 dias. Os resultados são expressos como médios e respectivos erros padrão, $\mathrm{n}=10$ animais por grupo

\begin{tabular}{cccccc}
\hline \multirow{2}{*}{ CÉLULAS } & \multirow{2}{*}{ SEXO } & CONTROLE & \multicolumn{3}{c}{ Senna occidentalis } \\
\cline { 4 - 6 } & & & $1 \%$ & $2 \%$ & $4 \%$ \\
\hline \multirow{2}{*}{ AST (U/L) } & MACHOS & $179,30 \pm 15,51$ & $211,00 \pm 35,22$ & $210,40 \pm 20,31$ & $183,10 \pm 14,67$ \\
& FÊMEAS & $254,00 \pm 45,33$ & $196,50 \pm 15,95$ & $236,50 \pm 26,61$ & $253,60 \pm 38,24$ \\
ALT (U/L) & MACHOS & $59,40 \pm 3,61$ & $64,00 \pm 7,68$ & $56,10 \pm 3,71$ & $53,80 \pm 1,80$ \\
& FÊMEAS & $74,10 \pm 18,77$ & $54,90 \pm 16,06$ & $61,40 \pm 3,38$ & $59,40 \pm 7,86$ \\
FOSFATASE ALCALINA (U/L) & MACHOS & $216,70 \pm 12,44$ & $163,70 \pm 15,73$ & $176,00 \pm 10,44$ & $205,80 \pm 20,93$ \\
& FÊMEAS & $120,80 \pm 7,57$ & $101,90 \pm 8,67$ & $107,50 \pm 11,10$ & $125,80 \pm 13,07$ \\
URÉIA (mg/dL) & MACHOS & $70,20 \pm 5,19$ & $83,10 \pm 4,41$ & $60,10 \pm 3,44$ & $69,20 \pm 7,27$ \\
& FÊMEAS & $61,30 \pm 0,65$ & $67,60 \pm 2,94$ & $63,40 \pm 3,70$ & $68,10 \pm 4,39$ \\
CREATININA (mg/dL) & MACHOS & $0,65 \pm 0,03$ & $0,65 \pm 0,05$ & $0,60 \pm 0,02$ & $0,64 \pm 0,04$ \\
& FÊMEAS & $0,69 \pm 0,04$ & $0,70 \pm 0,04$ & $0,68 \pm 0,04$ & $3,34 \pm 0,90$ \\
PROTEÍNA TOTAL (g/L) & MACHOS & $7,09 \pm 0,12$ & $6,82 \pm 0,32$ & $6,82 \pm 0,31$ & $7,21 \pm 0,13$ \\
& FÊMEAS & $7,66 \pm 0,22$ & $6,63 \pm 0,19$ & $7,07 \pm 0,10$ & $7,40 \pm 0,21$ \\
ALBUMINA (g/L) & MACHOS & $3,96 \pm 0,20$ & $3,83 \pm 0,24$ & $3,99 \pm 0,14$ & $4,07 \pm 0,15$ \\
& FÊMEAS & $4,48 \pm 0,08$ & $3,96 \pm 0,19$ & $4,48 \pm 0,18$ & $4,33 \pm 0,09$ \\
GLICOSE (mmol/L) & MACHOS & $396,60 \pm 31,42$ & $386,60 \pm 29,28$ & $361,80 \pm 29,62$ & $354,70 \pm 20,31$ \\
& FÊMEAS & $293,40 \pm 37,31$ & $259,60 \pm 36,18$ & $257,50 \pm 18,94$ & $256,60 \pm 18,41$ \\
COLESTEROL TOTAL (mg/dL) & MACHOS & $76,50 \pm 6,70$ & $79,50 \pm 6,30$ & $71,10 \pm 4,31$ & $72,80 \pm 3,16$ \\
& FÊMEAS & $80,50 \pm 4,09$ & $74,90 \pm 4,75$ & $82,20 \pm 3,43$ & $78,60 \pm 4,08$ \\
TRIGLICERÍDEOS (mg/dL) & MACHOS & $99,60 \pm 14,41$ & $109,20 \pm 13,82$ & $92,20 \pm 10,66$ & $80,10 \pm 8,19$ \\
& FÊMEAS & $104,20 \pm 11,12$ & $93,40 \pm 9,28$ & $95,40 \pm 12,94$ & $99,20 \pm 6,03$ \\
\hline
\end{tabular}

Fonte: (SANTOS, M. V., 2015).

$\mathrm{AST}=$ aspartatoaminotransferase; $\mathrm{ALT}=$ alanina aminotransferase; $p>0,05$, Anova de uma via

\subsubsection{Peso real e relativo de órgãos}

A tabela 10 e a figura 12 mostram os resultados referentes aos pesos real e relativo dos órgãos de ratos machos expostos ou não (controle) a diferentes concentrações de $S$. occidentalis incorporadas à ração durante 28 dias. A Anova de uma via mostrou que houve diferenças significantes entre os grupos em relação apenas ao peso relativo do pulmão $[F(3 / 36)=4,92 p=0,006]$. O Teste Dunnet mostrou que houve aumento significante desse parâmetro nos animais do grupo $1 \%(p<0,01)$, em relação ao grupo controle. 
Tabela 10 - Peso real (em g) e Peso relativo de órgãos (em g - peso do órgão / peso corpóreo x 100) de machos expostos à Senna occidentalis durante 28 dias a diferentes concentrações de Senna occidentalis incorporadas na ração. Dados expressos em média \pm erro padrão ( $n=10$ animais por grupo). $p<0,01$, Anova de uma via seguida do teste de Dunnet

\begin{tabular}{cccccc}
\hline \multirow{2}{*}{ ÓRGÃO } & \multirow{2}{*}{ PESO } & \multirow{2}{*}{ CONTROLE } & \multicolumn{3}{c}{ Senna occidentalis } \\
\cline { 4 - 6 } & & & $1 \%$ & $2 \%$ & $4 \%$ \\
\hline \multirow{2}{*}{ RINS } & REAL & $2,41 \pm 0,12$ & $2,27 \pm 0,24$ & $2,49 \pm 0,06$ & $2,26 \pm 0,08$ \\
& RELATIVO & $0,69 \pm 0,04$ & $0,69 \pm 0,09$ & $0,70 \pm 0,02$ & $0,70 \pm 0,04$ \\
PULMÃO & REAL & $1,53 \pm 0,07$ & $1,72 \pm 0,79$ & $1,77 \pm 0,06$ & $1,64 \pm 0,02$ \\
& RELATIVO & $0,43 \pm 0,02$ & $0,62 \pm 0,06 * *$ & $0,50 \pm 0,02$ & $0,49 \pm 0,02$ \\
CORAÇÃO & REAL & $1,30 \pm 0,07$ & $0,86 \pm 0,06$ & $1,20 \pm 0,02$ & $1,03 \pm 0,11$ \\
& RELATIVO & $0,37 \pm 0,03$ & $0,51 \pm 0,04$ & $0,34 \pm 0,01$ & $0,32 \pm 0,04$ \\
FÍGADO & REAL & $11,78 \pm 0,64$ & $10,49 \pm 0,81$ & $11,22 \pm 0,20$ & $10,89 \pm 0,39$ \\
& RELATIVO & $3,16 \pm 0,35$ & $3,62 \pm 0,21$ & $3,15 \pm 0,05$ & $3,32 \pm 0,07$ \\
BAÇO & REAL & $0,80 \pm 0,05$ & $0,71 \pm 0,07$ & $0,86 \pm 0,03$ & $0,88 \pm 0,05$ \\
& RELATIVO & $0,23 \pm 0,01$ & $0,25 \pm 0,03$ & $0,24 \pm 0,01$ & $0,27 \pm 0,01$ \\
ADRENAL & REAL & $0,06 \pm 0,004$ & $0,16 \pm 0,10$ & $0,06 \pm 0,005$ & $0,06 \pm 0,004$ \\
& RELATIVO & $0,02 \pm 0,001$ & $0,06 \pm 0,05$ & $0,02 \pm 0,001$ & $0,02 \pm 0,001$ \\
TESTÍCULOS & REAL & $3,52 \pm 0,08$ & $3,31 \pm 0,12$ & $3,56 \pm 0,10$ & $3,62 \pm 0,13$ \\
& RELATIVO & $1,01 \pm 0,06$ & $1,16 \pm 0,05$ & $1,00 \pm 0,02$ & $1,12 \pm 0,07$ \\
EPIDÍDIMOS & REAL & $1,23 \pm 0,08$ & $1,07 \pm 0,04$ & $1,22 \pm 0,04$ & $1,10 \pm 0,05$ \\
& RELATIVO & $0,35 \pm 0,02$ & $0,38 \pm 0,02$ & $0,34 \pm 0,01$ & $0,34 \pm 0,02$ \\
VESÍCULA & REAL & $0,99 \pm 0,10$ & $0,92 \pm 0,14$ & $1,04 \pm 0,06$ & $0,95 \pm 0,06$ \\
SEMINAL & RELATIVO & $0,29 \pm 0,04$ & $0,31 \pm 0,05$ & $0,29 \pm 0,02$ & $0,29 \pm 0,01$ \\
& REAL & $0,32 \pm 0,03$ & $0,30 \pm 0,03$ & $0,35 \pm 0,02$ & $0,25 \pm 0,04$ \\
PRÓSTATA & RELATIVO & $0,09 \pm 0,01$ & $0,10 \pm 0,01$ & $0,10 \pm 0,01$ & $0,07 \pm 0,01$ \\
\hline
\end{tabular}

Fonte: (SANTOS, M. V., 2015). 
Figura 12 - Peso relativo do pulmão (em g - peso do órgão / peso corpóreo $x$ 100) de machos expostos ou não (controle) à Senna occidentalisem diferentes concentrações incorporadas à ração, durante 28. Dados expressos em média \pm erro padrão $(n=10$ animais por grupo). ${ }^{* *}<<0,01$, Anova de uma via seguida do teste de Dunnet

PULMÃO MACHO

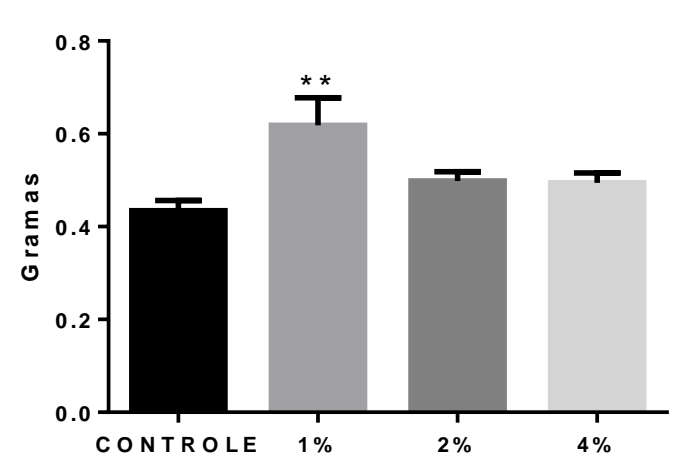

Fonte: (SANTOS, M. V., 2015).

A tabela 11 e figura 13 mostram os pesos real e relativo dos órgãos das fêmeas expostas ou não (controle) a diferentes concentrações de $S$. occidentalis incorporadas à ração durante 28 dias. A Anova de uma via mostrou que houve diferenças significantes entre os grupos apenas no parâmetro do peso relativo do útero $[F(3 / 36)=4,86, p=0,006]$, com diminuição desse órgão em fêmeas de $1 \%$ (pósteste Dunnet, $p<0,01$ ), em relação ao grupo controle. Nos demais pesos de órgãos e pesos relativos destes não foram observadas diferenças significantes entre os grupos. 
Tabela 11 - Peso real (em g) e relativo de órgãos (em g - peso do órgão / peso corpóreo x 100) de fêmeas expostas à Senna occidentalis durante 28 dias a diferentes concentrações de Senna occidentalis incorporadas na ração. Dados expressos em média \pm erro padrão $(n=10$ animais por grupo). ${ }^{*} p<0,05, p<0,01$, Anova de uma via seguida do teste de Dunnet

\begin{tabular}{cccccc}
\hline \multirow{2}{*}{ ÓRGÃO } & \multirow{2}{*}{ PESO } & \multirow{2}{*}{ CONTROLE } & \multicolumn{3}{c}{ Senna occidentalis } \\
\cline { 4 - 6 } & & & $1 \%$ & $2 \%$ & $4 \%$ \\
\hline \multirow{2}{*}{ RINS } & REAL & $1,58 \pm 0,03$ & $1,36 \pm 0,12$ & $1,42 \pm 0,07$ & $1,43 \pm 0,05$ \\
& RELATIVO & $0,71 \pm 0,02$ & $0,78 \pm 0,03$ & $0,76 \pm 0,02$ & $0,76 \pm 0,02$ \\
PULMÃO & REAL & $1,35 \pm 0,04$ & $1,16 \pm 0,07$ & $1,06 \pm 0,07$ & $1,18 \pm 0,04$ \\
& RELATIVO & $0,61 \pm 0,03$ & $0,70 \pm 0,07$ & $0,55 \pm 0,02$ & $0,63 \pm 0,02$ \\
CORAÇÃOO & REAL & $0,92 \pm 0,12$ & $0,86 \pm 0,06$ & $1,44 \pm 0,71$ & $0,86 \pm 0,06$ \\
& RELATIVO & $0,41 \pm 0,04$ & $0,51 \pm 0,04$ & $0,39 \pm 0,02$ & $0,46 \pm 0,03$ \\
FÍGADO & REAL & $8,05 \pm 0,23$ & $6,40 \pm 0,70$ & $7,25 \pm 0,30$ & $6,84 \pm 0,39$ \\
& RELATIVO & $3,61 \pm 0,08$ & $3,61 \pm 0,19$ & $3,81 \pm 0,12$ & $3,60 \pm 0,12$ \\
BAÇO & REAL & $0,63 \pm 0,03$ & $0,51 \pm 0,04$ & $0,62 \pm 0,04$ & $0,55 \pm 0,02$ \\
& RELATIVO & $0,28 \pm 0,01$ & $0,29 \pm 0,01$ & $0,31 \pm 0,01$ & $0,29 \pm 0,01$ \\
ADRENAL & REAL & $0,05 \pm 0,007$ & $0,06 \pm 0,007$ & $0,07 \pm 0,01$ & $0,07 \pm 0,01$ \\
& RELATIVO & $0,02 \pm 0,002$ & $0,03 \pm 0,003$ & $0,08 \pm 0,05$ & $0,04 \pm 0,004$ \\
ÚTERO & REAL & $0,47 \pm 0,04$ & $0,23 \pm 0,04$ & $0,39 \pm 0,03$ & $0,33 \pm 0,05$ \\
& RELATIVO & $0,21 \pm 0,02$ & $0,12 \pm 0,01 * *$ & $0,21 \pm 0,02$ & $0,17 \pm 0,02$ \\
\multirow{2}{*}{ OVÁRIO } & REAL & $0,11 \pm 0,01$ & $0,08 \pm 0,01$ & $0,09 \pm 0,007$ & $0,09 \pm 0,01$ \\
& RELATIVO & $0,05 \pm 0,003$ & $0,04 \pm 0,004$ & $0,05 \pm 0,03$ & $0,10 \pm 0,05$ \\
\hline
\end{tabular}

Fonte: (SANTOS, M. V., 2015).

Figura 13 - Peso relativo do útero (em $\mathrm{g}$ - peso do órgão / peso corpóreo x 100) de fêmeas expostas ou não (controle) à Senna occidentalis durante 28 dias a diferentesconcentrações incorporadas à ração. Dados expressos em média \pm erro padrão $(n=10$ animais por grupo). $p<0,01$, Anova de uma via seguida do teste de Dunnet

ÚTERO

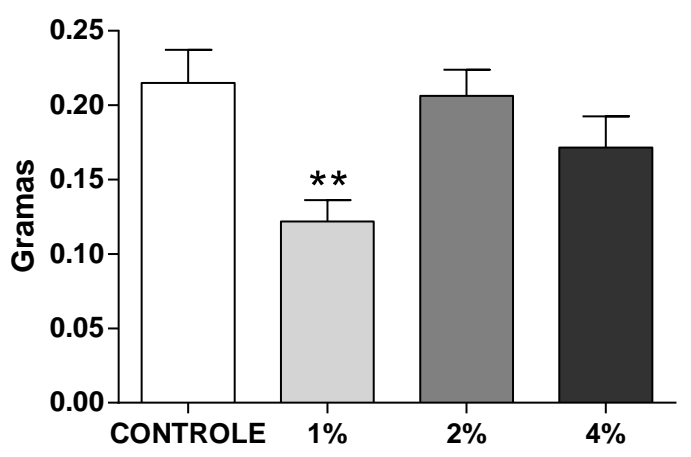

Fonte: (SANTOS, M. V., 2015). 


\subsubsection{Estudo anatomopatológico}

Durante a necropsia dos animais não foi observado nada digno de nota. No estudo histopatológico, de modo geral, observamos que os animais tanto machos quanto fêmeas de todos os grupos tratados, apresentaram fígado congesto, com ausência de degeneração hepática, de vacuolização e de sinais inflamatórios, e dentro da normalidade nos demais aspectos; quanto ao baço, este apresentou congestão da polpa vermelha, e dentro da normalidade nos demais aspectos; a suprarrenal apresentou-se dentro dos padrões histológicos da normalidade, com ausência de congestão e de sinais degenerativos; o pulmão estava atelectásico (perda alveolar) e congesto sem sinais inflamatórios com ausência de pneumonia intersticial, de quadro inflamatório, de degenerações ou de necrose; o miocárdio estava dentro dos padrões histológicos da normalidade com ausência de necrose ou congestão e de sinais inflamatórios; quanto aos rins, estes estavam dentro dos padrões histológicos da normalidade com ausência de degeneração ou de necrose de túbulos renais, nefrose tubular aguda, edema e congestão.

Embora a análise histopatológica tenha mostrado poucas alterações, observamos que os animais do grupo controle apresentaram alterações parecidas ou até mais evidentes do que os animais expostos.

\subsection{EXPOSIÇÃO À S. OCCIDENTALIS POR 90 DIAS}

Dentre os grupos experimentais que receberam diferentes concentrações de S. occidentalis na ração por 90 dias, constatou-se a ocorrência de óbito nos grupos que receberam as maiores concentrações da planta. Os animais do grupo 3\% começaram a entrar em óbito a partir do 63ํ dia de exposição, enquanto os animais do grupo 4\% deram início ao óbito a partir do 41ํ de exposição; os ratos destes grupos que apresentaram sinais de sofrimento foram submetidos à eutanásia (tabela 12). Em função da redução do número de animais dos grupos 3 e 4\%, não foram realizadas avaliações comportamentais, exames bioquímicos, hematológicos, peso real e relativo de órgãos e análises histológicas nestes grupos. 
Tabela 12 - Número de óbitos ou de eutanásia de ratos expostos a 3 ou 4\% deSenna occidentalis na ração durante 90 dias

\begin{tabular}{|c|c|c|c|}
\hline \multirow{2}{*}{ SEMANA } & \multirow[t]{2}{*}{ SEXO } & \multicolumn{2}{|c|}{ Senna occidentalis } \\
\hline & & $3 \%$ & $4 \%$ \\
\hline \multirow{2}{*}{5} & MACHOS & & \\
\hline & FÊMEAS & & \\
\hline \multirow{2}{*}{6} & MACHOS & & 2 óbitos \\
\hline & FÊMEAS & & 1 óbito \\
\hline \multirow{2}{*}{7} & MACHOS & & 3 óbitos \\
\hline & FÊMEAS & & 2 óbitos \\
\hline \multirow{2}{*}{8} & MACHOS & & \\
\hline & FÊMEAS & & 2 óbitos \\
\hline \multirow{2}{*}{9} & MACHOS & 2 óbitos & \\
\hline & FÊMEAS & 1óbito & \\
\hline \multirow{2}{*}{10} & MACHOS & 1óbito & \\
\hline & FÊMEAS & 1 óbito & \\
\hline \multirow{2}{*}{11} & MACHOS & 1óbito; 1 eutanásia & \\
\hline & FÊMEAS & 1 óbito & \\
\hline \multirow{2}{*}{12} & MACHOS & & \\
\hline & FÊMEAS & 1óbito; 1 eutanásia & \\
\hline \multirow{2}{*}{13} & MACHOS & & \\
\hline & FÊMEAS & 1 eutanásia & \\
\hline \multirow{2}{*}{ Total } & MACHOS & 4 óbitos; 1 eutanásia & 5 óbitos \\
\hline & FÊMEAS & 4 óbitos; 1 eutanásia & 5 óbitos \\
\hline
\end{tabular}

Fonte: (SANTOS, M. V., 2015).

\subsubsection{Consumo de água e de ração, peso corpóreo e avaliação clínica}

O consumo de água e de ração não foram submetidos a análise estatística, uma vez que cada grupo foi constituído de 10 animais, os quais foram alojados em duas caixas moradias distintas ( $n=5$ animais por caixa), sendo obtido apenas 0 consumo médio semanal de cada grupo. Esses dados são ilustrados pela figura 14 . Assim, nota-se algumas flutuações no consumo de água e de ração entre os grupos, em particular, no de ração dos machos. 
Figura 14 - Consumo médio semanal de água $(\mathrm{ml})$ e de ração $(\mathrm{g})$ de cinco ratos por caixa moradia (machos e fêmeas) expostos ou não (controle) a Senna occidentalis na ração (1 e $2 \%$ ), durante 90 dias
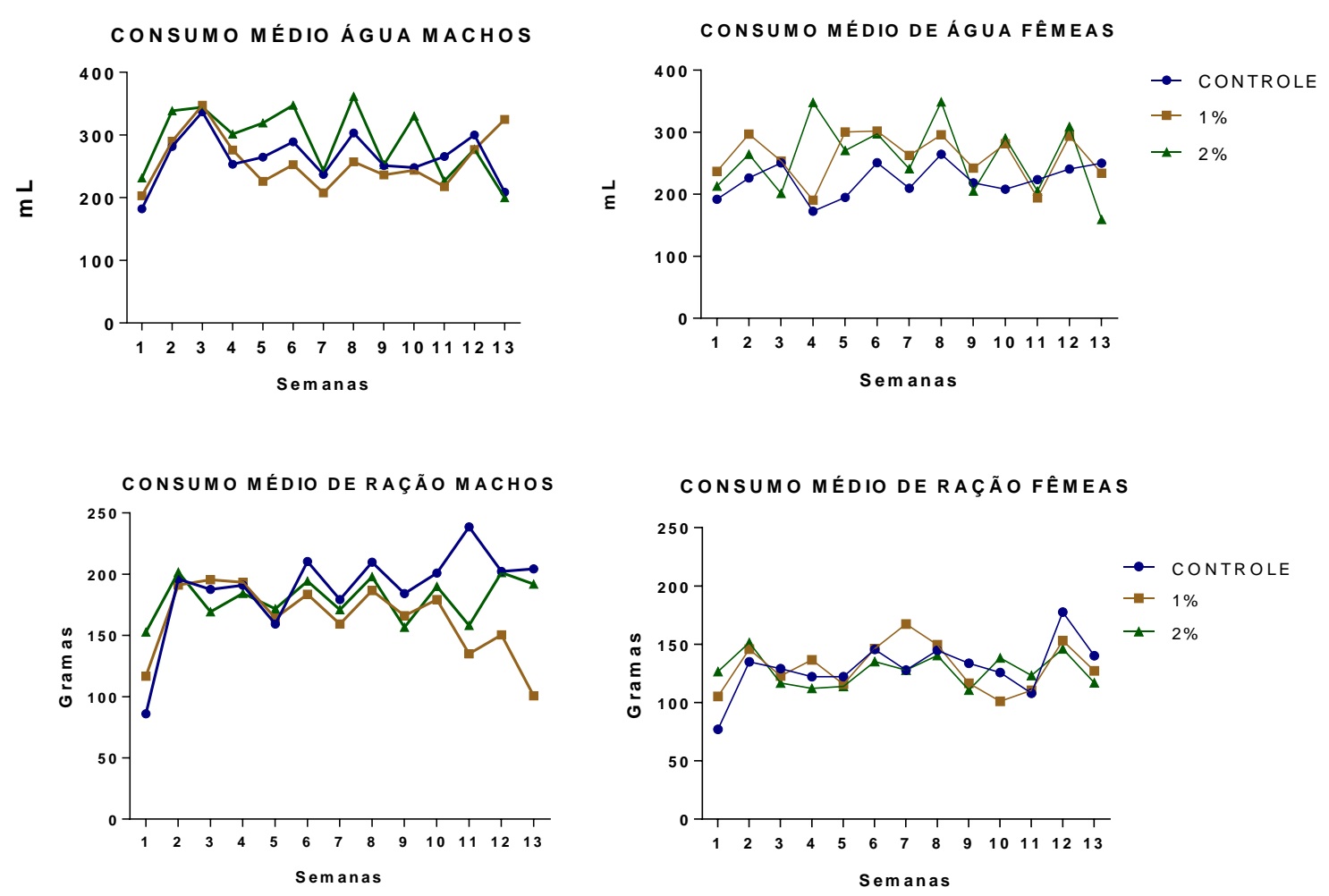

Fonte: (SANTOS, M. V., 2015).

A tabela 13 e as figuras 15 e 16 mostram os resultados referentes ao peso corpóreo de machos e fêmeas expostos ou não (controle) à Senna occidentalis por 90 dias em diferentes concentrações na ração. Nos machos, a Anova de duas vias mostrou que houve diferenças significantes entre os grupos em relação ao tratamento $[F(2 / 27)=5,91 \quad p=0,08$; semanas $[F(12 / 324)=95,58, \quad p<0,0001]$, sem interação entre os fatores. $O$ pós-teste de Bonferroni apontou redução significante nas $10^{\mathrm{a}}$, e $13^{\mathrm{a}}$ semanas de tratamento para ratos de $1 \%(\mathrm{p}<0,5) ; 9^{\mathrm{a}}, 10^{\mathrm{a}}, 11^{\mathrm{a}}, 12^{\mathrm{a}} \mathrm{e}$ $13^{\mathrm{a}}$ semana de tratamento para ratos de $2 \%$ quando comparados ao grupo controle.

Em fêmeas, a anova de duas vias mostrou que houve diferenças significantes entre os grupos em relação ao tratamento $[F(2 / 27)=11,72, p=0,0002]$; semanas $[F(12 / 324)=12,54, p<0,0001]$, com interação entre os fatores $[F(24 / 324)=2,66$, $p<0,0001)$. O pós-teste Bonferroni mostrou diminuição significante do peso na: $6^{a}$ e $9^{\text {a }}$ semana de tratamento para ratas de $1 \%(p<0,05)$; nas fêmeas de $2 \%$ houve 
diminuição nas 6⿳a semana $(p<0,05)$, $7^{\text {a }}$ semana $(p<0,01)$, $8^{\underline{a}}$ semana $(p<0,01), 11^{\text {a }}$ semana $(p<0,001), 12^{a}$ semana $(p<0,0001)$ e $13^{\text {a }}$ semana $(p<, 0001)$ quando comparadas às do grupo controle.

Tabela 13 - Peso corpóreo (em gramas) dos machos e fêmeas expostos ou não (controle) à Senna occidentalis por 90 dias em diferentes concentrações na ração. Dados expressos em média \pm erro padrão $(n=10$ animais/ grupo. ${ }^{*} p<0,05,{ }^{* *} p<0,01,{ }^{* *} p<0,001 e^{* * *} p<0,0001$, Anova de duas vias seguida do teste de Bonferroni

\begin{tabular}{|c|c|c|c|c|}
\hline \multirow{2}{*}{ SEMANA } & \multirow{2}{*}{ SEXO } & \multirow{2}{*}{ CONTROLE } & \multicolumn{2}{|c|}{ Senna occidentalis } \\
\hline & & & $1 \%$ & $2 \%$ \\
\hline \multirow[t]{2}{*}{1} & MACHOS & $290,92 \pm 7,78$ & $270,36 \pm 8,88$ & $286,40 \pm 8,98$ \\
\hline & FÊMEAS & $197,72 \pm 2,75$ & $203,93 \pm 2,40$ & $193,84 \pm 4,16$ \\
\hline \multirow[t]{2}{*}{2} & MACHOS & $313,15 \pm 7,59$ & $279,26 \pm 15,55$ & $307,50 \pm 6,25$ \\
\hline & FÊMEAS & $202,82 \pm 2,84$ & $206,63 \pm 2,75$ & $194,85 \pm 4,34$ \\
\hline \multirow[t]{2}{*}{3} & MACHOS & $313,68 \pm 9,66$ & $282,57 \pm 16,42$ & $305,98 \pm 12,92$ \\
\hline & FÊMEAS & $209,78 \pm 2,83$ & $211,04 \pm 3,19$ & $202,73 \pm 4,72$ \\
\hline \multirow[t]{2}{*}{4} & MACHOS & $352,35 \pm 8,36$ & $323,32 \pm 13,27$ & $324,05 \pm 13,06$ \\
\hline & FÊMEAS & $217,27 \pm 2,72$ & $214,72 \pm 3,01$ & $205,27 \pm 4,82$ \\
\hline \multirow[t]{2}{*}{5} & MACHOS & $369,78 \pm 8,34$ & $334,88 \pm 7,36$ & $347,69 \pm 5,88$ \\
\hline & FÊMEAS & $226,23 \pm 2,39$ & $221,80 \pm 4,69$ & $207,03 \pm 5,23$ \\
\hline \multirow[t]{2}{*}{6} & MACHOS & $377,58 \pm 9,69$ & $348,26 \pm 9,39$ & $349,03 \pm 6,49$ \\
\hline & FÊMEAS & $229,74 \pm 2,73$ & $206,49 \pm 21,06 *$ & $208,09 \pm 5,82$ \\
\hline \multirow[t]{2}{*}{7} & MACHOS & $377,91 \pm 14,60$ & $361,28 \pm 8,69$ & $359,00 \pm 6,12$ \\
\hline & FÊMEAS & $233,09 \pm 3,29$ & $225,16 \pm 4,75$ & $208,39 \pm 6,59 * *$ \\
\hline \multirow[t]{2}{*}{8} & MACHOS & $393,89 \pm 12,51$ & $372,42 \pm 9,35$ & $366,05 \pm 7,62$ \\
\hline & FÊMEAS & $235,59 \pm 3,47$ & $230,40 \pm 4,31$ & $209,46 \pm 6,09 * *$ \\
\hline \multirow[t]{2}{*}{9} & MACHOS & $409,27 \pm 11,20$ & $379,22 \pm 8,91$ & $363,64 \pm 5,71 * *$ \\
\hline & FÊMEAS & $235,14 \pm 3,42$ & $212,37 \pm 6,01^{*}$ & $220,72 \pm 7,35$ \\
\hline \multirow[t]{2}{*}{10} & MACHOS & $415,42 \pm 11,26$ & $381,87 \pm 7,36^{*}$ & $369,09 \pm 6,41 * *$ \\
\hline & FÊMEAS & $238,09 \pm 3,25$ & $221,10 \pm 6,09$ & $224,85 \pm 7,57$ \\
\hline \multirow[t]{2}{*}{11} & MACHOS & $424,94 \pm 13,32$ & $401,60 \pm 8,04$ & $385,79 \pm 9,49^{*}$ \\
\hline & FÊMEAS & $244,66 \pm 4,45$ & $245,18 \pm 10,04$ & $210,07 \pm 10,55^{* * *}$ \\
\hline \multirow[t]{2}{*}{12} & MACHOS & $438,61 \pm 12,85$ & $408,00 \pm 8,98$ & $395,54 \pm 12,27^{* *}$ \\
\hline & FÊMEAS & $246,98 \pm 4,64$ & $237,03 \pm 5,01$ & $203,62 \pm 6,83^{* * * *}$ \\
\hline \multirow[t]{2}{*}{13} & MACHOS & $451,99 \pm 12,25$ & $416,90 \pm 9,43^{*}$ & $401,14 \pm 12,15^{* *}$ \\
\hline & FÊMEAS & $229,5 \pm 4,86$ & $241,39 \pm 5,14$ & $203,55 \pm 7,27 * * * *$ \\
\hline
\end{tabular}

Fonte: (SANTOS, M. V., 2015). 
Figura 15- Peso corpóreo (em gramas) de machos expostos ou não (controle) à Senna occidentalis durante 90 dias em diferentes concentrações incorporadas à ração. Dados expressos em média \pm erro padrão ( $n=10$ animais/ grupo. ${ }^{*} p<0,05,{ }^{* *} p<0,01$. Anova de duas vias seguida do teste de Bonferroni

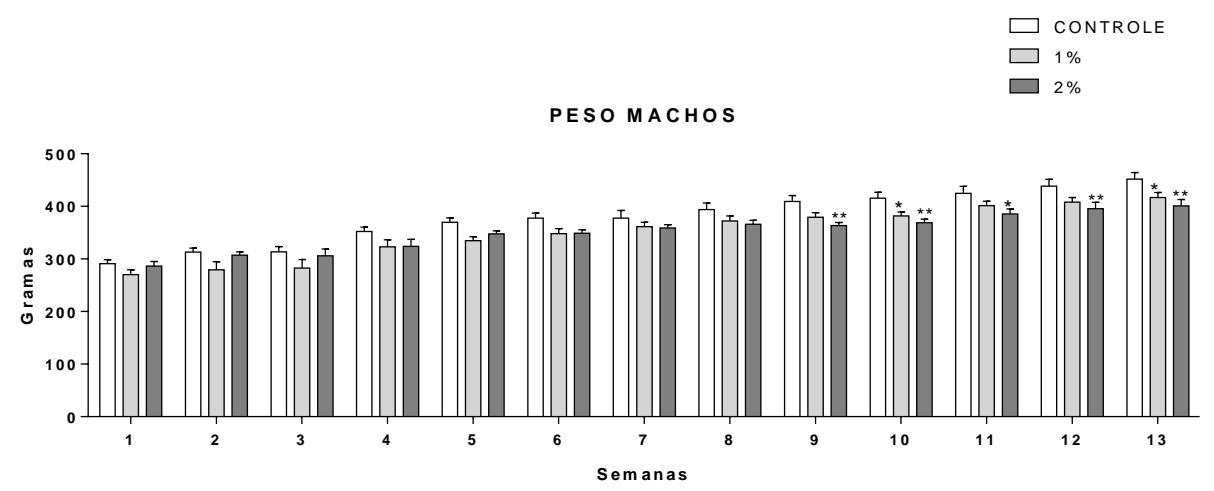

Fonte: (SANTOS, M. V., 2015).

Figura 16- Peso corpóreo (em gramas) de fêmeas expostas ou não (controle) à Senna occidentalis durante 90 dias em diferentes concentrações na ração. Dados expressos em média \pm erro padrão ( $n=10$ animais/ grupo. ${ }^{*} \mathrm{p}<0,05,{ }^{* *} \mathrm{p}<0,01$; ${ }^{* * *} p<0,001 e^{* \star * *} p<0,0001$, Anova de duas vias seguida do teste de Bonferroni

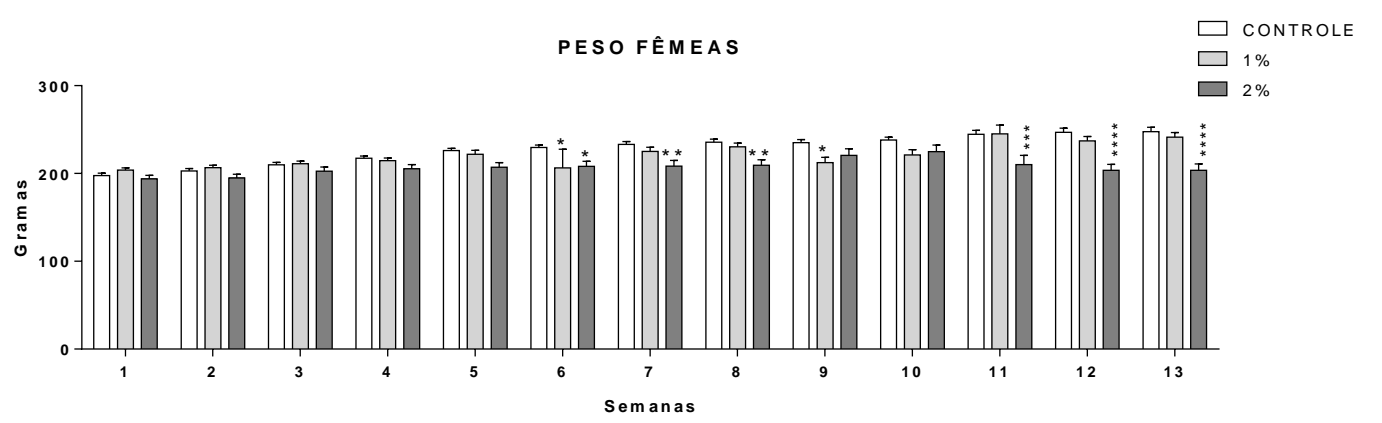

Fonte: (SANTOS, M. V., 2015).

Dentre os oito parâmetros da avaliação clínica observados, apenas um deles, a piloereção, mostrou alteração tanto em machos quanto em fêmeas. As tabelas $14 \mathrm{e}$ 15 e as figuras 17 e 18 mostram essas alterações em ratos expostos a diferentes concentrações de $S$. occidentalis incorporadas à ração durante 90 dias. A Anova de duas vias mostrou diferença significante em relação ao tratamento $[F(2 / 27)=91,09$, $p<0,0001]$; aos dias de observação $[F(18 / 486)=154,2, p<0,0001]$; com interação entre os fatores $[F(36 / 486)=38,77, p<0,0001$. O pós-teste de Bonferroni apontou aumento significante do escore no grupo $1 \%$ e $2 \%$ no $70^{\circ}, 77^{\circ}, 84^{\circ}$ e $91^{\circ}$ dia de observação ( $p<0,0001$ para todos os dias de observação, e ambos os grupos). 
Em fêmeas, a Anova de duas vias mostrou diferenças significantes em relação ao tratamento $[F(2 / 27)=87,09 p<0,0001]$; aos dias de observação $[F(18 / 486)=62,06$, $p<0,0001]$; com interação entre os fatores $[(F 36 / 486)=22,57, p<0,0001]$. O pós-teste de Bonferroni mostrou aumento do escore no grupo $1 \%$ na $70^{\circ}(p<0,0001), 77^{\circ}$ $(p<0,0001), 84^{\circ}(p<0,001)$ e $91^{\circ}(p<0,0001)$ dia de observação, e o grupo $2 \%$ apresentou aumento do escore no $63^{\circ}, 70^{\circ}, 77^{\circ}, 84^{\circ}$ e $91^{\circ}$ dia de observação ( $p<0,0001$ para todos os dias de observação).

Tabela 14 - Parâmetro piloereção da avaliação clínica de machos expostos ou não (controle) à Senna occidentalisincorporadas à ração durante 90 dias. Dados expressos em media \pm erro padrão dos escores obtidos nos dias de observação. $\mathrm{N}=10$ animais por grupo. ${ }^{* * *} p<0,0001$. Anova de duas vias seguida do pós-teste Bonferroni

\begin{tabular}{|c|c|c|c|}
\hline \multirow{2}{*}{$\begin{array}{c}\text { DIAS DE } \\
\text { OBSERVAÇÃO }\end{array}$} & \multirow{2}{*}{ CONTROLE } & \multicolumn{2}{|c|}{ S. occidentalis } \\
\hline & & $1 \%$ & $2 \%$ \\
\hline $1^{0}$ & $0 \pm 0$ & $0 \pm 0$ & $0 \pm 0$ \\
\hline $2^{\circ}$ & $0 \pm 0$ & $0 \pm 0$ & $0 \pm 0$ \\
\hline $3^{\circ}$ & $0 \pm 0$ & $0 \pm 0$ & $0 \pm 0$ \\
\hline $4^{0}$ & $0 \pm 0$ & $0 \pm 0$ & $0 \pm 0$ \\
\hline $5^{\circ}$ & $0 \pm 0$ & $0 \pm 0$ & $0 \pm 0$ \\
\hline $6^{0}$ & $0 \pm 0$ & $0 \pm 0$ & $0 \pm 0$ \\
\hline $7^{\circ}$ & $0 \pm 0$ & $0 \pm 0$ & $0 \pm 0$ \\
\hline $14^{\circ}$ & $0 \pm 0$ & $0 \pm 0$ & $0 \pm 0$ \\
\hline $21^{\circ}$ & $0 \pm 0$ & $0 \pm 0$ & $0 \pm 0$ \\
\hline $28^{\circ}$ & $0 \pm 0$ & $0 \pm 0$ & $0 \pm 0$ \\
\hline $35^{\circ}$ & $0 \pm 0$ & $0 \pm 0$ & $0 \pm 0$ \\
\hline $42^{\circ}$ & $0 \pm 0$ & $0 \pm 0$ & $0 \pm 0$ \\
\hline $49^{\circ}$ & $0 \pm 0$ & $0 \pm 0$ & $0 \pm 0$ \\
\hline $56^{\circ}$ & $0 \pm 0$ & $0 \pm 0$ & $0 \pm 0$ \\
\hline $63^{\circ}$ & $0 \pm 0$ & $0 \pm 0$ & $0 \pm 0$ \\
\hline $70^{\circ}$ & $0 \pm 0$ & $0,70 \pm 0,15 * * * *$ & $0,80 \pm 0,13 * * * *$ \\
\hline $77^{\circ}$ & $0 \pm 0$ & $0,90 \pm 0,18 * * * *$ & $1,10 \pm 0,18 * * * *$ \\
\hline $84^{\circ}$ & $0 \pm 0$ & $1,60 \pm 0,16 * * * *$ & $1,60 \pm 0,16 * * * *$ \\
\hline $91^{\circ}$ & $0 \pm 0$ & $1,90 \pm 0,10 * * * *$ & $1,90 \pm 0,10 * * * *$ \\
\hline
\end{tabular}

Fonte: (SANTOS, M. V., 2015).

Escores: $0=$ ausência do sinal; $1=$ raros sinais; $2=$ poucos sinais; $3=$ sinais moderados; $4=$ sinais intensos. 
Tabela 15 - Parâmetro piloereção da avaliação clínica de fêmeas expostas ou não (controle) à Senna occidentalis incorporadas à ração durante 90 dias. . Dados expressos em media \pm erro padrão dos escores obtidos nos dias de observação. $\mathrm{N}=10$ animais por grupo. ${ }^{* * *}, p<0,001,{ }^{* * * *} p<0,0001$. Anova de duas vias seguida do pós-teste Bonferroni

\begin{tabular}{cccc}
\hline \multirow{2}{*}{ DIAS DE OBSERVAÇÃO } & CONTROLE & \multicolumn{2}{c}{ S. occidentalis } \\
\cline { 2 - 4 } $1^{\circ}$ & $0 \pm 0$ & $0 \pm 0$ & $2 \%$ \\
$2^{\circ}$ & $0 \pm 0$ & $0 \pm 0$ & $0 \pm 0$ \\
$3^{\circ}$ & $0 \pm 0$ & $0 \pm 0$ & $0 \pm 0$ \\
$4^{\circ}$ & $0 \pm 0$ & $0 \pm 0$ & $0 \pm 0$ \\
$5^{\circ}$ & $0 \pm 0$ & $0 \pm 0$ & $0 \pm 0$ \\
$6^{\circ}$ & $0 \pm 0$ & $0 \pm 0$ & $0 \pm 0$ \\
$7^{\circ}$ & $0 \pm 0$ & $0 \pm 0$ & $0 \pm 0$ \\
$14^{\circ}$ & $0 \pm 0$ & $0 \pm 0$ & $0 \pm 0$ \\
$21^{\circ}$ & $0 \pm 0$ & $0 \pm 0$ & $0 \pm 0$ \\
$28^{\circ}$ & $0 \pm 0$ & $0 \pm 0$ & $0 \pm 0$ \\
$35^{\circ}$ & $0 \pm 0$ & $0 \pm 0$ & $0 \pm 0$ \\
$42^{\circ}$ & $0 \pm 0$ & $0 \pm 0$ & $0 \pm 0$ \\
$49^{\circ}$ & $0 \pm 0$ & $0 \pm 0$ & $0 \pm 0$ \\
$56^{\circ}$ & $0 \pm 0$ & $0 \pm 0$ & $0 \pm 0$ \\
$63^{\circ}$ & $0 \pm 0$ & $0 \pm 0$ & $0,80 \pm 0,13^{* * * *}$ \\
$70^{\circ}$ & $0 \pm 0$ & $0,60 \pm 0,16^{* * * *}$ & $1,10 \pm 0,18^{* * * *}$ \\
$77^{\circ}$ & $0 \pm 0$ & $1,10 \pm 0,10^{* * * * *}$ & $1,60 \pm 0,16^{* * * *}$ \\
$84^{\circ}$ & $0 \pm 0$ & $0,40 \pm 0,16^{* * *}$ & $1,50 \pm 0,17^{* * * *}$ \\
$91^{\circ}$ & $0 \pm 0$ & $0,80 \pm 0,29 * * *$ & $1,70 \pm 0,15^{* * * *}$ \\
\hline & & &
\end{tabular}

Fonte: (SANTOS, M. V., 2015).

Escores: $0=$ ausência do sinal; $1=$ raros sinais; $2=$ poucos sinais; $3=$ sinais moderados; $4=$ sinais intensos. 
Figura 17 - Parâmetro piloereção da avaliação clínica de machos expostos ou não (controle) à Senna occidentalis incorporadas à ração durante 90 dias. Dados expressos em media \pm erro padrão dos escores obtidos nos dias de observação. $\mathrm{N}=10$ animais por grupo. ${ }^{* * * *} p<0,0001$. Anova de duas vias seguida do pós-teste Bonferroni

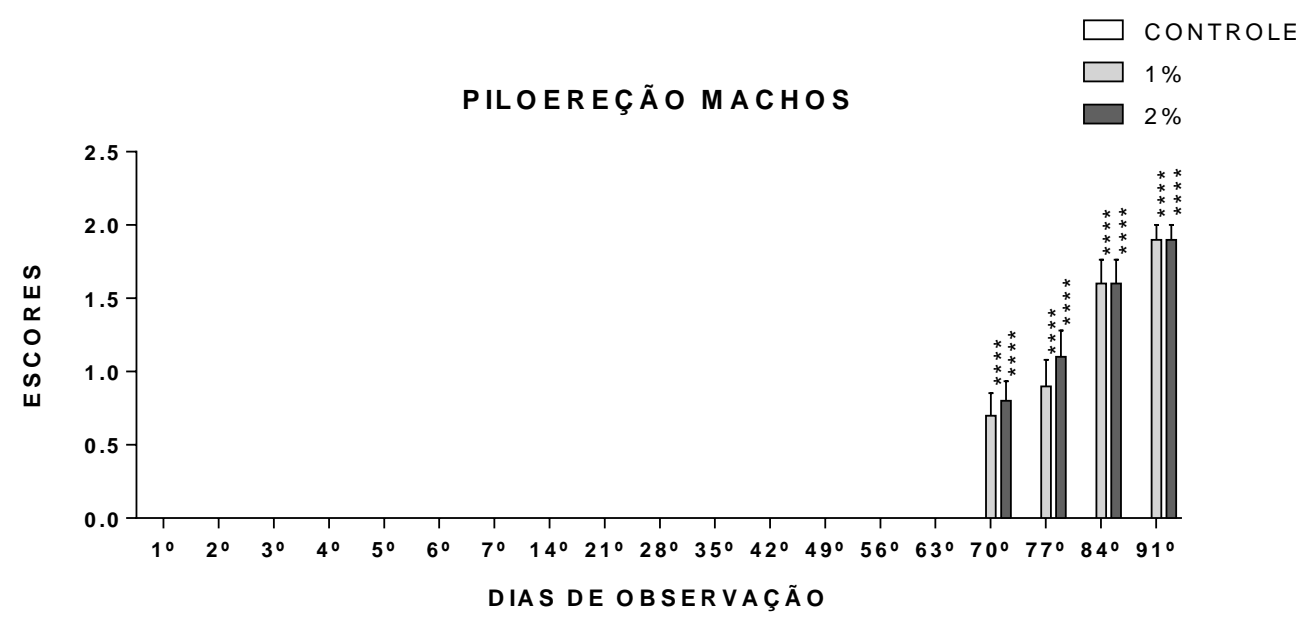

Fonte: (SANTOS, M. V., 2015).

Figura 18- Parâmetro piloereção da avaliação clínica de fêmeas expostas ou não (controle) à Senna occidentalis incorporadas à ração durante 90 dias. Dados expressos em media \pm erro padrão dos escores obtidos nos dias de observação. $\mathrm{N}=10$ animais por grupo. ${ }^{\star * *} p<0,001,{ }^{* * \star} p<0,0001$. Anova de duas vias seguida do pós-teste Bonferroni

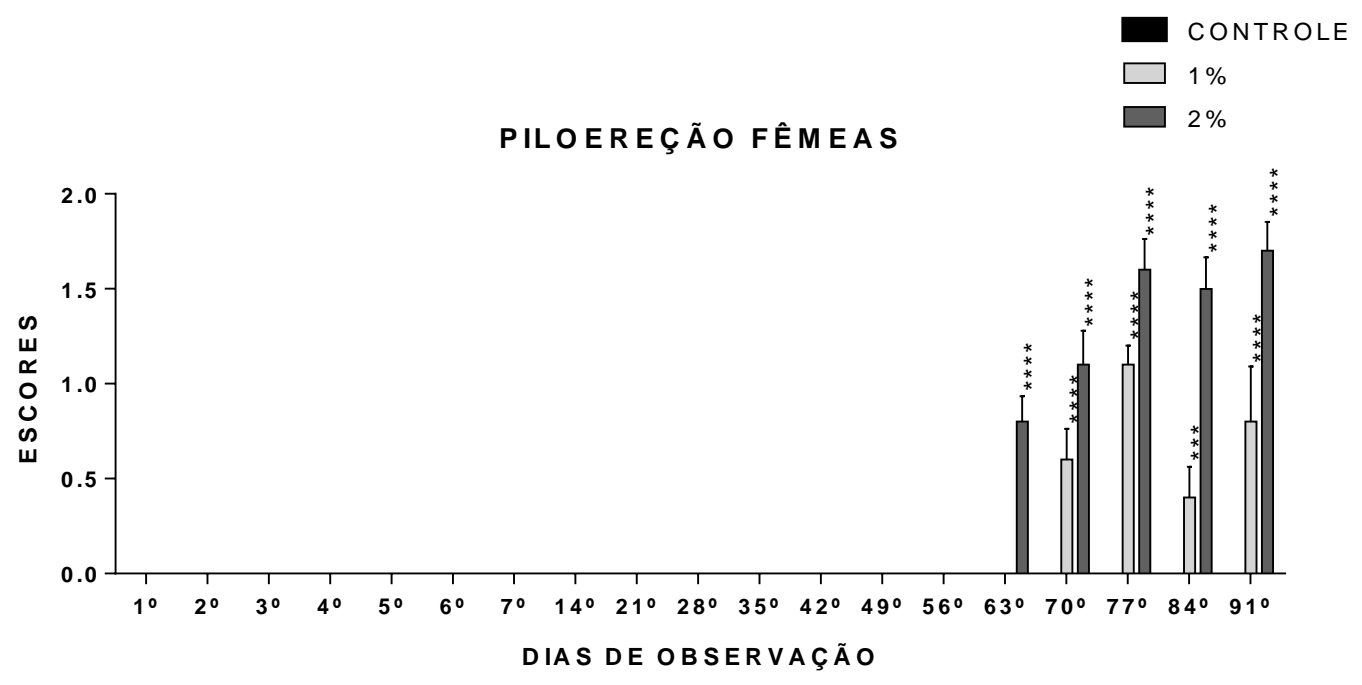

Fonte: (SANTOS, M. V., 2015). 


\subsubsection{Campo aberto}

A tabela 16 e a figuras 19 e 20mostram os resultados do comportamento no de Campo Aberto dos animais expostos ou não (controle) à S. occidentalis durante 90 dias em diferentes concentrações incorporadas à ração. Em machos, a Anova de uma via mostrou que houve diferença significante entre os grupos apenas na frequência de levantar $[F(2 / 27)=8,13 p=0,002]$. O pós-teste Dunnet mostrou que houve diminuição significante do levantar em ratos do grupo $1 \%(p<0,05)$, em relação àqueles do grupo controle.

Em fêmeas, a Anova de uma via mostrou diferenças significantes entre os grupos na frequência de: locomoção $[F(2 / 27)=6,52 p=0,005]$, com redução desse parâmetro nas fêmeas tratadas de $2 \%$ (pós-teste Dunnet, $p<0,01$ ); levantar $[F(2 / 27)=4,20 p=0,02]$, com diminuição em fêmeas dom grupo $2 \%$ (pós-teste Dunnet, $\mathrm{p}<0,05)$; e grooming $[F(2 / 27)=13,33 \mathrm{p}<0,0001]$, com aumento significante desse parâmetro em fêmeas do grupo 1\% (pós-teste Dunnet, $p<0,05$ ) e de $2 \%$ (pós-teste Dunnet, $p<0,0001)$, em relação ao grupo controle.

\begin{tabular}{|c|c|c|c|c|}
\hline COMPORTAMENTO & SEXO & CONTROIF & Senna 1\% & Senna 2\% \\
\hline \multirow{2}{*}{ LOCOMOÇÃO } & MACHOS & $102.80+13.12$ & $98.20+6.04$ & $117.5 \pm 10.83$ \\
\hline & FÊMEAS & $116,00 \pm 12,80$ & $102,80 \pm 5,97$ & $83,60 \pm 4,52 * *$ \\
\hline \multirow{2}{*}{ LEVANTAR } & MACHOS & $26,00 \pm 3,85$ & $11,60 \pm 1,16$ & $32,10 \pm 4,97$ \\
\hline & FÊMEAS & $24,90 \pm 2,07$ & $25,60 \pm 4,14^{*}$ & $15,20 \pm 1,63 *$ \\
\hline \multirow{2}{*}{ GROOMING } & MACHOS & $6,60 \pm 1,23$ & $9,60 \pm 1,23$ & $7,50 \pm 1,21$ \\
\hline & FÊMEAS & $2,20 \pm 0,81$ & $6,50 \pm 1,41 *$ & $11,00 \pm 1,30 * * * *$ \\
\hline
\end{tabular}

Fonte: (SANTOS, M. V., 2015). 
Figura 19 - Parâmetros de atividade geral (em frequência) observados em machos no campo aberto, no $91^{\circ}$ dia de exposição ou não (controle) á Senna occidentalisdurante 90 dias em diferentes concentrações incorporadas a ração. Dados expressos em média \pm erro padrão ( $n=10$ animais/grupo). ${ }^{*} p<0,05$, Anova seguida do teste de Dunnet
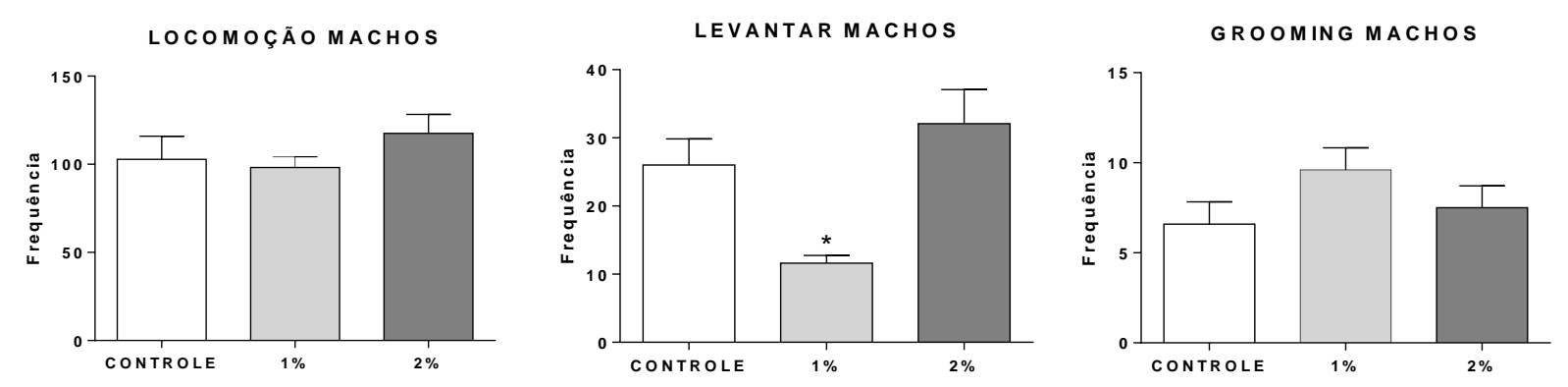

Fonte: (SANTOS, M. V., 2015).

Figura 20 - Parâmetros de atividade geral (em frequência) observados em fêmeas no campo aberto, no $91^{\circ}$ dia de exposição ou não (controle) á Senna occidentalisdurante 90 dias em diferentes concentrações incorporadas a ração. Dados expressos em média \pm erro padrão ( $n=10$ animais/grupo). ${ }^{*} p<0,05,{ }^{* *} p<0,01,{ }^{* * * *} p<0,0001$. Anova seguida do teste de Dunnet
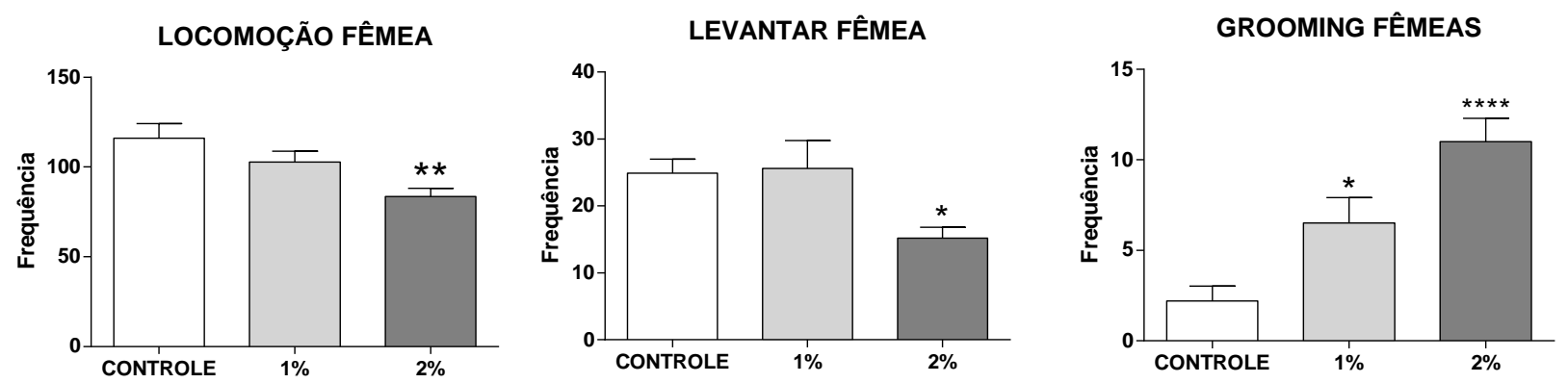

Fonte: (SANTOS, M. V., 2015).

\subsubsection{Labirinto em cruz elevado}

A tabela 17 e as figuras 21 e 22 apresentam os resultados do teste de Labirinto em Cruz Elevado, dos animais expostos após à S. occidentalis por 90 dias. Em machos, considerando aos resultados obtidos dos parâmetros em porcentagem, o teste de Kruskal-Wallis mostrou diferenças significantes entre os grupos apenas na \%TBA [KW $(3 / 11,34), p=0,003]$, e o pós-teste Dunn's mostrou que houve diminuição 
em ratos do grupo $1 \%(p<0,01)$, quando comparados ao grupo controle. Ainda em machos, a Anova de uma via mostrou diferenças significantes entre os grupos em relação à frequência: grooming $[F(2 / 26)=12,73 p=0,0001]$, com diminuição desse parâmetro em ratos do grupo $2 \%$ (pós-teste Dunnet, $p<0,01$ ); e avaliação de risco $[F(2,27)=23,82 p<0,0001]$, com diminuição dessa frequência em animais dos grupos 1 e $2 \%$ (pós-teste Dunnet, $p<0,0001$ ), em relação aos animais do grupo controle.

Em fêmeas foram observadas diferenças significantes entre os grupos apenas no parâmetro \%TBA [KW $(3 / 10,48), p=0,0053]$. O pós-teste Dunn's mostrou que houve diminuição significante neste parâmetro em ratas do grupo $1 \%(p<0,01)$, em relação aos animais do grupo controle.

\begin{tabular}{|c|c|c|c|c|}
\hline PARÂMETROS & SEXO & CONTROIF & Senna 1\% & Senna $2 \%$ \\
\hline \multirow[b]{2}{*}{$\%$ EBA } & MACHOS & & $2,00 \pm 1,65$ & $6,00 \pm 5,00$ \\
\hline & FÊMEAS & $14,00 \pm 7,84$ & $15,00 \pm 6,21$ & $2,00 \pm 1,67$ \\
\hline \multirow{2}{*}{$\%$ TBA } & MACHOS & $10,00 \pm 1,24$ & $4,00 \pm 0,52 * *$ & $7,00 \pm 1,45$ \\
\hline & FÊMEAS & $11,00 \pm 3,24$ & $3,00 \pm 0,82^{* *}$ & $7,00 \pm 1,72$ \\
\hline \multirow{2}{*}{$\begin{array}{l}\text { N. T. CRUZ. } \\
(B A+B F)^{3}\end{array}$} & MACHOS & $6,70 \pm 1,09$ & $7,90 \pm 0,59$ & $5,80 \pm 0,99$ \\
\hline & FÊMEAS & $8,40 \pm 1,23$ & $6,60 \pm 0,56$ & $7,10 \pm 0,62$ \\
\hline \multirow{2}{*}{ GROOMING } & MACHOS & $6,00 \pm 0,90$ & $7,00 \pm 0,96$ & $4,00 \pm 0,88^{* *}$ \\
\hline & FÊMEAS & $2,00 \pm 0,70$ & $3,00 \pm 0,88$ & $2,00 \pm 0,52$ \\
\hline \multirow{2}{*}{ AVAL. RISCO } & MACHOS & $21,00 \pm 1,96$ & $10,00 \pm 1,01 * * * *$ & $6,00 \pm 1,57^{* * * *}$ \\
\hline & FÊMEAS & $8,00 \pm 0,78$ & $7,00 \pm 0,80$ & $7,00 \pm 1,21$ \\
\hline OLHAR PARA & MACHOS & $8,00 \pm 1,10$ & $4,00 \pm 0,94$ & $5,00 \pm 1,10$ \\
\hline BAIXO & FÊMEAS & $6,00 \pm 0,91$ & $5,00 \pm 0,90$ & $7,00 \pm 1,66$ \\
\hline
\end{tabular}

Fonte: (SANTOS, M. V., 2015).

${ }^{1} \% \mathrm{EBA}=\%$ de entradas nos braços abertos; ${ }^{2} \% \mathrm{TBA}=\%$ de tempo nos braços abertos; ${ }^{3}$ número total de cruzamentos entre os braços abertos e fechados 
Figura 21- Parâmetros do comportamento de machos observados no labirinto em cruz elevado, no $91^{\circ}$ e $92^{\circ}$ dia de exposição ou não (controle) á Senna occidentalisdurante 90 dias em diferentes concentrações incorporadas à ração. \%EBA = \% de entrada nos braços abertos; \%TBA = \% de tempo nos braços abertos; Aval. Risco = avaliação de risco. Dados expressos em média \pm erro padrão $\left(n=10\right.$ animais por grupo). ${ }^{*} p<0,05$; ${ }^{* *} p<0,01 ;{ }^{* * *} p<0,001 ;{ }^{* * * *} p<0,0001$,Anova seguida do teste de Dunnet (para dados paramétricos) e Kruskal-Wallis seguido do teste de Dunn's (para dados não paramétricos)
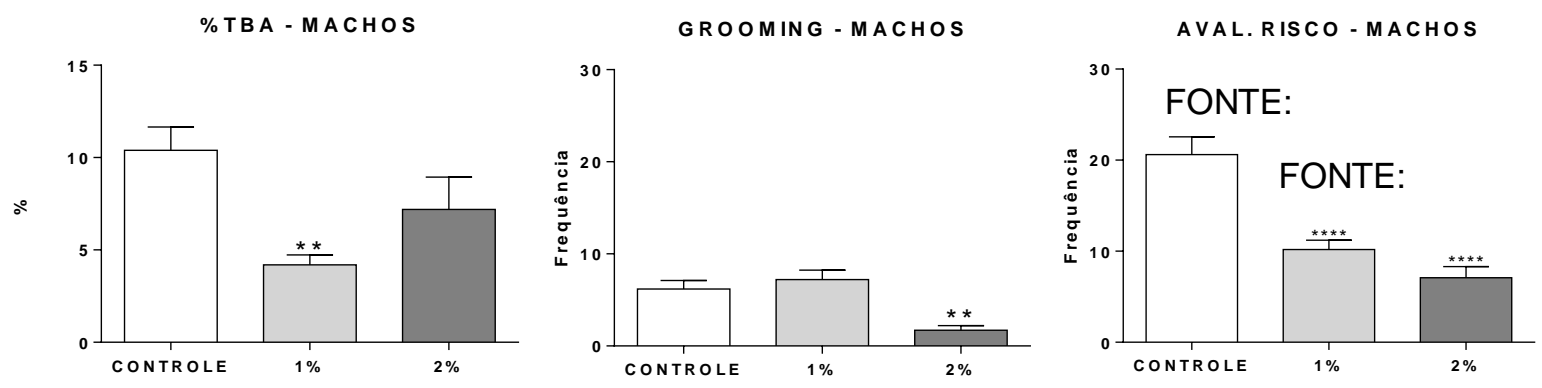

Fonte: SANTOS, M. V., 2015.

Figura 22 - Porcentagem de tempo nos braços abertos (\%TBA) observada no labirinto em cruz elevado, em fêmeas, no $91^{\circ}$ e $92^{\circ}$ dia de exposição ou não (controle) á Senna occidentalis durante 90 dias em diferentes concentrações incorporadas a ração. Dados expressos em média \pm erro padrão ( $n=10$ animais por grupo). ${ }^{* \star} p<0,01$, Kruskal-Wallis seguido do teste de Dunn's

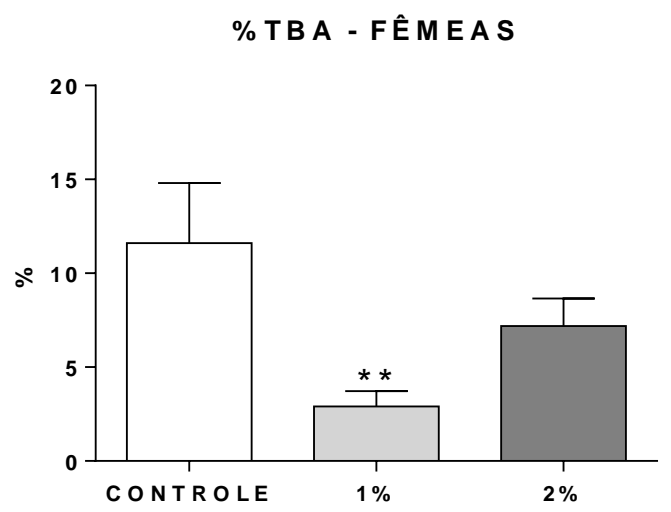

Fonte: (SANTOS, M. V., 2015).

\subsubsection{Reconhecimento de Objetos}

A tabela 18 apresenta os resultados do teste comportamental de Reconhecimento de Objetos de machos e fêmeas expostos ou não (controle) à diferentes concentrações de $S$. occidentalis incorporadas à ração durante 90 dias. A 
Anova de uma via não mostrou diferenças significantes entre os grupos, tanto em machos como em fêmeas.

\begin{abstract}
Tabela 18 - Índice de Reconhecimento de Objetos, observado em machos e fêmeas no $93^{\circ}$ e 94 dia de exposição ou não (controle) á Senna occidentalis durante 90 dias em diferentes concentrações incorporadas à ração. Dados expressos em média \pm erro padrão ( $\mathrm{n}=10$ animais/grupo)
\end{abstract}

\begin{tabular}{rcccccc}
\hline \multirow{2}{*}{ SEXO } & \multicolumn{2}{c}{ CONTROLE } & \multicolumn{2}{c}{ Senna 1\% } & \multicolumn{2}{c}{ Senna 2\% } \\
& $\mathbf{2 h}$ & $\mathbf{2 4 h}$ & $\mathbf{2 h}$ & $\mathbf{2 4 h}$ & $\mathbf{2 h}$ & $\mathbf{2 4 h}$ \\
\hline MACHOS & $0,50 \pm 0,05$ & $0,50 \pm 0,10$ & $0,49 \pm 0,09$ & $0,53 \pm 0,09$ & $0,47 \pm 0,10$ & $0,46 \pm 0,10$ \\
FÊMEAS & $0,46 \pm 0,05$ & $0,51 \pm 0,05$ & $0,48 \pm 0,06$ & $0,54 \pm 0,11$ & $0,59 \pm 0,08$ & $0,54 \pm 0,04$ \\
Fonte: (SANTOS, M. V., 2015). & & & & \\
p>0,05, Anova de uma via.
\end{tabular}

\title{
4.2.5 Hemograma
}

A tabela 19 (série vermelha) e 20 (série branca) e as figuras 23, 24 e 25 apresentam os resultados referentes à avaliação dos parâmetros hematológicos de ratos machos e fêmeas expostos ou não (controle) a diferentes concentrações de $S$. occidentalis incorporadas à ração durante 90 dias.

Em machos, dentre os parâmetros hematológicos da série vermelha e da branca, a Anova de uma via mostrou diferenças significantes entre os grupos apenas no parâmetro HCM $[F(2 / 12)=24,40, p<0,0001]$. O pós-teste Dunnet revelou aumento significante desse parâmetro nos ratos dos grupos $1 \%(p<0,001)$ e $2 \%$ ( $p<0,0001)$, em relação aos animais do grupo controle (Tabela 19 e Figura 23).

Em fêmeas, nos parâmetros hematológicos da séria vermelha, a Anova de uma via mostrou diferenças significantes entre os grupos nos parâmetros: HGB $[F(2 / 12)=4,823, p<0,029]$, com aumento no grupo 2\% (pós-teste Dunnet, $p<0,05$ ); $\mathrm{HCM}[\mathrm{F}(2 / 12)=50,98, \mathrm{p}<0,0001]$, com aumento em ratas dos grupos 1 e $2 \%$ (pósteste Dunnet, $\mathrm{p}<0,0001)$; e $\mathrm{CHCM}[\mathrm{F}(2 / 12)=30,56, \mathrm{p}<0,0001]$, com aumento deste em ratas dos grupos 1\% (pós-teste Dunnet, $p<0,01$ ) e 2\% (pós-teste Dunnet, $p<0,0001$ ), em relação aos animais do grupo controle (Tabela 19 e Figura 24).

Ainda em fêmeas, nos parâmetros da série branca, a Anova de uma via mostrou diferenças entre os grupos nos parâmetros: linfócitos $[F(2 / 12)=13,54$, 
$\mathrm{p}=0,001$ ], com diminuição nas ratas do grupo 1\% (pós-teste Dunnet, $p<0,001$ ); basófilos $[F(2 / 12)=10,29, p=0,002]$, onde houve diminuição nos grupos 1 e 2\% (pósteste Dunnet, $p<0,01)$; e neutrófilos $[F(2 / 12)=0,15, p=0,86]$, com aumento em animais do grupo 1\% (pós-teste Dunnet, $\mathrm{p}<0,001$ ), em relação aos animais do grupo controle (Tabela 20 e Figura 25).

Tabela 19 - Parâmetros hematológicos (série vermelha)machos e fêmeas expostos ou não (controle) á Senna occidentalis durante 90 dias. Os resultados são expressos como médios e respectivos erros padrão, $n=5$ animais por grupo. " $p<0,05 ;{ }^{* *} p<0,01 ;{ }^{* * *} p<0,0001$, Anova seguida do teste de Dunnet

\begin{tabular}{|c|c|c|c|c|}
\hline \multirow{2}{*}{ CÉLULAS } & \multirow{2}{*}{ SEXO } & \multirow{2}{*}{ CONTROLE } & \multicolumn{2}{|c|}{ Senna occidentalis } \\
\hline & & & $1 \%$ & $2 \%$ \\
\hline \multirow{2}{*}{$\operatorname{VCM}\left(\mu^{3}\right)$} & MACHOS & $53,8 \pm 0,33$ & $54,60 \pm 0,24$ & $54,60 \pm 0,40$ \\
\hline & FÊMEAS & $57,20 \pm 0,37$ & $58,00 \pm 0,45$ & $57,40 \pm 0,40$ \\
\hline \multirow{2}{*}{$\mathrm{HCM}(\mathrm{g} / \mathrm{dL})$} & MACHOS & $19,82 \pm 0,06$ & $20,66 \pm 0,06$ & $20,60 \pm 0,14$ \\
\hline & FÊMEAS & $20,62 \pm 0,04$ & $21,22 \pm 0,04 * * * *$ & $21,42 \pm 0,09 * * * *$ \\
\hline \multirow{2}{*}{$\begin{array}{c}\text { HEMÁCEAS } \\
\left(\text { Milhões } / \mathrm{mm}^{3} \text { ) }\right.\end{array}$} & MACHOS & $7,55 \pm 0,07$ & $7,40 \pm 0,15$ & $7,24 \pm 0,15$ \\
\hline & FÊMEAS & $6,82 \pm 0,14$ & $6,89 \pm 0,05$ & $6,8 \pm 0,14$ \\
\hline \multirow{2}{*}{$\mathrm{HGB}(\mathrm{g} / \mathrm{dL})$} & MACHOS & $15,08 \pm 0,14$ & $15,36 \pm 0,24$ & $15,28 \pm 0,17$ \\
\hline & FÊMEAS & $14,14 \pm 0,12$ & $14,62 \pm 0,18$ & $14,86 \pm 0,19 *$ \\
\hline \multirow{2}{*}{$\mathrm{Ht}(\%)$} & MACHOS & $41,12 \pm 0,43$ & $40,56 \pm 0,87$ & $39,94 \pm 0,86$ \\
\hline & FÊMEAS & $39,3 \pm 0,31$ & $40,40 \pm 0,31$ & $39,94 \pm 0,61$ \\
\hline \multirow{2}{*}{$\mathrm{CHCM}(\mathrm{g} / \mathrm{dL})$} & MACHOS & $36,82 \pm 0,24$ & $37,78 \pm 0,20 * * * *$ & $37,80 \pm 0,45 * * *$ \\
\hline & FÊMEAS & $35,72 \pm 0,08$ & $36,66 \pm 0,19 * *$ & $37,30 \pm 0,14 * * * *$ \\
\hline
\end{tabular}

VCM = volume corpuscular médio; $\mathrm{HCM}=$ hemoglobina corpuscular média; $\mathrm{HGB}=$ hemoglobinaHt = hematócrito; $\mathrm{CHCM}=$ concentração de hemoglobina corpuscular média 
Tabela 20 - Parâmetros hematológicos (série branca) de machos e fêmeas expostos ou não (controle) á Senna occidentalis durante 90 dias. Os resultados são expressos como médios e respectivos erros padrão, $n=5$ animais por grupo. ; $p<0,01$; $p<0,0001$, Anova seguida do teste de Dunnet

\begin{tabular}{ccccc}
\hline \multirow{2}{*}{ CÉLULAS } & \multirow{2}{*}{ SEXO } & \multirow{2}{*}{ CONTROLE } & \multicolumn{2}{c}{ Senna occidentalis } \\
& & & $1 \%$ & $2 \%$ \\
\hline LEUCÓCITOS & MACHOS & $3,64 \pm 0,04$ & $3,92 \pm 0,93$ & $3,68 \pm 0,42$ \\
$\left(\times 10^{3} / \mathrm{mm}^{3}\right)$ & FÊMEAS & $6,60 \pm 0,09$ & $5,38 \pm 0,55$ & $6,66 \pm 1,18$ \\
& MACHOS & $4,20 \pm 1,30$ & $3,00 \pm 0,74$ & $1,20 \pm 0,39$ \\
MONÓCITOS & FÊMEAS & $0,40 \pm 0,26$ & $0 \pm 0$ & $0,80 \pm 0,39$ \\
& MACHOS & $70,00 \pm 2,01$ & $70,00 \pm 2,45$ & $71,60 \pm 1,57$ \\
LINFÓCITOS & FÊMEAS & $79,00 \pm 1,44$ & $65,80 \pm 2,02^{* * *}$ & $74,00 \pm 2,14$ \\
& MACHOS & $1,00 \pm 0,47$ & $0,40 \pm 0,26$ & $1,00 \pm 0,33$ \\
BASÓFILOS & FÊMEAS & $1,20 \pm 0,39$ & $0 \pm 0 * *$ & $0 \pm 0 * *$ \\
\multirow{2}{*}{ EOSINÓFILOS } & MACHOS & $0,40 \pm 0,26$ & $0,40 \pm 0,42$ & $0,20 \pm 0,21$ \\
& FÊMEAS & $0,20 \pm 0,21$ & $0,40 \pm 0,26$ & $0,40 \pm 0,26$ \\
NEUTRÓFILOS & MACHOS & $25,20 \pm 2,15$ & $27,00 \pm 3,62$ & $25,40 \pm 1,80$ \\
& FÊMEAS & $21,20 \pm 2,41$ & $37,20 \pm 2,18 * *$ & $25,20 \pm 1,97$ \\
\hline
\end{tabular}

Fonte: (SANTOS, M. V., 2015).

Figura 23- Valores de hemoglobina corpuscular média (HCM) de machos expostos ou não (controle) á Senna occidentalis durante 90 dias em diferentes concentrações incorporadas à ração. Os resultados são expressos como médios e respectivos erros padrão, $n=5$ animais por grupo. $p<0,05 ;{ }^{* *} p<0,01 ;{ }^{* * *} p<0,0001$, Anova seguida do teste de Dunnet

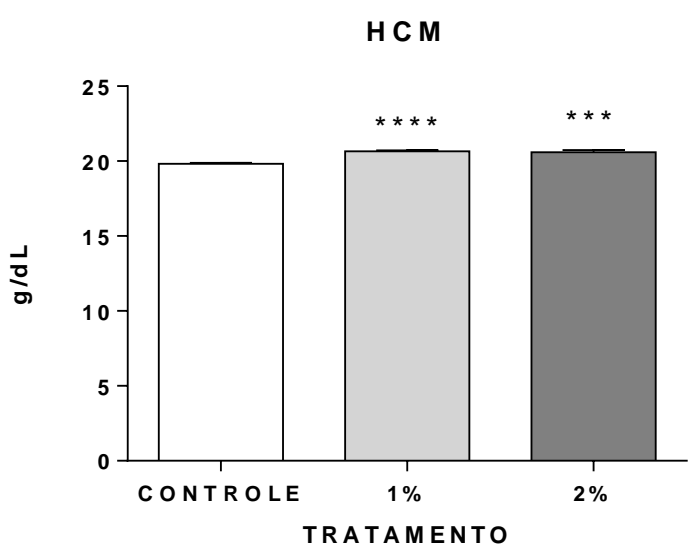

Fonte: (SANTOS, M. V., 2015). 
Figura 24 - Parâmetros hematológicos (série vermelha) de fêmeas expostas ou não (controle) á Senna occidentalis durante 90 dias em diferentes concentrações incorporadas à ração. Os resultados são expressos como médios e respectivos erros padrão, $n=5$ animais por grupo. ${ }^{*}<<0,05 ;{ }^{* *} p<0,01 ;{ }^{* * *} p<0,0001$, Anova seguida do teste de Dunnet
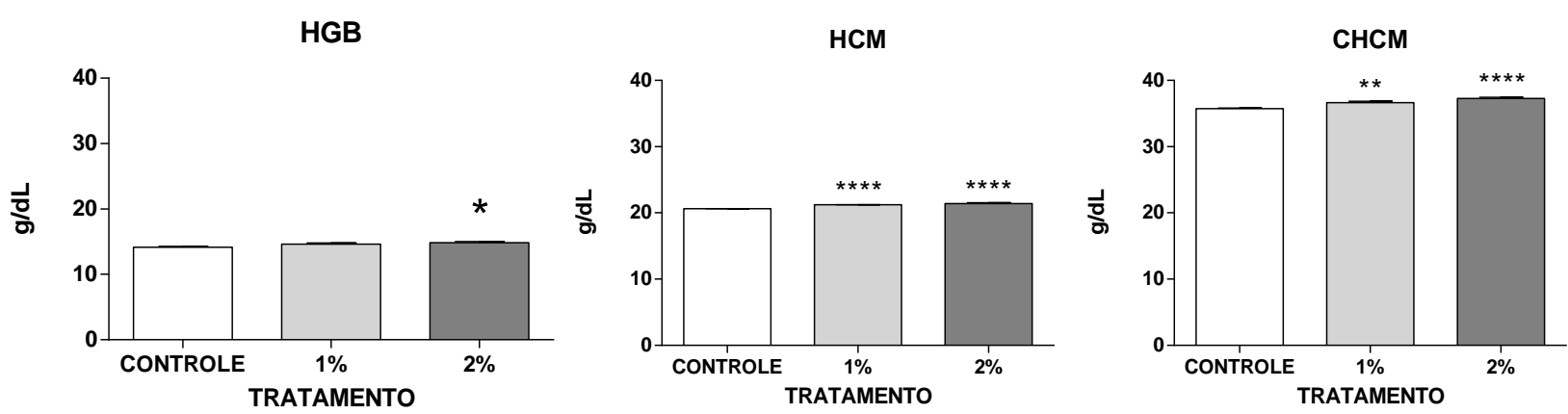

Fonte: SANTOS, M. V., 2015.

Figura 25- Parâmetros hematológicos (série branca) de fêmeas expostas ou não (controle) á Senna occidentalis durante 90 dias em diferentes concentrações incorporadas à ração. Os resultados são expressos como médios e respectivos erros padrão, $n=5$ animais por grupo. ${ }^{* *} \mathrm{p}<0,01 ;{ }^{* * *} \mathrm{p}<0,001$, Anova seguida do teste de Dunnet

LINFÓCITOS FÊMEAS

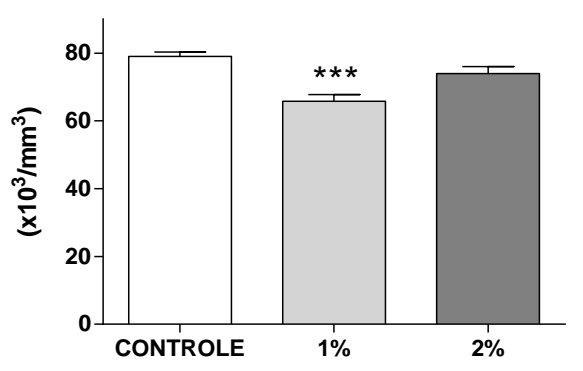

BASÓFILOS FÊMEAS

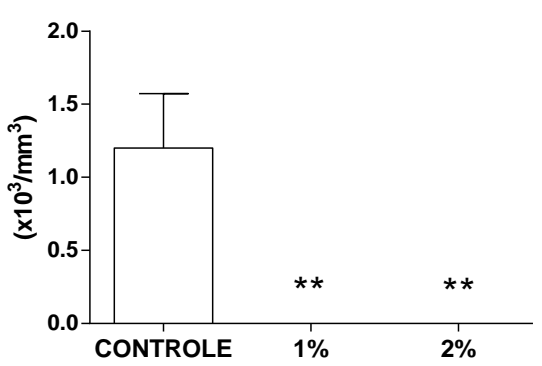

NEUTRÓFILOS FÊMEAS

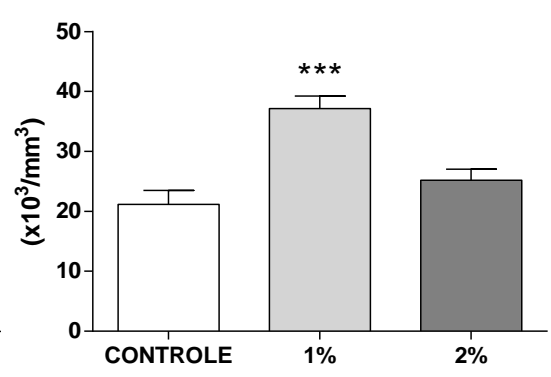

Fonte: (SANTOS, M. V., 2015).

\subsubsection{Bioquímica sérica}

A tabela 21 apresenta os resultados referentes aos parâmetros bioquímicos séricos de ratos machos e fêmeas expostos ou não (controle) a diferentes concentrações de $S$. occidentalis incorporadas à ração durante 90 dias. A Anova de 
uma via não mostrou diferenças significantes entre os grupos em nenhum dos parâmetros avaliados, em ambos os gêneros.
Tabela 21 - Parâmetros bioquímicos séricos machos e machos expostos ou não (controle) á Senna occidentalis durante 90 dias em diferentes concentrações incorporadas à ração. Os resultados são expressos como médios e respectivos erros padrão, $n=5$ animais por grupo. ( $p>0,05$, Anova)

\begin{tabular}{ccccc}
\hline CÉLULA & SEXo & CONTROLE & \multicolumn{2}{c}{ Senna occidentalis } \\
& & & $\mathbf{1} \%$ \\
\hline \multirow{2}{*}{ AST (U/L) } & Macho & $220,70 \pm 21,65$ & $202,20 \pm 13,85$ & $209,60 \pm 16,71$ \\
& Fêmea & $239,50 \pm 18,87$ & $238,40 \pm 21,12$ & $265,80 \pm 18,55$ \\
ALT (U/L) & Macho & $74,50 \pm 10,68$ & $70,40 \pm 10,48$ & $70,80 \pm 10,11$ \\
FOSFATSE ALCALINA & Fêmea & $93,90 \pm 9,67$ & $91,30 \pm 11,78$ & $86,20 \pm 12,28$ \\
(U/L) & Macho & $154,80 \pm 13,40$ & $133,80 \pm 5,35$ & $151,00 \pm 7,07$ \\
URÉlA (mg/dL) & Fêmea & $74,30 \pm 3,73$ & $105,70 \pm 9,98$ & $103,80 \pm 13,90$ \\
& Macho & $66,80 \pm 3,52$ & $73,00 \pm 3,02$ & $66,50 \pm 1,94$ \\
CREATININA (mg/dL) & Macho & $1,26 \pm 0,11$ & $1,43 \pm 0,12$ & $1,06 \pm 0,06$ \\
& Fêmea & $1,21 \pm 0,15$ & $1,20 \pm 0,14$ & $1,17 \pm 0,16$ \\
PROTEÍNATOTAL(mg/dL) & Macho & $6,51 \pm 0,46$ & $6,55 \pm 0,20$ & $6,40 \pm 0,30$ \\
& Fêmea & $10,19 \pm 2,93$ & $7,60 \pm 0,18$ & $6,94 \pm 0,14$ \\
ALBUMINA (g/dL) & Macho & $4,26 \pm 0,07$ & $4,18 \pm 0,12$ & $4,12 \pm 0,06$ \\
& Fêmea & $4,74 \pm 0,11$ & $4,70 \pm 0,09$ & $4,59 \pm 0,06$ \\
GLICOSE (mmol/L) & Macho & $406,1 \pm 44,62$ & $406,20 \pm 36,00$ & $420,00 \pm 22,78$ \\
& Fêmea & $339,80 \pm 35,69$ & $309,00 \pm 15,35$ & $307,40 \pm 24,23$ \\
COLESTEROL TOTAL & Macho & $74,50 \pm 11,50$ & $70,40 \pm 7,15$ & $59,70 \pm 7,18$ \\
(mg/dL) & Fêmea & $89,90 \pm 10,75$ & $83,00 \pm 9,40$ & $85,80 \pm 13,11$ \\
TRIGLICERÍDEOS & Macho & $109,20 \pm 7,86$ & $135,00 \pm 13,98$ & $89,20 \pm 6,62$ \\
(mg/dL) & Fêmea & $178,20 \pm 19,00$ & $142,00 \pm 23,03$ & $127,70 \pm 19,06$ \\
\hline
\end{tabular}

Fonte: (SANTOS, M. V., 2015).

$\mathrm{AST}=$ aspartatoaminotransferase; $\mathrm{ALT}=$ alanina aminotransferase; $\mathrm{FA}=$ fosfatasealcalina

\subsubsection{Peso real e relativo de órgãos}

A tabela 22 e a figura 26 mostram os resultados referentes ao peso relativo de órgãos dos machos expostos ou não (controle) a diferentes concentrações de $S$. occidentalis incorporadas à ração durante 90 dias. A Anova de uma via não mostrou 
diferenças significantes entre os grupos no peso relativo de nenhum dos órgãos avaliados. Por outro lado, a Anova de uma via mostrou diferenças significantes entre os grupos em relação ao peso relativo dos seguintes órgãos: baço $[F(2 / 27)=11,58$ $p=0,0002$ ], com aumento nos ratos do grupo $2 \%$ (pós-teste Dunnet, $p<0,001$ ); adrenal $[F(2 / 27)=3,25, p=0,05]$, com aumento deste em ratos do grupo $1 \%$ (pós-teste Dunnet, $p<0,05)$; rins $[F(2 / 27)=13,56 p<0,0001]$, com aumento desse parâmetro nos animais do grupo $2 \%$ (pós-teste Dunnet, $p<0,001$ ); próstata $[F(2 / 26)=7,56 p=0,003]$, com diminuição nos grupos $1 \%$ (pós-teste Dunnet, $p<0,01$ ) e 2\% (pós-teste Dunnet, $p<0,05)$; epidídimo $[F(2 / 27)=7,80 p=0,002]$, com aumento em ratos do grupo $2 \%$ (pós-teste Dunnet, $p<0,01$ ); testículos $[F(2 / 27)=9,70 p-=0,0007]$ com aumento em ratos do grupo $2 \%$ (pós-teste Dunnet, $p<0,001$ ); e vesícula seminal $[F(2 / 27)=3,87$ $\mathrm{p}=0,03$ ], com aumento em animais do grupo $2 \%$ (pós-teste Dunnet, $p<, 05$ ), em relação aos animais do grupo controle. 
Tabela 22 - Peso real (em g) e Peso relativo de órgãos (em g - peso do órgão / peso corpóreo x 100) de machos expostos à Senna occidentalis durante 90 dias a diferentes concentrações de Senna occidentalis incorporadas na ração. Dados expressos em média \pm erro padrão ( $n=10$ animais por grupo). ${ }^{*} p<0,05,{ }^{* *} p<0,01,{ }^{* * *} p<0,001$, Anova seguida do teste de Dunnet

\begin{tabular}{cclll}
\hline \multirow{2}{*}{ ORGÃO } & PESO & CONTROLE & \multicolumn{2}{c}{$\begin{array}{c}\text { Senna occidentalis } \\
1 \%\end{array}$} \\
& & & \multicolumn{1}{c}{$2 \%$} \\
\hline \multirow{2}{*}{ CORAÇÃO } & REAL & $1,487 \pm 0,049$ & $1,347 \pm 0,033$ & $1,344 \pm 0,049$ \\
& RELATIVO & $0,326 \pm 0,009$ & $0,311 \pm 0,007$ & $0,339 \pm 0,013$ \\
FÍGADO & REAL & $13,537 \pm 0,360$ & $12,533 \pm 0,547$ & $12,247 \pm 0,523$ \\
& RELATIVO & $2,979 \pm 0,084$ & $2,971 \pm 0,088$ & $2,837 \pm 0,240$ \\
PULMÃO & REAL & $2,564 \pm 0,0119$ & $2,304 \pm 0,263$ & $2,222 \pm 0,120$ \\
& RELATIVO & $0,569 \pm 0,038$ & $0,546 \pm 0,055$ & $0,577 \pm 0,027$ \\
BAÇO & REAL & $0,924 \pm 0,044$ & $0,886 \pm 0,033$ & $0,952 \pm 0,018$ \\
& RELATIVO & $0,202 \pm 0,007$ & $0,208 \pm 0,006$ & $0,240 \pm 0,004^{* * *}$ \\
ADRENAL & REAL & $0,046 \pm 0,004$ & $0,054 \pm 0,003$ & $0,050 \pm 0,004$ \\
& RELATIVO & $0,010 \pm 0,001$ & $0,014 \pm 0,001 *$ & $0,013 \pm 0,001$ \\
RIM & REAL & $2,720 \pm 0,079$ & $2,462 \pm 0,058$ & $2,706 \pm 0,115$ \\
PRÓSTATA & RELATIVO & $0,590 \pm 0,011$ & $0,579 \pm 0,012$ & $0,682 \pm 0,022^{* * *}$ \\
& REAL & $0,806 \pm 0,130$ & $0,456 \pm 0,033$ & $0,424 \pm 0,022$ \\
& RELATIVO & $0,170 \pm 0,027$ & $0,087 \pm 0,014 * *$ & $0,113 \pm 0,007$ \\
EPIDÍDIMO & REAL & $1,376 \pm 0,046$ & $1,252 \pm 0,052$ & $1,351 \pm 0,040$ \\
& RELATIVO & $0,288 \pm 0,017$ & $0,297 \pm 0,011$ & $0,343 \pm 0,011^{* *}$ \\
TESTÍCULO & REAL & $3,724 \pm 0,088$ & $3,620 \pm 0,078$ & $3,910 \pm 0,087$ \\
& RELATIVO & $0,813 \pm 0,027$ & $0,881 \pm 0,029$ & $0,998 \pm 0,032^{* * *}$ \\
VESÍCULA & REAL & $1,249 \pm 0,118$ & $1,348 \pm 0,060$ & $1,491 \pm 0,120$ \\
SEMINAL & RELATIVO & $0,276 \pm 0,027$ & $0,322 \pm 0,016$ & $0,377 \pm 0,031^{*}$ \\
\hline
\end{tabular}

Fonte: (SANTOS, M. V., 2015). 
Figura 26 - Peso relativo de órgãos (em g - peso do órgão / peso corpóreo x 100) de machos expostos ou não (controle) à Senna occidentalis durante 90 dias a diferentes concentrações de Senna occidentalis incorporadas na ração. Dados expressos em média \pm erro padrão ( $n=10$ animais por grupo). ${ }^{\star} p<0,05, p<0,01,{ }^{* \star *} p<0,001$, Anova seguida do teste de Dunnet

RINS

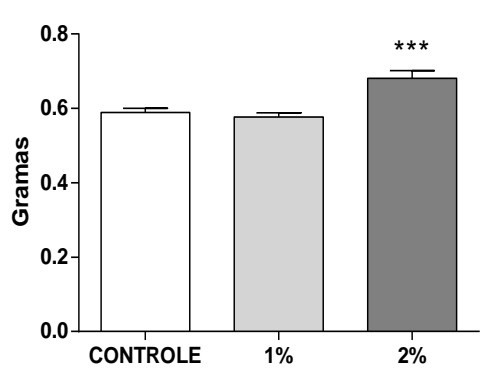

PRÓSTATA

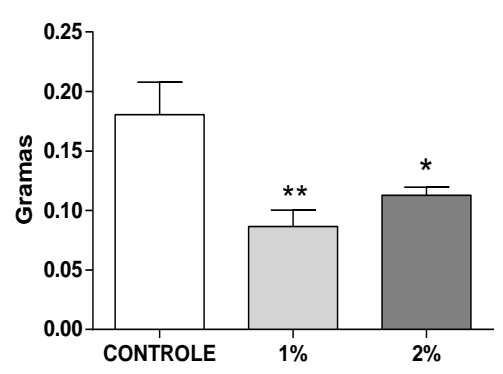

EPIDÍDIMOS

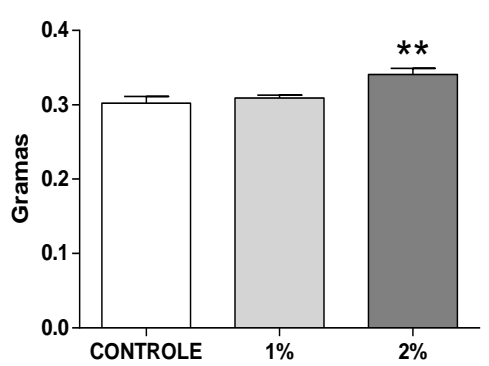

TESTÍCULOS

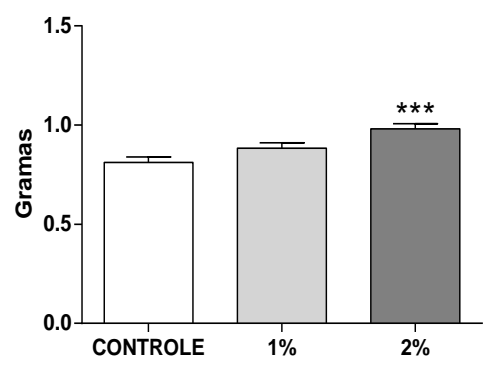

VESÍCULA SEMINAL

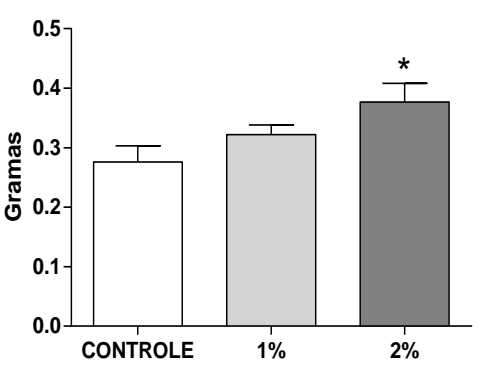

Fonte: (SANTOS, M. V., 2015).

A tabela 23 e a figura 27 mostram os resultados referentes aos pesos real e relativo dos órgãos das fêmeas expostas ou não (controle) à $S$. occidentalis em diferentes concentrações durante 90 dias. A Anova de uma via não mostrou diferenças significantes entre os grupos no peso relativo de nenhum dos órgãos avaliados. Por outro lado, a Anova de uma via mostrou diferenças significantes entre os grupos no peso relativo dos seguintes órgãos: baço $[F(2 / 27)=14,50 p<0,0001]$, com aumento em animais do grupo 2\%, (pós-teste Dunnet, $p<0,0001$ ); rins $[F(2 / 27)=5,99 \mathrm{p}=0,007]$ com o aumento em ratas do grupo $2 \%$ (pós-teste Dunnet, $\mathrm{p}<0,01)$; coração $[\mathrm{F}(2 / 27)=19,08 \mathrm{p}<0,0001]$, com aumento em ratas do grupo $2 \%$ (pós-teste Dunnet, $\mathrm{p}<0,0001)$; e fígado [F(2/27)3,29, $\mathrm{p}=0,05]$, com aumento em animais do grupo $2 \%$ (pós-teste Dunnet, $p<0,05$ ), em relação às fêmeas do grupo controle. 
Tabela 23 - Peso real (em g) e Peso relativo de órgãos (em g - peso do órgão / peso corpóreo x 100) de fêmeas expostas ou não (controle) à Senna occidentalis durante 90 dias a diferentes concentrações de Senna occidentalis incorporadas na ração. Dados expressos em média \pm erro padrão ( $n=10$ animais por grupo). ${ }^{*} p<0,05, p<0,01,{ }^{* * *} p<0,001$, Anova seguida do teste de Dunnet

\begin{tabular}{|c|c|c|c|c|}
\hline \multirow{2}{*}{ ORGÃO } & \multirow{2}{*}{ PESO } & \multirow{2}{*}{ CONTROLE } & \multicolumn{2}{|c|}{ Senna occidentalis } \\
\hline & & & $1 \%$ & $2 \%$ \\
\hline \multirow{2}{*}{ CORAÇÃO } & REAL & $0,908 \pm 0,026$ & $0,881 \pm 0,038$ & $0,959 \pm 0,014$ \\
\hline & RELATIVO & $0,364 \pm 0,011$ & $0,364 \pm 0,013$ & $0,463 \pm 0,014 * * *$ \\
\hline \multirow{2}{*}{ FÍGADO } & REAL & $8,011 \pm 0,342$ & $8,074 \pm 0,382$ & $7,672 \pm 0,276$ \\
\hline & RELATIVO & $3,202 \pm 0,109$ & $3,345 \pm 0,140$ & $3,659 \pm 0,137 *$ \\
\hline \multirow{2}{*}{ PULMÃO } & REAL & $1,527 \pm 0,095$ & $1,565 \pm 0,054$ & $1,384 \pm 0,091$ \\
\hline & RELATIVO & $0,610 \pm 0,031$ & $0,642 \pm 0,024$ & $0,665 \pm 0,038$ \\
\hline \multirow{2}{*}{ BAÇO } & REAL & $0,632 \pm 0,020$ & $0,629 \pm 0,020$ & $0,705 \pm 0,021$ \\
\hline & RELATIVO & $0,253 \pm 0,009$ & $0,259 \pm 0,011$ & $0,331 \pm 0,014 * * *$ \\
\hline \multirow{2}{*}{ ADRENAL } & REAL & $0,063 \pm 0,003$ & $0,064 \pm 0,002$ & $0,062 \pm 0,005$ \\
\hline & RELATIVO & $0,025 \pm 0,002$ & $0,027 \pm 0,001$ & $0,029 \pm 0,002$ \\
\hline \multirow{2}{*}{ RIM } & REAL & $1,632 \pm 0,032$ & $1,624 \pm 0,072$ & $1,573 \pm 0,037$ \\
\hline & RELATIVO & $0,331 \pm 0,007$ & $0,690 \pm 0,027$ & $0,749 \pm 0,026^{* *}$ \\
\hline \multirow[t]{2}{*}{ ÚTERO } & REAL & $0,525 \pm 0,024$ & $0,531 \pm 0,076$ & $0,805 \pm 0,226$ \\
\hline & RELATIVO & $0,211 \pm 0,010$ & $0,220 \pm 0,034$ & $0,414 \pm 0,109$ \\
\hline \multirow{2}{*}{ OVÁRIO } & REAL & $0,125 \pm 0,005$ & $0,106 \pm 0,007$ & $0,104 \pm 0,010$ \\
\hline & RELATIVO & $0,049 \pm 0,002$ & $0,045 \pm 0,003$ & $0,049 \pm 0,004$ \\
\hline
\end{tabular}

Fonte: (SANTOS, M. V., 2015). 
Figura 27 - Peso relativo de órgãos (em g - peso do órgão / peso corpóreo x 100) de fêmeas expostas ou não (controle) à Senna occidentalis durante 90 dias a diferentes concentrações de Senna occidentalis incorporadas na ração. Dados expressos em média \pm erro padrão ( $n=10$ animais por grupo). ${ }^{*} p<0,05,{ }^{* *} p<0,01,{ }^{* * *} p<0,001$, Anova seguida do teste de Dunnet

B A Ç O

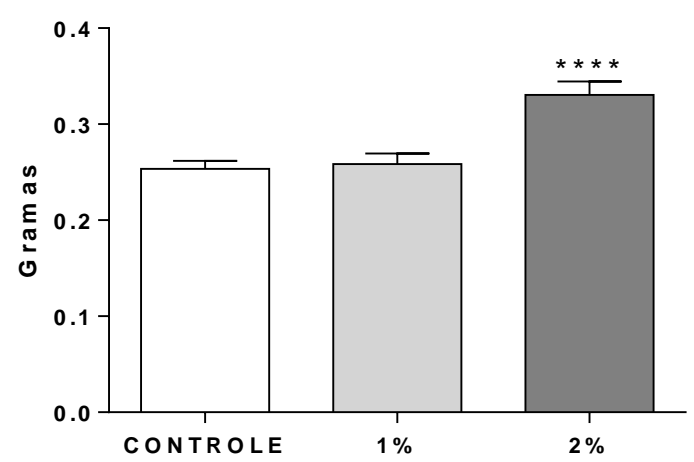

CORAÇÃ O

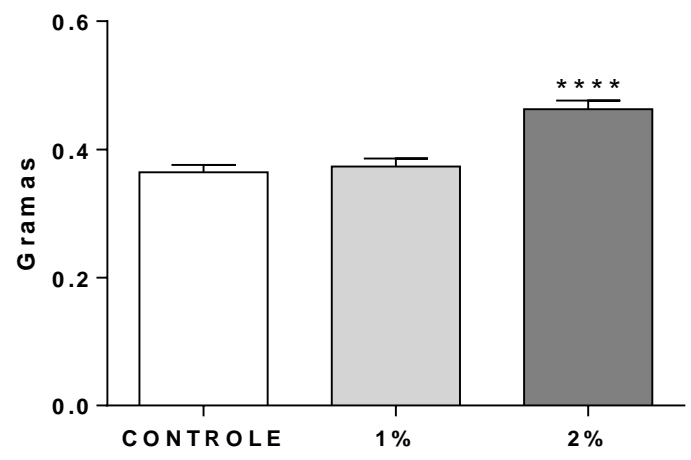

RINS

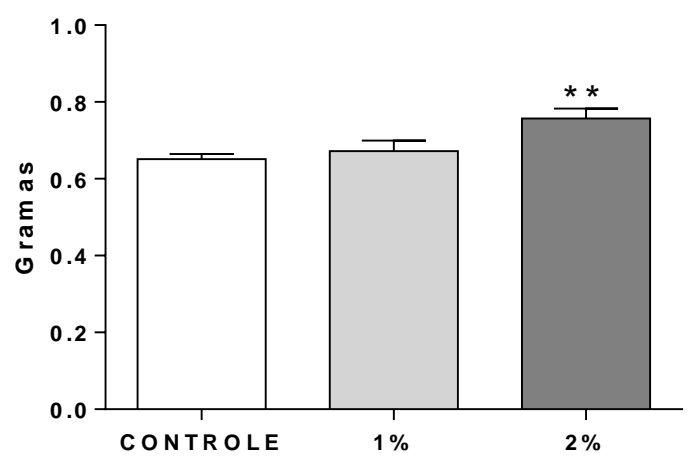

FÍG A D O

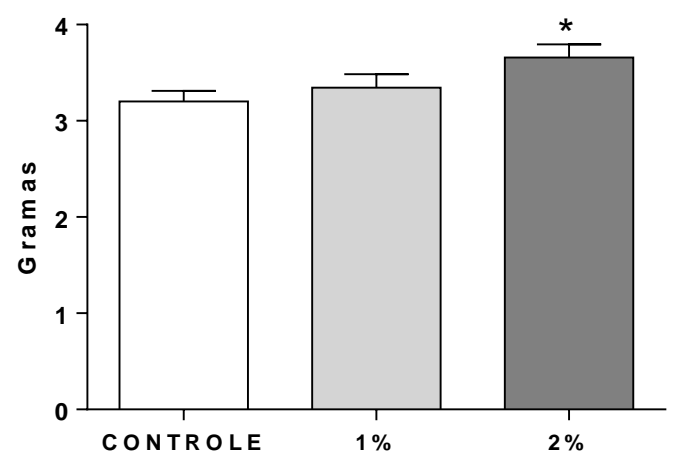

Fonte: (SANTOS, M. V., 2015).

\subsubsection{Estudo anatomopatológico}

Assim como observado no tratamento de 28 dias, na necropsia dos animais de 90 dias, não foi observado nada digno de nota.

No estudo histopatológico, de modo geral, observamos que os animais tanto machos quanto fêmeas de todos os grupos tratados, apresentaram fígado, baço, suprarrenal, pulmão, coração e rins com padrão dentro da normalidade, exceto por: fígado congesto; baço com congestão em polpa vermelha; e, pulmão atelectásico e congesto. 
Embora a análise histopatológica tenha mostrado poucas alterações, observamos que os animais do grupo controle apresentaram alterações similares ou até mais evidentes do que os animais expostos. 


\section{DISCUSSÃO}

No presente estudo foram empregadas, inicialmente, as concentrações de $1 \%, 2 \%$ e $4 \%$ de sementes de $S$. occidentalis incorporadas na ração comercial, baseadas em estudos prévios de nosso laboratório (BARBOSA-FERREIRA et al., 2005; CARVALHO, 2013), e embasados nos guidelines OECD 407, 408 e 424 que sugerem o emprego de pelo menos três doses nos estudos de toxicidade. Porém, durante a realização do estudo de 90 dias de exposição à planta, a maior concentração (4\%) mostrou-se bastante tóxica, havendo óbito de animais desse grupo (a partir do $41^{\circ}$ dia após o início da exposição), sendo então substituída essa concentração pela de 3\%. Embora tenhamos empregado essa concentração menor $(3 \%)$, esta também se mostrou tóxica, com óbito de animais ocorrendo mais tardiamente, a partir do $63^{\circ}$ dia após o início da exposição às sementes da planta. Por esse motivo o estudo de 90 dias de exposição às sementes da planta foi concluído com o emprego de apenas duas concentrações de sementes na ração (1 e $2 \%)$.

Consumo de água e de ração, bem como mensuração do peso corpóreo são parâmetros úteis para indicar toxicidade causada pela administração contínua de substâncias químicas (STEVENS; GALLO, 1989). No presente trabalho, tanto no estudo de 28 dias como no de 90 dias foram observadas apenas algumas flutuações no consumo de água e de ração, porém constatou-se redução do peso corpóreo dos animais (machos e fêmeas) em ambos os estudos. Em machos, no estudo de 28 dias não foram observadas alterações no peso corpóreo dos animais dos grupos experimentais, porém no estudo de 90 dias observou-se redução do peso corpóreo, que no grupo de $1 \%$ ocorreu na $10^{\mathrm{a}}$ e $13^{\mathrm{a}}$ semana de tratamento, enquanto no grupo $2 \%$ começou na $9^{\text {a }}$ semana e se manteve até o final da exposição à planta. Em fêmeas, no estudo de 28 dias, a redução de peso corpóreo foi constatada apenas no grupo $4 \%$, desde a primeira semana de exposição à planta, enquanto no estudo de 90 dias, as fêmeas dos grupos 1 e $2 \%$ mostraram redução do peso corpóreo a partir da $6^{\text {a }}$ semana de exposição à planta, sendo esse efeito mantido no grupo $2 \%$ até o término do experimento. Esses achados sugerem que a toxicidade à planta é concentração-dependente e que as fêmeas são mais susceptíveis. No mesmo sentido, Mariano-Souza (2005) também observou queda de peso em ratos expostos 
à $S$. occidentalis incorporadas à ração apenas na concentração de $4 \%$ por um período de 14 dias, sem alteração nos grupos de 1 e $2 \%$. Ainda, redução no ganho de peso foi constatada por Carvalho (2013), trabalhando com ratas prenhes, as quais receberam 2 e $3 \%$ de sementes de $S$. occidentalis incorporadas à ração após a $2^{\underline{a}}$ semana do início da exposição ( $3^{\underline{a}}$ semana de gestação).

Há estudos que relatam que a perda de peso causada pela planta poderia estar relacionada à produção de lesão intestinal em ratos, promovendo, assim, a deficiência na absorção de nutrientes (NADAL et al., 2003; SOSSAl; NASONE; CANTALAMESSA, 2007). Entretanto, Brusick e Menges (1997) observaram que a administração da planta in natura, bem como das frações dos derivados antranóides não causou lesões no trato digestivo dos ratos.

Outra hipótese relacionada à toxicidade da $S$. occidentalis que poderia estar relacionada à perda de peso é o seu efeito laxante. Sabe-se que os antranóides, derivados das antraquinonas constituintes naturais dessa planta, são agentes laxantes eficazes (JOO, 1998; FUKUDA et al., 2009), sendo esta a principal finalidade fitoterápica pela qual a planta vem sendo popularmente e amplamente utilizada (SOYUNCU; CETE; NOKAY, 2008). Após a ingestão dos antranóides, no intestino a flora bacteriana biotransforma esses compostos, liberando dois metabólitos ativos, os quais apresentam mecanismos de ação independentes: a indução do aumento da motilidade intestinal e a alteração da absorção e secreção intestinal (SOSSAI; NASONE; CANTALAMESSA, 2007). Contudo, no presente estudo, fezes amolecidas foram observadas apenas no grupo $4 \%$ durante a primeira semana de exposição à planta, tanto em machos como em fêmeas, não sendo constatado efeito laxante nas semanas subsequentes.

A avaliação de toxicidade clínica (screening hipocrático) é um recurso simples que fornece uma estimativa geral da natureza farmacológica e toxicológica de uma substância desconhecida sobre o estado consciente e disposição do animal, bem como sobre a atividade e coordenação do sistema motor, reflexos, atividade sobre o sistema nervoso central e sistema nervoso autônomo (LUClO et al., 2000).

No presente trabalho, o emprego do screening hipocrático mostrou alteração apenas em um dos parâmetros avaliados, sendo este a piloereção, tanto na exposição à planta por 28 dias, como por 90 dias, em ambos os gêneros. No estudo de 28 dias a piloereção foi observada apenas no grupo 4\%, a partir do 14ㅇdiamantendo-se até o final do experimento, em macho e fêmeas. No estudo de 
90 dias, este parâmetro manifestou-se a partir do $70^{\circ}$ diaem machos dos grupos 1 e $2 \%$, enquanto em fêmeas do grupo $2 \%$ a partir do 63 ㅇa dia do grupo $1 \%$ a partir do $70^{\circ}$ dia. Esses achados sugerem que a toxicidade à planta é concentraçãodependente e que as fêmeas são mais susceptíveis, corroborando os resultados da avaliação do peso corpóreo.

A piloereção é uma reação fisiológica do sistema nervoso autônomo simpático que pode estar presente em situações de desconforto e dor (YASBEK, 2008; BENEDEK et al., 2010). Este é um dos sinais clínicos que está presente no quadro de dor de roedores, sendo que na dor branda a piloereção é parcial, na moderada é marcante e quando há piloereção marcante acompanhada de sinais de desidratação e/ou desnutrição, a dor é considerada intensa (STASIAK et al., 2003; DAMY et al., 2010; FELASA, 2015). Portanto, no presente estudo pode-se sugerir que os animais expostos à $S$. occidentalis manifestaram dor branda.

O teste de Campo Aberto, introduzido na década de 1930, correlacionava a atividade motora e o número de bolos fecais com a emocionalidade do animal (HALL, 1936). Atualmente, esse teste é amplamente utilizado para medir respostas comportamentais, como atividade motora, hiperatividade e comportamentos exploratórios, além de refletir o estado emocional do animal (ARCHER, 1973; LISTER, 1990; TREMML et al., 1998; BELZUNG; CRUSIO; GERLAI, 1999). Dependendo do nível de exploração do ambiente, o campo aberto pode ser útil para indicar ansiedade (quando os estímulos ansiogênicos são suficientes para indicar perigo), exploração (caso os estímulos ansiogênicos não sejam excessivos a ponto de inibir o comportamento do animal) e, ainda, atividade locomotora (quando a arena deixa de ser novidade) (BELZUNG, 2001; SANDINI; UDO; SPINOSA, 2012). Em particular, considerando o parâmetro de locomoção, Penke et al. (2001) propõe que a redução da locomoção pode indicar aumento da ansiedade, sendo reflexo da hiperrresponsividade do eixo hipotálamo-pituitária-adrenal (HPA).

Outro parâmetro também avaliado no Campo Aberto é o grooming; esse comportamento é tido como complexo e requer cuidado na avaliação, pois ocorre em diferentes espécies animais, como os roedores, e em vários contextos, como, por exemplo, como uma atividade de comportamento deslocado ("displacement behavior") no momento de indecisão e conflito comportamental, e como reação a uma situação recente de ativação, despertar ou estresse (SPRUIJT et al. 1992; LECKMAN et al., 1994).O aumento do grooming pode também ser considerado 
indicativo de desordens ansiosas (ALDRIDGE; BERRIDGE; ROSEN, 2004; NUNES, 2012).

No presente trabalho a avaliação dos animais no Campo Aberto mostrou alterações comportamentais apenas em fêmeas. No estudo de 28 dias, as fêmeas dos grupos2 e 4\% apresentaram redução significante de locomoção e aumento significante de grooming; no estudo de 90 dias, o mesmo foi observado no grupo $2 \%$. Esses achados sugerem que em fêmeas expostas à planta apresentaram comportamento indicativo de ansiedade.

O Labirinto em Cruz Elevado é um aparato confiável e valioso para o estudo da neurobiologia da ansiedade, utilizado nos estudos de seleção de drogas ansiolíticas e ansiogênicas, bem como para avaliação dos seus mecanismos de ação (HALLER; ALICKLI, 2012). Além disso, o Labirinto em Cruz Elevado também é empregado para a compreensão das bases biológicas relacionadas à aprendizagem, memória, dor e vários subtipos de transtornos de ansiedade (CAROBREZ; BERTOGLIO, 2005). A medida das categorias comportamentais deste teste reflete 0 conflito entre a tendência natural do animal em explorar ambientes novos e evitar situações potencialmente perigosas (PELLOW et al.,1985; RODGERS et al., 1997).O comportamento normal do roedor neste labirinto consiste em explorar o aparato tanto horizontal (EBF e EBA), quanto verticalmente (frequência de levantar), com preferência pelos BF e realizar a avaliação de risco (parâmetro conflitante entre explorar ambiente novo e a aversão pelo BA) (RODGERS; DALVI, 1997). Blanchard et al. (2001) associa a redução na frequência de avaliação de risco neste aparato com maior índice de ansiedade. Sabe-se também que drogas ansiogênicas, como a cafeína e anfetamina, administrada a roedores reduzem a porcentagem de entradas e tempo gasto nos braços abertos do Labirinto em Cruz Elevado (PELLOW et al.,1985; CAROBREZ; BERTOGLIO, 2005).

Nesse trabalho observou-se tanto na exposição por 28 dias quanto na de 90 dias redução da \%TBA no grupo 1\% em ambos os gêneros, bem como redução na frequência da avaliação de risco em machos de todos os grupos expostos à planta. Esses achados sugerem que a exposição à planta foi capaz de desencadear, tanto em machos como em fêmeas, um estado comportamental sugestivo de ansiedade, corroborando, em parte, os resultados obtidos no Campo Aberto em que as fêmeas mostraram redução da locomoção e aumento do grooming, comportamentos indicativos de ansiedade. 
As avaliações dos parâmetros hematológicos e bioquímicos séricos são úteis para investigar possíveis efeitos tóxicos nos tecidos causados pela exposição a diferentes agentes. No presente trabalho, tanto no estudo de 28 dias como no de 90 dias, não foram encontradas diferenças entre os grupos na avaliação bioquímica sérica e algumas diferenças significantes foram constatadas entre os grupos experimentais na avaliação hematológica, contudo estes valores encontram-se dentro da variação fisiológica da espécie (SHARP; LAREGINA, 2012). Carvalho et al. (2009), em um estudo realizado para comparar achados hematológicos de diversos centros de pesquisa, constataram grande variação desses parâmetros em ratos Wistar, ressaltando a dificuldade de fazer especulações sobre esses resultados.

$\mathrm{Na}$ avaliação anatomopatológica poucas alterações foram encontradas no estudo de 28 dias (aumento do peso relativo do pulmão dos machos do grupo 1\% e diminuição do peso relativo do útero do grupo 1\%), não sendo encontrados achados histopatológicos.

No estudo de 90 dias foram encontradas alterações no peso relativos dos órgãos apenas no grupo $2 \%$, sendo observado em machos aumento de baço, adrenal, rins, epidídimos, testículos e vesícula seminal, mas diminuição em próstata; em fêmeas foi observado aumento de baço, fígado, rins e coração. Esses achados não foram acompanhados de alteração histopatológicas.

Esses resultados sugerem uma possível ação tóxica não específica da $S$. occidentalis nos diferentes órgãos avaliados, podendo estar relacionada ao mecanismo de ação tóxico da diantrona, o desacoplamento da fosforilação oxidativa mitocondrial, promovendo dano celular especialmente nos órgãos com maior demanda de oxigênio (VIEGAS et al., 2006; LOMBARDO; KIYOTA; KANEKO, 2009).

Considerando, em particular, em machos as alterações no peso relativo da adrenal, próstata, testículos, epidídimos e vesícula seminal, estas podem estar associadas com a interferência no eixo hipotálamo-hipófise-adrenal e/ou hipotálamohipófise-gonadal. Vale destacar que há relatos na literatura que associam o consumo de Senna spp a casos de infertilidade em ratos e seres humanos (YADAV; JAIN, 1999; BADAMI et al., 2003; STUART, 2003). Assim sendo, há necessidade de mais estudos para melhor esclarecer essas alterações encontradas no trato reprodutivo masculino. 
Embora no presente trabalho alterações histopatológicas nos tecidos avaliados não tenham sido encontradas, há relatos na literatura relacionando a intoxicação por $S$. occidentalis a alterações principalmente em musculatura esquelética, cardíaca, parênquima renal e hepático. Na musculatura esquelética observaram-se vários graus de degeneração, necrose e ruptura de fibras musculares, associadas, algumas vezes, a processos proliferativos e regenerativos em animais a campo (BARROS, 1999; RAFFI et al., 2003). No coração as lesões musculares são mais brandas, sendo evidenciado normalmente lesões focais, com vacuolização e fibrose; no rim comumente encontra-se necrose e degeneração das células epiteliais dos túbulos e material homogêneo eosinofílico intratubular (nefrose hemoglobinúrica);no fígado observa-se pequenos focos necróticos de distribuição aleatória, infiltrados por neutrófilos, vacuolização hepática (BARROS, 1999; RAFFI et al., 2003; CARMO et al., 2011).

Esses resultados, em conjunto, mostraram que a exposição a diferentes concentrações das sementes de S. occidentalis na ração de ratos por 28 e 90 dias foi capaz de causar toxicidade, bem como um estado comportamental sugestivo de ansiedade, sendo esses efeitos concentração-dependente, tempo-dependente e sugerindo ser as fêmeas mais susceptíveis. 
CONCLUST̃O 


\section{CONCLUSÃO}

A exposição a diferentes concentrações das sementes de $S$. occidentalis na ração de ratos por 28 e 90 dias foi capaz de causar toxicidade caracterizada pela ocorrência de óbitos, redução de peso corpóreo e piloereção, bem como promoveu um estado comportamental sugestivo de ansiedade, sendo esses efeitos concentração-dependente, tempo-dependente e sugerindo ser as fêmeas mais susceptíveis. Por outro lado, embora avaliações de parâmetros hematológicos e bioquímicos séricos sejam úteis para investigar possíveis efeitos tóxicos nos tecidos causados pela exposição a diferentes agentes, no presente trabalho não foram encontradas alterações nestes parâmetros em ratos expostos à planta, e poucas alterações foram encontradas no peso relativo de órgãos sem, contudo, causar alteração histopatológicas. 
REFEREAMCIAS 


\section{REFERÊNCIAS}

ARAGAO T. P.; LYRA M. M.; SILVA M. G.; ANDRADE B. A.; FERREIRA P. A.; ORTEGA L. F.; SILVA S. D.; SILVA J. C.; FRAGA M. C.; WANDERLEY A. G.; LAFAYETTE S. S. Toxicological reproductive study of Cassia occidentalis $L$. in female Wistar rats. Journal of Ethnopharmacology, Pernambuco, v. 123, n. 1, p. 163-166, 2009.

ALDRIDGE, J. W.; BERRIDGE, K. C.; ROSEN, A. R. Basal ganglia neural mechanisms of natural movement sequences. Candian Journal Physiology and Pharmacology, Canadá, v. 82, p. 732-739, 2004.

ARCHER, J. Tests for emotionality in rats and mice. A review. Animal Behaviour, Inglaterra, v. 21, n 2, p. 205-235, 1973.

BADAMI, S.; ANEESH, R.; SANKAR, S.; SATHISHKUMAR, M. N. Antifertility activity of Derris brevis variety coriacea. Journal of Ethnopharmacology, Índia, v. 84, n. 1, p. 99-104, 2003.

BADKE, M. R.; BUDÓ, M. D. L. D.; SILVA, F. M. da; RESSEL, L. B. Planta medicinais: o saber sustentado na prática do cotidiano popular. Escola Anna Nery, Rio Grande do Sul,. v. 15, n. 1, p. 132-139, Janeiro-Março de 2011.

BARBOSA-FERREIRA, M.; DAGLI, M. L. Z.; MAIORKA, P. C.; GORNIAK, S. L. Subacute intoxication by Senna occidentalis seeds in rats. Food and Chemical Toxicology, São Paulo, v. 43, n. 4, p. 497-503, 2005.

BARBOSA-FERREIRA, M.; PFISTER, J. A.; GOTARDO, A. T.; MAIORKA, P. C.; GÓRNIAK, S. L. Intoxication by Senna occidentalis seeds in pregnant goats: prenatal and postnatal evaluation. Experimental and Toxicologic Pathology, São Paulo, v. 63, n. 3, p. 263-268, 2011.

BARBOSA-FERREIRA, M. Proposta de modelo para estudo de toxicologia perinatal em ruminantes: avaliação dos efeitos tóxicos da Senna occidentalis em caprinos, Estado de São Paulo. 2008. 185 f. Tese (Doutorado em Ciências) Faculdade de Medicina Veterinária, Universidade de São Paulo, São Paulo, 2013.

BARROS, C. S. L. Intoxicações por plantas que afetam o sistema muscular, p.201203. In: RIET-CORREA F.; MÉNDEZ, M. C.; SCHILD, A. L. (Ed.). Intoxicações por plantas e micotoxicoses em animais domésticos. Pelotas: Hemisfério Sul do Brasil, 1993. 
BARROS, C. S. L.; ILHA, M. R. S.; BEZERRA, P. S.; LANGOHR, I. M.; KOMMERS, G. D. Intoxicação por Senna occidentalis (Leg. Caesalpinoideae) em bovinos em pastoreio. Pesquisa Veterinaria Brasileira, Rio Grande do Sul, v. 19, n. 2, p. 68$70,1999$.

BELZUNG, C.; CRUSIO, W. E.; GERLAI, R. T. Chapter 4.11 Measuring rodent exploratory behavior. Techniques in the Behavioral and Neural Sciences, v. 13, p. 738-749, 1999.

BELZUNG, C. Rodents models of anxiety-like behaviors: are they predictive for compounsd acting via non-benzodiazepine mechanisms? Current Opinions in Investigational Drugs, v. 2, p. 1108-1111, 2001.

BENEDEK, M.; WILFLING, B.; LUKAS-WOLFBAUER, R.; KATZUR, B. H.; KAERNBACH, C. Objective and continuous meansurement of piloerection. Psychophysiology, Áustria, v. 47, n. 1, p. 983-993, 2010.

BORGHETTI, F.; FERREIRA, A. G. Interpretação de resultados de germinação. In: BORGHETTI, F. (Org.). Germinação: do básico ao aplicado. Porto Alegre: Artmed, 2004. p. 209-222.

BRUSICK, D.; MENGS, U. Assessment of the genotoxic risk from laxative Senna products. Environmental and Molecular Mutagenesis, Virgínia, v. 29, n. 1,p. 1-9, 1997.

CARMO, P. M. S.; IRIGOYEN, L. F.; LUCENA, R. B.; FIGHERA, R. A.; KOMMERS, G. D.; BARROS, C. S. L. Spontaneous coffee senna poisoning in cattle: report on 16 outbreaks. Pesquisa Veterinária Brasileira, Rio Grande do Sul, v. 31, n. 2, p.139_ 146, 2011.

CAROBREZ, A. P.; BERTOGLIO, L. J. Ethological and temporal analyses of anxietylike behavior: the elevated plus-maze model 20 years on. Neuroscience and Biobehavioral Reviews, v. 29, p. 1193-1205, 2005.

CARVALHO, G. D.; MASSENO, A. P. B.; ZANINI, M. S.; ZANINI, S. F.; PORFIRIO, L. C.; MACHADO, J. P.; MAUAD, H. Avaliação clínica de ratos de laboratório (Rattus noverficus linhagem Wistar): parâmetros sanitários, biológicos e fisiológicos. Revista Ceres, v. 56, n. 1, p. 51-57, 2009. occidentalis durante o período perinatal em ratos, Estado de São Paulo. 2013. 
72 f. Tese (Mestrado em Ciências) - Faculdade de Medicina Veterinária, Universidade de São Paulo, São Paulo, 2013.

CAVALIERE, M. J.; CALORE, E. E.; HARAGUCHI, M.; GORNIAK, S. L.; DAGLI, M. L. Z.; RASPANTINI, P. C.; CALORE, N. M. P.; WEG, R. Mitochondrial myopathy in Senna occidentalis - seed - fed chickem. Ecotoxicology and Environmental safety, São Paulo, v. 37, n. 2, p. 181-185, 1997.

CORDEIRO, J. M. P.; FÉLIX, L. P. Conhecimento botânico medicinal sobre espécies vegetais nativas da caatinga e plantas espontâneas no agreste da Paraíba, Brasil. Revista Brasileira de Plantas Medicinais, Campinas, v. 16, n. 3, p. 685-692, 2014.

CORRÊA, M. P. Dicionário das plantas úteis do Brasil e das exóticas cultivadas. Rio de Janeiro: Ministério da Agricultura, 1926.

CRUZ, J. G. P.; SILVA, A. C.; LIMA, D. D.; DAL MAGRO, D. D.; MULLER, D. F.;, CRUZ, J. N. Efeitos do extrato de Ginkgo bilola (EGb 761) e da natação repetida sobre a memória, ansiedade e atividade motora de ratos. Journal of Basic and Applied pharmaceutical Sciencies,.v. 31, n. 2, p. 149-155, 2010.

DAMY, S. B.; CAMARGO, R. S.; CHAMMAS, R.; FIGUEIREDO, L. F. P. D. Aspectos fundamentais da experimentação animal - aplicações em cirurgia experimental. Revista Associação de Medicina Brasileira, São Paulo, v. 56, n. 1, p. 103-111, 2010.

DELMUT, M. B.; PARENTE, L. M.; PAULA, J. R.; CONCEIÇÃO, E. C.; SANTOS, A. S.; PFRIMER, I. A H. Cassia occidentalis: effect on healing skin wounds induced by Bothrops moojeni in mice. Journal of Pharmaceutical Technology and Drug Research, Goiânia, v. 2, n. 1, p. 1-10, 2013. Disponível em: <http://doi.org/10.7243/2050-120X-2-10, 2013>. Acesso em: inserir a data que você acessou a site. p. ex. 12 abr. 2015.

ENNACEUR, A.; DELACOUR, J. A new one-trial test for neurobiological studies of memory in rats. I: Behavioral data. Behavioral Brain Research, França, v. 31, n. 1, p. 47-59, 1988.

FELASA. FEDERATION OF EUROPEAN LABORATORY ANIMAL SCIENCE. Pain and distress in labortory rodents and lagomorphs. falta data. Disponivel em: http://www.felasa>. Acesso em: 13 maio 2015.

FUKUDA, I.; ATSUSHI, K.; NISHIUMI, S.; KAWASE, M.; NISHIKIORI, R.; FUJITAKE, $\mathrm{N}$; ASHIDA, $\mathrm{H}$. Structure-activity relationship of anthraquinones on the supression of DNA-binding activity of the aryl hydrocarbon receptor induced by $2,3,7$, 
8tetrachlorodibenzo-p-dioxin. Journal of Bioscience and Bioengineering, Japão, v. 107, n. 3, p. 296-300, 2009.

HALLER, J. ALICKI, M. Current animal models of anxiety, anxiety disorders, and anxiolytic drugs. Current Opinions, v. 25, p. 59-64, 2012.

HARAGUCHI, M.; GORNIAK, S. L.; CALORE, E. E.; CAVALIERE, M. J.; RASPANTINI, P. C.; CALORE, N. M.; DAGLI, M. L. Muscle degeneration in chicks caused by Senna occidentalis seeds. Avian Pathology: Journal of the W.V.P.A., São Paulo, v. 27. n. 4, p. 346-351, 1998.

IRWINM H. S.; BARNEBY, R. C. The American Cassiinae - a synoptycal revision of leguminosae, tribe Cassieae, subtribe Cassiinae in the new world. Memoirs of the New York Botanical Garden, v. 35, n. 1, p. 1-454, 1982.

JAFRI, M. A.; SUBHANI, M. J.; JAVED, K.; SINGH, S. Hepatoprotective activity of leaves of C.occidentalis against paracetamol and ethyl alcohol intoxication in rats. Journal of Ethnopharmacology, Índia, v. 66, n. 3, p. 355-61, 1999.

JOO, J. S.; EHRENPREIS, E. D.; GONZALES, L.; KAYE, M.; WEXNER, B.; WEXNER, S.; STEVEN, D.; ZAITMAN, D.; SECRETS, K. R. N. Alterations in colonic anatomy induced by chronic stimulant laxatives; the cathartic colon revisited. Journal of Clinical Gastroenterology, v. 26, n. 4, p. 283-286, 1998.

LECKMAN, J. F.; GOODMAN, W. K.; NORTH, W. G.; CHAPPELLI, P. B.; PRICE, L. H.; PAULS, D. L.; ANDERSON, G. M.; RIDDLE, M. A.; McSWIGGAN- HARDIN, M.; McDOUGLE, C. J.; BARR, L. C.; COHEN, D. J. Elevated cerebrospinal fluid leves of oxytocin in obsessive-compulsive disorder: comparison with Tourette, syndrome and healthy controls. Archives of General Psychiatry, v. 51, p. 782-789, 1994.

LEWIS, D. C.; SHIBAMOTO, T. Effects of Cassia obtusifolia (Sicklepod) extracts and anthraquinones on muscle mithocondrial function. Toxicon, v. 27, n. 5, p. 519-529, 1989.

LISTER, R. G. Ethologically-based animal models of anxiety disorders.

Pharmacology and Therapeutics, v. 46, p. 321-340, 1990.

LOMBARDO, M.; KIYOTA, S.; KANEKO, T. M. Aspéctos étnicos, biológicos e químicos de Senna occientalis ( Fabaceae). Revista Ciências Farmacêuticas Básica Aplicada, São Paulo, v. 30, n. 1, p. 1-9, 2009. 
LOMBARDO, M.; KIYOTA, S.; KATO, E. T. M.; MATHOR, M. B.; PINTO, T. D. J. A.; KANEKO, T. M. Evaluation of in vitro biological properties of Senna occidentalis. Acta Scientiarum. Biological Science, Maringá, v. 37, n. 1, p. 9-13, 2015.

LORENZI, H. Plantas daninhas do Brasil: terrestres, aquáticas, parasitas e tóxicas. 2. ed. Nova Odessa: Instituto Plantarum, 2000.

LUCIO, E. M. R. A.; ROSALEN, P. L.; SHARAPIN, N.; SOUZA, A. R. M. B. Avalição toxicológica aguda e screening hipocrático da epiisopilosina, alcaloide secundário dae Pilocarpus microphyllus Stapf. Revista Brasileira de Farmacognosia, v. 9, n. 10, p.23-25, 2000.

MARIANO-SOUZA, D. P. Avaliação dos efeitos tóxicos da Senna occidentalis em ratos. Parâmetros: bioquímicos, hematológicos, anatomopatológicos e inflamatórios, Estado de São Paulo. 2005. 164 f. Tese (Mestrado em Ciências) Faculdade de Medicina Veterinária e Zootecnia, Universidade de São Paulo, São Paulo, 2005.

MARIANO-SOUZA, D. P. Efeitos tóxicos da Senna occidentalis sobre o sistema linfohematopoiético: avaliação da exposição de ratos durante a fase de crescimento e pré-natal, Estado de São Paulo. 2009. 230 f. Tese (Doutorado em Ciências) - Faculdade de Medicina Veterinária e Zootecnia, Universidade de São Paulo, São Paulo, 2009.

MEDOUA, G. N.; MBOFUNG, C. M. F. Kinectics studies of some physicochemical substances during roasting and preparation of bevarage made by Cassia occidentalis seeds. LWTFood Science and Technology, Cameroon, v. 40, n. 4, p. 730-736, 2007.

MÉNDEZ, M. C.; RIET-CORREA, F. Plantas tóxicas e micotoxicoses: plantas que causam necrose segmentar muscular. Pelotas: Laboratório Regional de Diagnóstico, Faculdade de Medicina Veterinária, UFPel; Editora e Gráfica Universitária, 2000.p. 58- 61.

MONIZ, A. C.; CRUZ- CASALLAS, P. E.; SALZGEBER, S. A.; VAROLI, F. M. F.; SPINOSA, H. S.; BERNARDI, M. M. Behavioral and endochine changes induced by perinatal fenvalerate exposure in female rats. Neurotoxicology and Teratology, $v$. 27, n. 4, p. 609-614, 2005.

NADAL, S. R.; CALORE, E. E.; MANZIONE, C. R.; PUGA, F. R.; PEREZ, N. $M$. Effects of long-term administration os Senna occidentalis seeds in the large bowel of rats. Pathology Research and Practice, São Paulo, v. 199, n. 11, p. 733-737, 2003. 
NAKAGE, A. P. M.; MACARI, M.; NAKAGHI, L. S.; MALHIEROS, E. B.; VASQUES, L. H.; SECATO, E. R. Haematological and hormonal studies from broiler chickens fed with corn contaminants: Crotalaria spectabilis and Senna occidentalis. Brasilian Journal VeterinaryResearch Animal Science, São Paulo, v. 37, n. 5, p. 377-381, 2000.

NUNES, H. C.; PEZZATO, F. A.; HOSHINO, K. Self-grooping, experimental anxiety and paradoxical sleep deprivation in rats. Sleep Science, v. 5, n. 1, p. 19-23, 2015,

O'HARA, P. J.; PIERCE, K. R. A toxic cardiomyopathy caused by Cassia occidentalis. II. Biochemical studies in poisoned rabbits. Veterinary Pathology, Texas, v. 11, n. 2, p. 110-124, 1974.

OLIVEIRA-FILHO, J. P.; CAGNINI, D. Q.; BADIAL, P. R.; PESSOA, M. A.; DEL PIERO, F.; BORGES, A. S. Hepatoencephalopathy syndrome due to Cassia occidentalis (Leguminosae, Caesalpinioideae) seed ingestion in horses. Equine Veterinary Journal, v. 45, n. 2, p. 240-244, 2013.

PELLOW, S.; CHOPIN, P.; FILE, S.; BRILEY, M. Validation of open:closed arm entries in an elevated plus-maze as a measure of anxiety in the rat. Journal of Neuroscience Methods, v. 14, n. 3, p. 149-167, 1985.

PENKE, Z.; FELSZEGHY, K.; FERNETTE, B.; SAGE, D.; NYAKAS, C.; BURLET, A. Postnatal maternal deprivation produces long-lasting modifications of the stress response, feeding and stress-related behavior in the rat. European Journal of Neuroscience, v. 14, n. 4, p. 747-755, 2001.

RAFFI, M. B.; SALLIS, E. S. V.; RECH, R. R.; GARMATZ, S. L.; BARROS, C. S. L. Intoxicação por Senna occidentalis em bovinos de pastoreio - relato de caso.

Revista da FZVA, UrUguaiana, v.10, n. 1, p. 131-136, 2003.

RODGERS, R. J. ; DALVI, A. Anxiety, defense and the elevated plus-maze. Neuroscience and Biobehabioral Reviews, v. 21, n. 6, p. 801-810, 1997.

RODGERS, R. J.; CAO, B. J.; DALVI, A.; HOLMES, A. Animal models of anxiety: an ethological perspective. Brazilian Journal of Medical and Biological Research, $v$. 30, p. 289-304, 1997. 
RODRIGUES, R. S.; FLORES, A. S.; MIOTTO, S. T. S.; BAPTISTA, L. R. D. M. O gênero Senna (Leguminosae, Caesalpinioideae) no Rio Grande do Sul, Brasil. Acta Botanica Brasilica, Rio Grande do Sul, v.19, n. 1, p. 1-16, 2005.

SANDINI, T. M.; UDO, M. S. B.; SPINOSA, H. S. Senecio Brasiliensis e alcalóides pirrolizidínicos: toxidade em animais e na saúde humana. Revista Biotemas, São Paulo, v. 26, n. 2, p. 83-92, 2013.

SHARMA, N.; TRIKHA, P.; ATHAR, M.; RAISUDDIN, S. Protective effect of Cassia occidentalis extract on chemical-induced chromosomal aberrations in mice. Drug Chemical Toxicology, v. 22, p. 643-653, 1999.

SHARP, P.; VILLANO, J. S. The laboratory Rat. 2. ed. falta local: CRC, 2012. p. 204. ou 204 p.?

SILVA, T. C.; GORNIAK, S. L.; OLORIS, S. C. S.; RASPANTINI, P. C.; HARAGUCHI, M.; DAGLI, M. L. Z. Effects of Senna occidentalis on chick bursa of Fabricius. Avian Pathology, SãoPaulo, v. 32, n. 6, p. 633-637, 2003.

SOSSAI, P.; NASONE, C.; CANTALAMESSA, F. Are herbs always good for you? A case of paralytic ileum using a herbal tisane. Phytotherapy Research, v. 21, n. 6, p. 587-588, 2007.

SOYUNCU, S.; CETE, Y.; NOKAY, A. E. Portal vein thrombosis related to Cassia angustifolia. Clinical Toxicology, v. 46, n. 8, p. 774-777, 2008.

SPINOSA, H. S.; GÓRNIAK, S. L.; PALERMO-NETO, J. Toxicologia aplicada à MedicinaVeterinária. São Paulo: Manole, 2008. v. 1.

SPRUJIT, B. M.; VAN, H.; JARAM, falta iniciais do autor; GISPEN, W. H. Ethology and neurobiology of grooming behavior. Physiological Reviews, v. 3, p. 825-852. falta data.

STEVENS, K. R.; GALO, M. Practical considerations in the conduct chronic toxicity studies. In: HAYES, a. w. (ed.). Principles and methods of toxicology. New York, Ravens Pres, p.237-250, 1989.

STUART, A. G. Herbs to avoid during pregnancy and lactation - Plantas a evitar durante embarazo y lactancia. University of Texas El Paso/ University of Texas Austin Cooperative Pharmacy Program, 2003. 
Tasaka, A. C.; WEG, R.; CALORE, E. E.; SINHORINI, I. L.; DAGLI, M. L. Z.; HARAGUCHI, M.; GORNIAK, S. L I. Toxicity of Senna occidentalis seed in rabbits. Veterinary Research Communications.V.24, p.573-582, 2000.

TASAKA, A. C.; SINHORINI, I. L.; DAGLI, M. L. Z. HARAGUCHI, M; GORNIAK, S. L.Perinatal study of Senna occidentalis. Intoxication in rabbits.Poisonous Plants and Related Toxins. Wallingford, p.459-464, 2004.

TAKEUTI, K. L.; RAYMUNDO, D. L.; BANDARRA, P. M.; OLIVEIRA, L. G. S.; BOABAID, F. M.; BARRETO, L.; DRIEMEIER, D. Surto de intoxicação por Senna occidentalis em bovinos em pastoreio. Acta Scientiae Veterinariae. Rio Grande do Sul, v.39, n.1: 954, p.1-4, Novembro de 2011.

TESKE, M.; TRENTINI, A. M. M. Compêndio de fitoterapia. Curitiba: Herbarium Laboratório Botânico 2o edição, 268p, 1994.

TOKARNIA, C. H.; DÖBEREINER, J.; PEIXOTO, P.V. Plantas tóxicas do Brasil. Plantas que causam degeneração e necrose musculares. Rio de Janeiro: Helianthus, p.145-150, 2000.

TONA, L.; MESIA, K.; NGIMBI, N.; CHRIMWAMI, B.; OKOND'AHOKA; CIMANGA, K.; DE BRUYNE, T.; APERS, S.; HERMANS, N.; TOTTE, J.; PIETERS, L.; VLIETINICK, A. J. In-vivo antimalarial activity of Cassia occidentalis, Morinda morindoides and Phyllanthus niruri. Annals of Tropical Medicine and Parasitology. V.95, n.1, p.47-57, Janeiro de 2001.

TREMML, P.; LIPP, H. P.; MÜLLER, U.; RICCERI, L., P.; WOLFER, D. Neurobehavioral development, adult, openfield exploration and swimming navigation learning in mice with a modifield I-amyloid precursor protein gene. Behavioural Brain Research. V.95, p.65-76, 1998.

VIEGAS, C. J.; REZENDE, A.; SILVA, D. H. S.; CASTRO-GAMBÔA, I.; BOLZANI, V. $S$. Aspectos químicos, biológicos e etnofarmacológicos do gênero Cassia. Química Nova. V.29, n.6, p.1279-1286, Agosto de 2006..

YADAV, R.; JAIN, G. C. Antifertility effect of aqueous extract of seeds of Cassia fistula in female rats. Advances in Contraception. v.15, n.4, p.293-301, 1999.

YADAV, J. P.; ARYA, V.; YADAV, S.; PANGHAL, M.; KUMAR, S.; DHANKHAR, S. Cassia occidentalis $L$.: a review on its ethnobotany, phytochemical and pharmacological profile. Fitoterapia. v.81, n.4, p.223-230, Junho de 2010. 
YAZBEK, K. V. B. Avaliação da dor e da qualidade de vida em cães com câncer. Revista Dor. São Paulo, v. 9, n. 3, p. 1297-1304, 2008. 